\title{
The truth and nothing but the truth? : the accuracy, completeness, and consistency of emotional memories
}

Citation for published version (APA):

Candel, I. E. L. (2003). The truth and nothing but the truth? : the accuracy, completeness, and consistency of emotional memories. [Doctoral Thesis, Maastricht University]. Universiteit Maastricht.

https://doi.org/10.26481/dis.20030328ic

Document status and date:

Published: 01/01/2003

DOI:

10.26481/dis.20030328ic

Document Version:

Publisher's PDF, also known as Version of record

Please check the document version of this publication:

- A submitted manuscript is the version of the article upon submission and before peer-review. There can be important differences between the submitted version and the official published version of record.

People interested in the research are advised to contact the author for the final version of the publication, or visit the DOI to the publisher's website.

- The final author version and the galley proof are versions of the publication after peer review.

- The final published version features the final layout of the paper including the volume, issue and page numbers.

Link to publication

\footnotetext{
General rights rights.

- You may freely distribute the URL identifying the publication in the public portal. please follow below link for the End User Agreement:

www.umlib.nl/taverne-license

Take down policy

If you believe that this document breaches copyright please contact us at:

repository@maastrichtuniversity.nl

providing details and we will investigate your claim.
}

Copyright and moral rights for the publications made accessible in the public portal are retained by the authors and/or other copyright owners and it is a condition of accessing publications that users recognise and abide by the legal requirements associated with these

- Users may download and print one copy of any publication from the public portal for the purpose of private study or research.

- You may not further distribute the material or use it for any profit-making activity or commercial gain

If the publication is distributed under the terms of Article $25 \mathrm{fa}$ of the Dutch Copyright Act, indicated by the "Taverne" license above, 
The truth and nothing but the truth?

The accuracy, completeness, and consistency of emotional memories

Ingrid Candel 
O.E.L. Candel, Maastricht 2003

Druk: Drukkerij Groenevelt BV Landgraaf

ISBN 90-9016645-9 


\section{The truth and nothing but the truth?}

The accuracy, completeness, and consistency of emotional memories

\section{PROEFSCHRIFT}

ter verkrijging van de graad van doctor aan de Universiteit Maastricht, op gezag van de Rector Magnificus, Prof. dr. A.C. Nieuwenhuijzen Kruseman, volgens het besluit van het College van Decanen, in het openbaar te verdedigen op vrijdag 28 maart om 16.00 uur

door

Ingrid Elisabeth Lodewijk Candel 


\section{Promotor:}

Prof. dr. H. L. G. J. Merckelbach

\section{Beoordelingscommissie:}

Prof. dr. H.F.M. Crombag (voorzitter)

Prof. dr. M.A. van den Hout

Dr. M. Jelicic

Prof. dr. P.J. van Koppen (NSCR, Universiteit Antwerpen)

Prof. dr. Ph. Spinhoven (Universiteit Leiden) 


\section{Contents}

Chapter 1 Errors in emotional memories: A short review

Chapter 2 Outline of this thesis

Chapter 3 Accuracy, completeness, and consistency of emotional memories

Chapter 4

Boundary distortions for neutral and emotional pictures

Chapter 5 How children remember neutral and emotional pictures:

Boundary extension in children's scene memories

Chapter 6

Korsakoff patients' memories of September 11,2001

Chapter 7 Peritraumatic dissociation as a predictor of PTSD:

A critical review

Chapter 8 Dissociative experiences are related to commissions in emotional memory

Chapter $9 \quad$ Fantasy proneness and thought suppression as predictors of the Medical Student Syndrome

Chapter $10 \quad$ General discussion

References

Summary

Samenvatting

Dankwoord 



\section{Chapter 1 Errors in emotional memories: A short review*}

\section{Introduction}

Extreme emotional experiences are part of the human condition. For example, Elliot (1997) conducted a population survey on the prevalence of extreme emotional experiences (i.e., traumatic experiences). Seventy two percent of all participants ( $N$ $=505$ ) reported some form of childhood or adult trauma ranging from accidents and catastrophes (e.g., natural disaster, major motor vehicle accident) to interpersonal trauma (e.g., physical assault, rape). Many trauma victims report highly vivid memories of the traumatic event (e.g., Van der Kolk, Blitz, Burr \& Hartmann, 1984). When these memories are intrusive in nature, they are called "flashbacks". Like nightmares and numbing, flashbacks constitute the symptoms of PostTraumatic Stress Disorder (PTSD; APA, 1994). To meet the criteria for PTSD at defined by the fourth edition of the Diagnostic and Statistical Manual of Mental Disorders (DSM-IV; APA, 1994), an individual must have experienced or witnessed an event that was threatening to the safety or integrity of themselves or others, and to which the person responded with intense fear, horror, or helplessness. However, even if a trauma victim does not meet the criteria for PTSD, he or she might have persistent and vivid traumatic memories.

The nature and reliability of these memories have been controversial issues in literature. Some authors claim that traumatic memories are highly accurate and stable over time. For example, Van der Kolk and Fisler (1995; p. 508) note that "....some aspects of traumatic events appear to get fixed in the mind, unaltered by the passage of time or by the intervention of subsequent experience." Similarly, Elin (1995; p. 238) claims that trauma victims "appear to have photographical recall of events that happened to them in the past." However, memory is a reconstructive activity. According to Hyman and Loftus (1998), we construct a version of the past based on remaining memories, general schematic knowledge, and the demands of

* Chapter 1 is an adjusted and translated version of the following Dutch articles: Candel, 1., \& Merckelbach, H. (2001). Traumatische herimeringen zijn niet perfect. De Psycholoog, 4, 170-174, and Candel, I., \& Merckelbach, H. (2002). Het geheugen voor negatieve gebeurtenissen. Nederlands Tijdschrift voor de Psychologie, 57, 1-9, and of the following Dutch chapter: Candel, I, Merckelbach, H., \& Wessel, I. (2002). Traumatische herinneringen. In P.J. van Koppen, D.J. Hessing, H.L.G.J. Merckelbach \& H.F.M. Crombag (Eds.), Het Recht van Binnen (p. 417-431). Dewenter: Kluwer BV. 
the context in which we remember. Reconstnction is not reproduction. Thus, both neutral and emotional memories for negative events (hereafter termed emotional memories) will often include errors. Indeed, empirical findings indicate that emotional memories have far less photographic qualities than some clinicians seem to assume. There are two approaches to evaluate these memories. One approach is to study real-life traumatic memories by interviewing witnesses or victims of actual traumatic events. The other approach is to investigate memory for emotional events in laboratory settings. In such lab studies, participants are exposed to emotional stimuli. Nexi, memory for these stimuli is tested. The rivalry between these two approaches is a recurrent issue in literature. According to Yuille and Cutshall (1989), real-life studies provide the only ecologically valid way to investigate the impact of emotion on memory. They argue that laboratory studies can never properly simulate a situation in which participants are threatened.. However, in reallife studies of highly emotional memories, we usually do not know what the original circumstances of the emotional event were. To evaluate the accuracy of emotional memories, we do need objective facts. Only in the laboratory we are able to control and to know these facts. We agree with Christianson (1992a; p. 303) in that "to become fully informed, convergent methods of investigation are helpful, and the use of multiple methods [...] all contribute to further our knowledge of emotion and memory." Field studies and laboratory studies complement each other in informing our knowledge of emotional memory. Both approaches use different paradigms to evaluate the qualities of emotional memories. We will briefly consider these approaches and paradigms below.

\section{Laboratory studies}

\section{Scene memory}

Before evaluating memory for emotional scenes, we first turn to memory for neutral scenes since this issue has been thoroughly studied. When people try to remember a photograph of a scene, they tend to remember having seen a wider scenery than was actually shown. This phenomenon is called boundary extension (Intraub \& Richardson, 1989). Evidence for this memory illusion has been obtained with a variety of memory tests. To begin with, extended boundaries are observed when people draw pictures from memory. In a so-called free recall drawing tasks, participants are asked to draw pictures from memory after their presentation (e.g., Intraub \& Richardson, 1989; Intraub \& Bodamer, 1993; Intraub \& Berkowits, 1996;

\footnotetext{
We prefer to use the term emotional memories for negative events rather than traumatic memories, since emotional memories for negative events cover the whole continum of memory for negative events rather than the extreme 2 endpoints of that continuum.
} 
Intraub, Gottesman, Willey \& Zuk, 1996; Intraub, Gottesman \& Bills, 1998). These drawings tend to contain more background than the original pictures (see for examples Figure 1.1). This finding has been obtained in studies that varied stimulus duration from $250 \mathrm{~ms}$ (Intraub et al., 1996) to $15 \mathrm{~s}$ (e.g., Intraub \& Richardson, 1989). Secondly, boundary extension can also be obtained with recognition tests (e.g., Gottesman \& Intraub, 2002; Intraub \& Berkowits, 1996; Intraub \& Bodamer, 1993). As a rule, such tests rely on the "camera distance" paradigm. In this paradigm, participants are confronted with test pictures after exposure to neutral target pictures. Next, they are asked to rate the test pictures in terms of closer-up, the same, or more wide-angled than the original targets. When the test pictures are exact replications of the targets, people tend to rate them as close-up versions of the original targets. This indicates that they remembered more of the scene than was actually shown. Similarly, when the test pictures show slightly less of the original target scene (close-up versions) or slightly more of a scene (wide-angle versions), asymmetrical responses occur. Viewers are much more likely to mistake wide-angle test pictures, rather than close-up test pictures, as copies of the original. Evidence for boundary extension has also been obtained when people are asked to move physically-boundaries of test pictures to match their recollections of the originals (Nyström, 1993).
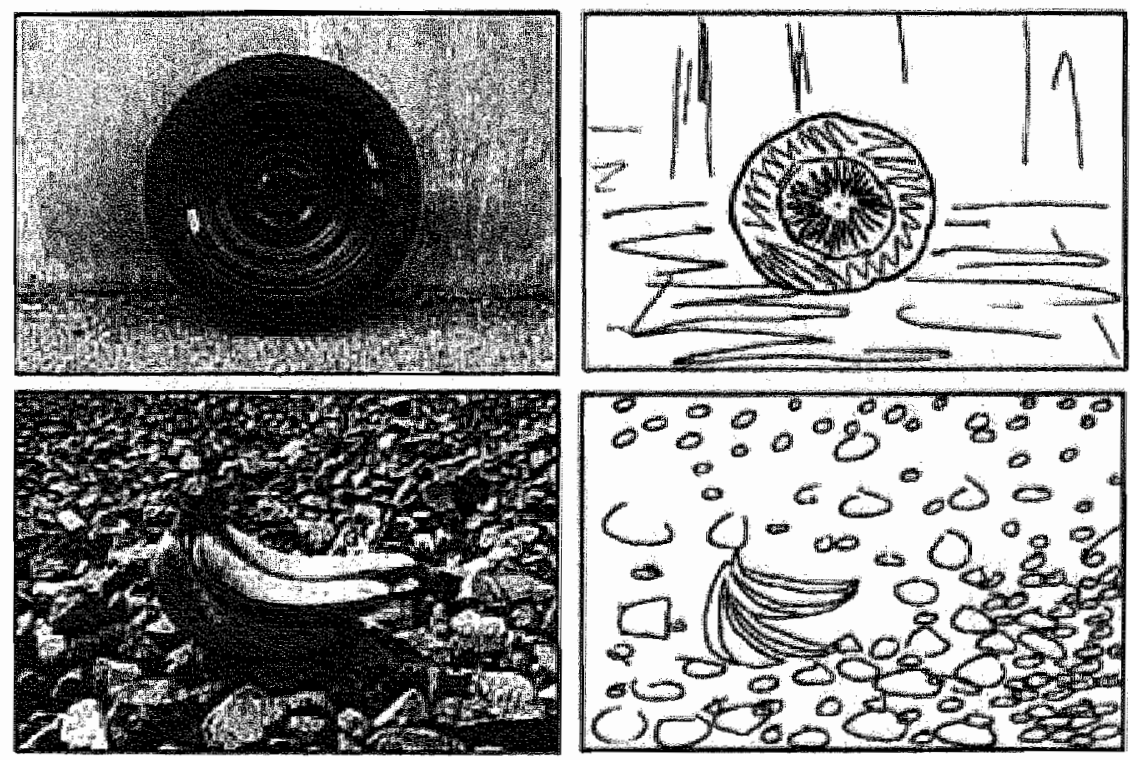

Figure 1.1 Two neutral pictures and their drawings showing boundary extension ${ }^{2}$

${ }^{2}$ butp://faculty-staff.ou.edu/G/Carmela.Gottesman-1/web 
Boundary extension appears to be a robust phenomenon. The phenomenon is so strong that even when participants are warned against it, the effect is not eliminated in their drawings (Intraub \& Bodamer, 1993). Moreover, boundary extension occurs even when viewers draw pictures immediately after each presentation rather than after presentation of the whole stimulus set (Seamon, Schlegel, Hiester, Landau \& Blumenthal, 2002). Not only lay people, but graphics artists as well extend pictures boundaries (un-published pilot study in Intraub, 2002). However, the boundary extension phenomenon is subject to two limitations. First, both drawing and recognition tests show that boundary extension is greatest for close-up views, and becomes less apparent when picture view widens. Wide-angle views often show no directional distortion of their boundaries. Second, over time (e.g., 2 days), the degree of boundary extension decreases (Intraub, Bender \& Mangels, 1992). Views normalize toward the average of a subset of pictures. Intraub and colleagues attribute this finding to a process called normalization or, in other words, regression to the mean. They refer to the dynamics of initial extension and subsequent normalization as the extension-normalization model.

Intraub and co-workers argue that boundary extension originates from continuation of background, whether it is a solid surface or merely appears to be a surface. This process is referred to as amodal continuation: the continuation of a surface behind an occluder to an indefinite endpoint. Such continuation may account for the boundary extension phenomenon in the following way. To understand a partial or incomplete view, the visual system must recognize that the scene continues beyond the current limits of that view. In doing so, people rely on a perceptual schema, constructed on the basis of their experience. This schema allows for extrapolations that are not part of the scene. However, the extrapolated information is incorporated in the viewers' memory of the picture. Close-up views, then, produce more extrapolation since they elicit a strong sense of expectancy. As views widen, the expected regions become increasingly available within the picture. Note that spatial extrapolation does not require a detailed background. Scenes have to be presented as truncated views. For example, a blank background behind an object will tend to be remembered with extended boundaries if it presents a truncated view of a continuous environment in which that object is situated. Boundary extension will not occur, however, if the blank background is not understood to be a truncated view as is true for drawn objects and cutout objects on blank backgrounds (Gottesman \& Intraub, 2002). Therefore, Gottesman and Intraub (2002; p. 598) conclude that "anticipatory spatial extrapolation in memory for scenes is not driven solely by bottom-up information [...]. Rather, anticipatory processes work interactively with external stimulation and internal expectations to help in perceiving a continuous world that can only be sensed piecemeal."

With the robust phenomenon of boundary extension for neutral scenes in mind, the question arises how viewers remember emotional scenes. Safer, Christianson, Autry, and Österlund (1998) argue that in remembering emotional 
scenes, boundary restriction or "tunnel memory" would occur. These authors rely on Easterbrook's claim (1959) that physiological arousal narrows the range of cue utilization. As a result, viewers attend relatively more to central aspects and less to peripheral aspects of an emotional scene. Thus, when viewing an emotional scene, attention automatically narrows to the critical details of the scene (the attentionalnarrowing hypothesis; Christianson, 1992a). This would result in accurate memory for these details, while memory for peripheral details would be inaccurate. Safer et al. (1998) used the camera distance paradigm to test this hypothesis. Only in experiment 4 of their study, they obtained evidence for boundary restriction in emotional scene memory. Nevertheless, the authors conclude that tunnel memory occurs in remembering emotional scenes.

\section{Event memory}

Like studies on scene memory, studies on event memory rely on exposure to emotional material. However, studies on event memory use dynamic rather than static stimulus material. More specifically, participants watch videotapes, series of slides or live staged events. Next, their memory is assessed. An illustrative example is a study in which participants watched a series of slides depicting either a neutral or an emotional version of a story in which a mother and her son visit the father at his workplace (Heuer \& Reisberg, 1990). The neutral version showed the father as a garage mechanic fixing a car, while the emotional version showed the father as a surgeon treating a victim of an accident. A recognition test assessed participants' memory for central and peripheral details of each slide. The results replicated earlier findings in showing that memory for the central details of the emotional event was relatively good, whereas memory for peripheral details was relatively poor (see for an overview Christianson, 1992a). This phenomenon is closely related to "weapon focus" (Steblay, 1992). It is thought that the attentional-narrowing hypothesis accounts for weapon focus. Emotional contents would draw attention to the central aspects of an event (e.g., a weapon), leaving the more peripheral contents (e.g., face of the perpetrator) outside of the focus of attention. Indeed, eye movement studies show that participants tend to fixate longer on the central items and shorter on the peripheral items of an emotional scene (Wessel, Van der Kooy \& Merckelbach, 2000). In addition, Christianson (1992a) suggests that post-stimulus elaboration (i.e., elaboration just after encoding) promotes the asymmetric pattern in emotional memory. Thinking about and reacting empathically to emotion-arousing details would result in elaborative processing of these details, whereas neutral, low arousing details would be associated with shallow maintenance processing. In the words of Christianson and Lindholm (1998; p. 168): "This mode of processing [...] will promote memory of central detail information and the gist of the emotional event but actively inhibit processing of details that are irrelevant, spatially peripheral to the emotion-eliciting event or the source of emotional stress, or both." 
Although the asymmetrical recall pattern of central and peripheral emotional details is a recurrent finding in many experimental studies that addressed this issue, there is one complication. That complication has to do with the definition of central and peripheral details. Christianson (1992a) embraces a perceptual-spatial definition, such that aspects linked to the emotional source are classified as central and contents preceding or following the emotional event, and those irrelevant or spatially non-central to the emotional core, as peripheral. On the other hand, Heuer and Reisberg (1990) advocate a conceptual definition. They define aspects, which cannot be excluded or changed without altering the plot (i.e., gist) as central, and contents irrelevant to the plot as peripheral. Although some studies (e.g., Wessel \& Merckelbach, 1998) favour the conceptual definition, the problem remains that such a definition is often necessarily post-hoc. Thus, it is often difficult, if not impossible, to determine in advance which details are central and which are peripheral. This is especially true for field studies.

\section{Field studies}

\section{Flashbulb memories}

Most people know exactly where they were and what they were doing when they heard about the September 11, 2001 attacks on the United States of America. These vivid memories for the circumstances surrounding the reception of news about a surprising or shocking event are termed flashbulb memories (Brown \& Kulik, 1977). They are assumed to be triggered by emotional factors (i.e., intensity of emotions, appraisal of the original event) and by social factors (i.e., social sharing of the news, media exposure). The term "flashbulb" suggests that these memories possess photographical qualities, i.e., precise, vivid, and long lasting. In order to evaluate the consistency of flashbulb memories, people are usually interviewed twice about the reception events (e.g., Davidson \& Glisky, 2002). Crossexperimental comparison indicates that the level of consistency varies widely. For example, Curci, Luminet, Finkenauer, and Gisle (2001) found that a considerable percentage of participants retained at least some reception events of the French president Mitterand's death. More specifically, after 1 year, $97 \%$ of the respondents consistently recalled the place where they had heard the news, whereas $74 \%$ consistently recalled the precise moment when they had heard the news. Davidson and Glisky (2002), however, found that only 32 to $42 \%$ of the reception events of the death of mother Teresa were exactly recalled after 6 months.

Winningham, Hyman, and Dinnel (2000) point out that researchers who asked their respondents to describe the reception events shortly after it occurred, generally find less consistency in respondents" reports than those who wait longer before obtaining a description of these events. There are two possible explanations 
as to why flashbulb memories are less consistent when public events are described by respondents shortly after their occurrence. First, inconsistent menories might occur as a result of post-event information (Loftus, 1975, 1979). After news about a disaster has been announced, people learn more about the event. They hear stories from other individuals about how they received the news and they are exposed to additional news about the event, for example, through media reports. All this information is incorporated in their own flashbulb memories. This incorporation may be relatively complete within a few days. Thus, exposure to post-hoc information may alter one"s flashbulb memories over time. An illustrative example of the effect of post-event information is the testimony of a helicopter pilot who witnessed the 1996-crash of a TWA Boeing in Long Island. Initially, this witness stated having seen an explosion on board of the plane. After media suggestion of a terrorist attack, the witness reported having seen fire resembling anti-aircraft guns (Loftus \& Castelle, 2000).

The second explanation for less consistent flashbulb memories after early reports has to do with forgetting. Most information is forgotten shortly after an event (Ebbinghaus, 1885/1913). Thus, flashbulb memories obtained shortly after the event will be more detailed compared to later ones. When initial event descriptions are delayed, some information is already lost resulting in increased consistency with later recollections.

\section{Personal significant emotional events}

Another research domain in the emotional memory field has to do with emotional events that are of a personal nature. In these studies, witnesses or victims of violence are interviewed about their experiences. For instance, Wagenaar and Groeneweg (1990) compared testimonies of survivors of the Nazi concentration camp "Erika". The testimonies were collected in the period 1943-1947 and approximately 40 years later. Results indicated that camp experiences were generally well remembered. However, specific but essential details were forgotten. For example, the majority of names of kapos and guards reported during the initial interview were forgotten after 40 years.

Inconsistent reports have also been found in combat veterans (e.g., Roemer, Litz, Orsillo, Ehlich \& Friedman, 1998; Southwick, Morgan III, Nicolaou \& Charney, 1997). After approximately 2 years, some of these veterans reported more trauma exposure (e.g., "seeing others killed or wounded", "being in an aircraft that is shot down") than shortly after their return from war-zone. Moreover, posttraumatic stress symptomatology was associated with increases in trauma exposure reports (but see Bramsen, Dirkzwager, Van Esch \& Van der Ploeg, 2001). The same results were found when motor vehicle accident (MVA) victims were interviewed about trauma symptoms 1 month and 2 years post trauma (Harvey \& Bryant, 2000). High levels of posttraumatic stress at 2 years were associated with 
errors of "addition" (i.e., recalling the presence of acute symptoms 2 years post trauma that were not reported during the initial interview). Similar changes in reports of emotional events were found in a study in which witnesses of a school shooting were interviewed twice about the incident (Schwarz, Kowalski \& McNally, 1993). "Enlargement" of emotional experiences after 18 months was associated with PTSD symptoms. Perhaps, then, individuals who became increasingly symptomatic over time unknowingly exaggerated their memory for emotional events as a way to understand or explain their emerging psychopathology. This phenomenon - seeking an explanation for one's problems has been referred to as "effort after meaning" (Tennant, 1983). However, since there were no objective reports of the trauma exposure available we cannot rule out the possibility that in their retrospective reports individuals underestimated their exposure and symptoms initially and later give more accurate appraisals.

In field studies, lack of objective reports is the rule rather than the exception. By interviewing witnesses or victims twice, we can evaluate the consistency of emotional memory. However, the question arises what can be said about the accuracy of these reports, since accuracy is defined as "agreement between the individual's recall and either an objective record of the event or social consensus from other participants of the event as to what occurred" (Fivush, 1993; p. 22). To the best of our knowledge, there are only a handful of field studies in which objective records were available. More specifically, there are two case studies in which eyewitness testimonies about an event could be evaluated against independent information, making it possible to determine the accuracy of the eyewitness accounts. The first is that of a 13-year-old child who audiotaped a sexually abusive incident that represented the last in a series of abusive incidents (Orbach \& Lamb, 1999). This tape provided a unique opportunity to evaluate the accuracy of the child's account by comparing information provided by the victim during the investigative interview with the audiotaped record of the incident. Of the 189 details that the victim provided about the recorded incident, over $50 \%$ was corroborated by the audio-tape ${ }^{3}$. The second case study involved four girls who were sexually abused by several adult men (Bidrose \& Goodman, 2000). Their reports were evaluated against evidence contained in photographic and audio-taped records of the sexual acts. There was evidence for 318 different acts in which the girls were involved. In total, 246 allegations were raised by the girls. For 194 $(78.9 \%)$ of these, photographs and audio-taped material provided supportive evidence. The remaining 52 allegations $(21.1 \%)$ were unsubstantiated. The girls omitted 124 abusive acts shown by the material. Another field study in which more or less objective records were available is that of Schelach and Nachson (2001).

"We can not rule out the possibility that the child listened to the tape before the investigative interview. If this is the case, it may have increased the accuracy of the account. 
Recently, these authors interviewed 5 survivors of Auschwitz and compared their recollections with information derived from two credible sources (i.e., books which contained detailed testimonies by camp survivors and liberators as well as documentation left behind by the fleeing Nazis). Overall level of accuracy was about $60 \%$. Moreover, victims' identification of crucial Nazi personalities was very poor.

\section{Accuracy, completeness, and consistency}

All studies reviewed above indicate that emotional memories do not have photographic qualities. Like neutral memories, they are malleable and fallible (see also Schacter, 1999 and Krause Shobe \& Kihlstrom, 1997). Both laboratory and field studies show that emotional memories have shortcomings in terms of their accuracy, completeness, and consistency. These concepts are often used as synonyms. For example, Schmolck, Buffalo, and Squire (2000) mix up consistency of flashbulb memories with their accuracy. Meanwhile, these three dimensions must be strictly distinguished.

\section{Accuracy}

As mentioned before, accuracy is defined as "agreement between the individual's recall and either an objective record of the event or social consensus from other participants of the event as to what occurred" (Fivush, 1993; p. 22). Both distortions and commission errors undermine the accuracy of memories. A distortion refers to a change in the details of an existing element (e.g., a red Volkswagen in stead of a green Volkswagen). A commission error or confabulation refers to the introduction of an entirely novel element (Gudjonson \& Clare, 1995), for example, a false report of a traumatic incident. Under normal conditions, commissions are relatively rare. In traditional memory tasks, commission errors account for less than $10 \%$ of all responses (Dunning \& Stern, 1992; Fisher \& Cutler, 1995). However, this percentage increases when individuals are forced to answer questions and when they are asked repeatedly to provide additional memory details within one session. On the other hand, the number of commissions decreases when individuals are punished for making them (Koriat \& Goldsmith, 1994). Schwartz, Fisher, and Hebert (1998) explored the relation between output order in free recall and the likelihood of commission errors. Their participants were asked to recall word lists (experiment 1), elements of a police film (experiment 2), and a conversation between a neuropsychologist and a patient (experiment 3). Overall, results indicated that commissions were more likely to occur at the end of participants" output. This finding is dubbed the output-order phenomenon. The authors argue that relaxation of the accuracy criterion is the mechanism behind the output-order phenomenon. 
That is, as participants progress further into their output, the accuracy criterion for producing a new response is relaxed. As a result, a response might be given that was witheld earlier in the output, with a more conservative criterion. Scaling down the response criterion may compensate for retrieval difficulties experienced at the end of the output.

\section{Completeness}

Distortions and commissions are manifestations of inaccuracy. However, accuracy does not guarantee completeness. Incomplete emotional memories may be the result of a) "normal" forgetting and of b) attentional narrowing. Focusing attention on critical details of an emotional event will result in good memory for these details, whereas memory for peripheral details is distorted or even lost or inaccessible. However, with repeated interviewing memories may become more complete (Bornstein, Liebel \& Scarberry, 1998; Scriver \& Safer, 1988; Turtle \& Yuille, 1994). This is explained in terms of "hypermnesia", which refers to increased net recall over longer retention intervals (Payne, 1987). It has been suggested that the critical factor underlying hypermnesia is not merely increasing retention intervals, per se, but multiple overt or covert retrieval attempts. While repeated interviewing seems to increase recall, this may also lead to commissions or distortions (Bornstein et al., 1998; Christianson \& Lindholm, 1998). According to Bornstein and colleagues (1998), there are two reasons for worrying not too much about increases in these errors over repeated testing. First, even though the number of commissions and distortions increased in their study, their absolute frequency remained relatively low. Secondly, as noted by Turtle and Yuille (1994), from a forensic perspective, an increase in new correct details outweighs a small increase in commissions and/or distortions.

\section{Consistency}

Consistency does not imply accuracy. Therefore, "measures of consistency between interviews should not be taken as indications of accuracy" (Woolnough \& MacLeod, 2001; p. 396). However, what can be said with some confidence about inconsistent memories is that at least one of them must be inaccurate and/or incomplete. Consistency has been a major topic in studies of flashbulb memories. Christianson and Engelberg (1999) showed that flashbulb memories of participants interviewed twice about the "Estonia" ferry disaster were far from consistent. Moreover, during the second interview, less than one third of the participants could accurately recall their emotional reactions at the time they learned about the news. Figure 1.2 shows how accuracy, completeness, and consistency are related. 


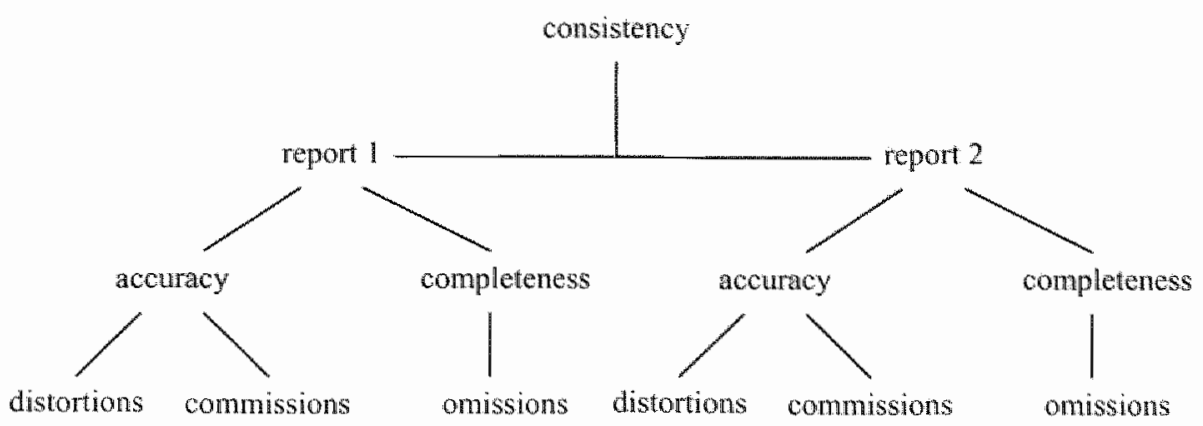

Figure 1.2 The relationship between accuracy, completeness, and consistency

\section{Self-reports}

As described above, the usual paradigm for studying emotional memories is to expose individuals to an event or to find individuals who survived a naturally occurring emotional event and then ask them questions about that event. A methodological problem inextricably bound up with this paradigm is that memory researchers have to rely on participants' self-reports. Unfortunately, the reliability of self-reports varies depending on the behaviour being reported, the social valence associated with that behaviour, and a host of other factors. In the words of Conte (1999; p. 79): "What people tell us about their own behaviour and experience may or may not be accurate." Schwarz (1999) showed that minor changes in question wording, question format, or question context can result in major changes in selfreports. While this is true for individuals in general, it is especially true for individuals who have certain characteristics. Above we addressed PTSD symptomatology. Individuals with PTSD symptoms tend to inflate their retrospective reports of emotional experiences (Roemer et al., 1998; Southwick et al., 1997). There are also good reasons to believe that individuals with dissociative experiences and/or high levels of fantasy proneness may give unreliable reports of their emotional experiences as well (Merckelbach \& Muris, 2001; Wilson and Barber, 1983).

Clinicians often assume that repeated traumatization leads to chronic, traitlike dissociative symptoms like derealization, depersonalisation, and psychogenic amnesia (Van der Kolk \& Van der Hart, 1989; Gershuny \& Thayer, 1999). According to this view, people who have learned to cope with trauma by dissociating are vulnerable to continue to do so in response to minor emotional events. Dissociation would serve an adaptive function in that it protects consciousness against painful memories. However, the initially adaptive function of dissociation may be transformed into a chronic maladaptive process. According to 
this so-called defence view of dissociation, emotional memories would have a fragmented nature. They would be organized in memory on sensori-motor and affective levels without semantic representations. As a result, accurate retrieval of emotional events would be problematic. Another personality characteristic associated with unreliable reports of emotional events is fantasy proneness. Fantasy prone individuals spend a large part of their time fantasizing and they typically "see", "hear", "touch", and fully experience what they fantasize (Wilson \& Barber, 1983). Moreover, these people tend to inflate ambiguous sensations. Spanos, Cross, Dickson, and DuBreuil (1993) interviewed 20 individuals about UFO-experiences. The more fantasy prone these individuals were, the more intense their UFOexperiences were. Interestingly, a surprisingly high number of fantasizers report false pregnancies (Wilson \& Barber, 1983). Another factor that may cast doubts on the self-reports of fantasy prone individuals is that they tend to report more traumata and depressive symptoms during adolescence compared to low fantasy prone individuals (Rhue \& Lynn, 1987; Rauschenberg \& Lynn, 1995). 


\section{Chapter 2 Outline of this thesis}

The issue of emotion and memory is a complex one. Cognitive, clinical, as well as biologically oriented scientists study this issue (see for a review Christianson, 1992b). As described in Chapter 1, emotion and memory can be studied using a laboratory or a field approach, yet each approach involves dozens of paradigms and topics. Topics in this domain include mood and memory, implicit and explicit emotional memory, and eyewitness memory, to mention but a few. With respect to eyewitness memory, many studies have focused on believability of eyewitness testimonies (e.g., Leippe, 1980), on the confidence-accuracy relationship of eyewitness testimonies (e.g., Malpass \& Devine, 1981), and on the relationship between post-event misinformation and accuracy (e.g., Loftus, 1975; Loftus, 1979). Relatively few studies have focused on the interrelationships between accuracy, completeness, and consistency of emotional memories. The studies in this dissertation concentrate on these three parameters. More specifically, we investigated how accurate, how complete, and how consistent emotional memories are. In doing so, we conducted both laboratory studies and field studies. These two approaches have both advantages and disadvantages. The main advantage of field studies is that the impact of the particular emotional event is, without doubt, high. However, reports about such a real-life event are hard to verify. As a result, it is impossible to evaluate the accuracy of these reports. Studies like those of Orbach and Lamb (1999) and Bidrose and Goodman (2000), in which the authors had access to objective records, are rare. This problem of ground truth also plays a role in studies on flashbulb memories. Usually, we do not know what the circumstances were in which participants received the news of the particular event. We only know what they claim them to be. Laboratory studies circumvent this problem. In these studies, we know the to-be-remembered material. As a result, we can compare memory in- and output and evaluate memory in terms of accuracy and completeness. The problem with lab studies, however, is their practical application. It may be clear, though, that both approaches are useful in research on emotion and memory. We agree with Christianson (1992b; p. 426) in that "we advocate the use of multiple methods, including interviews, simulations, staged events, and field research" and with Tulving (1991; p. 41-42) in that "memory, like countless other objects of scientific curiosity, can be studied and described at many different levels, from many different perspectives, using many different approaches and methods. There need not to be, and there is usually not, any conflict between these different approaches and different levels. Normally they are complementary." Only multiple 
methods lead to meaningful interpretations and generalizability. Studies using different paradigms, or the same paradigm in divers populations, contribute to a better understanding of emotion and memory. In the studies that are presented in the next chapters, different approaches, different paradigms and different populations are used. Thus, these chapters do not constitute a neat research program in which one single paradigm is repeatedly described. However, all studies have in common a focus on accuracy, completeness, and/or consistency of emotional memories. The central topic is: how accurate, complete and/or consistent are these memories? To address this general issue, five more specific research questions are formulated.

\section{Research questions}

1. What is the relation between accuracy, completeness, and consistency of emotional memories?

Although lawyers as well as lay people consider inconsistency of memories as an indication of their overall inaccuracy, there are only a handful empirical studies that addressed the alleged link between inconsistency and inaccuracy. Therefore, Chapter 3 describes a study on accuracy, completeness, and consistency of emotional memories. To disentangle the relationship between these parameters, we conducted a laboratory study on event memory. More specifically, eyewitnesses of a violent movie fragment were asked twice to give a detailed description of what they saw. These descriptions were evaluated in terms of their accuracy, completeness, and consistency. We then computed correlations between these three parameters.

\section{How accurate and complete are enotional memories?}

Our review on emotion and memory suggests that attentional narrowing may play an important role in emotional scene memory. Emotional scenes might be remembered in a "tunnel like", and, thus, incomplete fashion. Chapter 4 and Chapter 5 present laboratory studies that tested this hypothesis. The fist study investigated whether tunnel memory occurs in adults" scene memory. We used both the drawing paradigm and the camera distance paradigm to study this topic. These paradigms have been used many times in studies on neutral scene memory. The second study investigated the same memory illusion in a population of special interest to forensic psychologists, namely children. Such a study allows drawing conclusions on the robustness and developmental stability of distortions in emotional memories. 
Although some scientists attribute special photographic qualities to emotional memories, the fact is that errors may occur in both neutral and emotional memories. However, the question remains whether there is a difference between neutral and emotional memory. For example, are patients who are unable to form new memories about daily events, able to form memories related to highly emotional events? Chapter 6 describes a field study in which we investigated whether Korsakoff patients remember the 11/9 terrorist attacks on the United States of America and the circumstances in which they received this news (flashbulb memories). Korsakoff disease is characterized by both retrograde and anterograde amnesia. To the extent that Korsakoff patients would report accurate and consistent (flashbulb) memories, one would have a strong argument to argue that there is a difference between emotional and neutral memories.

4. Do victims who suffer from PTSD have accurate memories of their traumatic experience?

Several empirical studies conclude that peritraumatic dissociation is related to the development of PTSD. In general, these studies rely on retrospective self-reports of trauma victims with and without PTSD. In Chapter 7, literature on memory and on self-reports is reviewed to examine whether victims who suffer from PTSD are able to give accurate reports of what happened to them in the past. Most importantly, we critically evaluate whether the connection between peritraumatic dissociation and PTSD can be interpreted in causal terms.

5. Are dissociation andlor fantasy proneness and/or thought suppression related to errors in emotional memories?

As described in the first chapter, personality characteristics may affect the accuracy, completeness, and consistency of emotional memories. The relationship between trait-like dissociative and emotional memory is the focus of the study described in Chapter 8. This issue was examined in a laboratory study on event memory. Participants listened to an aversive story. Next, memory was tested using a free recall task. Memory reports were analysed in terms of their accuracy and completeness. The study described in Chapter 9 evaluated the contribution of fantasy proneness and thought suppression to inaccurate reports of ambiguous bodily experiences. Medical students completed a questionnaire on what has been termed the Medical Student Syndrome (MSS). If one would find a relation between fantasy proneness and thought suppression on the one hand, and MSS on the other hand, one may argue that individuals high on fantasy proneness and thought suppression exaggerate previous experiences. 



\title{
Chapter 3
}

\section{Accuracy, completeness, and consistency of emotional memories ${ }^{*}$}

\begin{abstract}
Judges and lawyers often consider inconsistent testimonies to be inaccurate. We tested this assumption by asking undergraduate students on two occasions separated by several weeks to provide detalled written accounts of a violent movie fragment $(N=41)$. Their testimonies were evaluated in terms of accuracy, completeness, and consistency. Both trestimonies tended to be rather accurate, accuracy rates being .89 and .88 , respectively. Moreover, participant's first testimonies were more complete than their second testimonies, completeness rates being .71 and .66 , respectively. Number of inconsistencies between the two testimonies was not related to the accuracy of either testimony, Pearson correlations being .03 $(p=.84)$ and $.14(p=.40)$ for the first and the second account: respectively. This shows that in general, inconsistencies are not valid predictors of testimonial inaccuracy.
\end{abstract}

"Candel, 1., Smeets, T., \& Merckelbach, H. (submitted for publication). 


\section{Introduction}

Eyewitnesses are usually interviewed multiple times about an emotional negative event. With repeated interrogations, inconsistencies between their testimonies may occur. Berman, Narby, and Cutler (1995) found that undergraduates perceive inconsistent eyewitnesses less credible than consistent eyewitnesses. Also judges and lawyers tend to believe that inconsistency is predictive of inaccuracy (Fisher \& Cutler, 1995). Inconsistencies involve both discrepancies between wo or more interviews and omissions in one or more testimonies (Brewer, Potter, Fisher, Bond \& Luszcz, 1999). In both cases, triers of fact consider an eyewitness to be inaccurate. Note that this heuristic assumes that there is an intimate association between consistency and accuracy. Meanwhile, Fisher and Cutler (1995) found correlations between consistency and accuracy to be rather modest, with $r$ 's ranging from .01 to 37 . These authors asked eyewitnesses to describe the offender of a staged robbery. Several days later, participants were asked once more to describe the offender. Inconsistencies within a witness' testimony were not predictive of global accuracy. These results are in line with those of Brewer et al. (1999). In their study, participants watched a videotape of a crime after which they completed a questionnaire containing questions about the event. Approximately two weeks later, witnesses completed the same questionnaire for a second time. The correlation between overall consistency and accuracy was .30. The authors concluded that one "cannot claim that consistency is a strong predictor of overall accuracy" (Brewer et al., 1999; p. 311).

The few studies that focussed on the consistency-accuracy link defined accuracy in terms of the number of correct details. However, this is only one index of accuracy. Another index is provided by the number of distortions and/or commission errors. A distortion is a major change in the details of an existing element (e.g." "a red Volkswagen" in stead of "a green Volkswagen"), while a commission error refers to the introduction of an entirely novel element (see Gudjonsson \& Clare, 1995). Even if a testimony is consistent and accurate in the sense that it contains no distortions or commissions, it may still be incomplete. Omission errors undermine the completeness of statements. People even tend to omit important details of highly emotional events. A good example is provided by the study of Bidrose and Goodman (2000) who compared allegations of four girls about sexual abuse with forensic evidence contained in photographs and audio raped records of the abuse. Although their levels of testimonial accuracy was high, their levels of omissions were also high, indicating incompleteness.

The airn of the current study was to examine the relationships between accuracy, consistency, and completeness of eyewitness testimonies. Participants watched an upsetting movie fragment. Immediately afterwards and with a delay of 
severall weeks, they were asked to give detailed descriptions of the persons and events they had seen.

\section{Method}

\section{Participants}

Participants were 52 undergraduate psychology students (46 women) at Maastricht University. Their mean age was 20 years $(S D=3.22$; range: $17-33$ years). Participants were tested individually. Three to four weeks after the first interview, participants received a questionnaire and a cover letter that invited them to write down the movie fragment they saw in as much detail as possible. Forty-one students (35 women) completed and returned this questionnaire (response rate 79\%). The mean age of this sample was 20 years $(S D=3.52$; range: 17-33). Participants received course credits in return for their participation.

\section{Movie fragment}

Participants watched an emotional fragment of the movie "American History $X$ " directed by Tony Kaye (1998). In this fragment, three Afro-Americans are stealing a car. The owner catches them, shoots two of them and horribly maltreats the third one. The fragment is extremely violent en upsetting and contains remarkable details (e.g., tattoos). The duration of the fragment is about $2 \mathrm{~min}$.

\section{Procedure}

Participants were invited into our lab and were asked to rate their anxiety level and their tension level on two $100 \mathrm{~mm}$ Visual Analog Scales (VAS's; anchors: $0=$ not at all; $100=$ extremely). Next, they watched the movie fragment. As part of a $5 \mathrm{~min}$ filler task, they rated the impact of the fragment, their anxiety level, and their tension level on $100 \mathrm{~mm}$ VAS's (anchors: $0=$ not at all; $100=$ extremely) and completed several personality questionnaires, which will not be considered here. Finally, they were asked to provide a detailed writien account of the incident displayed in the movie fragment. The instruction was as follows: "Imagine that the incident you saw in the movie was a real-life incident. You are an eyewitness and you have to make a statement in the police station. Write down the incident, that is all events and their order, all persons and their characteristics, and all central and peripheral details. All information might be important to the police. Please, write everything down in as much detail as possible." After three to four weeks ( $m=26$ days, $S D=4.5$ ) participants received a questionnaire with a cover letter reminding them of the movie fragment they had seen. Again, they were asked to write down the event in as much detail as possible. 


\section{Dependent measure}

A detailed answer guide was developed to evaluate participants' written account. This guide summarised offender, victim, and event characteristics (e.g., race, hair, tattoo, shooting, breaking glass, arrival of police car) that were clearly observable in the fragment. There were 31 such characteristics (table 3.1) in the 2 min fragment. An independent judge used this guide to compute number of correctly reported details, commissions, distortions, and omissions for written accounts obtained during the first and second test occasion. The maximum number of correctly recalled details was, of course, 31 . We computed an index of accuracy as follows: number of correctly recalled details / [number of correctly reported details + number commissions + number distortions]. Thus, if a witness recalled 7 items correctly, made 1 commission error and 1 distortion, his/her accuracy rate is $7 / 9$ or .78. Higher scores, then, indicate higher levels of accuracy. We also calculated a completeness rate, which was defined as [31 - number of omissions]/31. Thus, if a witness made 12 omission errors, his/her completeness rate is [31-12]/31 or .61. Again, higher rates indicate higher levels of completeness. Finally, we construed a measure of inconsistency. To this end, we compared for each participant his/her first and second account with each other. We counted the total number of direct discrepancies between the two accounts and the total number of additions and omissions in the second account relative to the first one, with higher scores indicating higher levels of inconsistency.

As a check on the reliability of our scoring system, we had a second rater evaluating the number of commissions, distortions, omissions, and inconsistencies in 10 arbitrarily selected accounts. Across these 10 accounts, the inter-rater agreement was .77 for number of commissions, .73 for number of distortions, .99 for number of omissions, and .74 for number of inconsistencies. Thus, these data support the reliability of our system. 
Table 3.1 Answer guide

$\begin{array}{ll}\text { Perpetrator: } & \text { White } \\ & \text { Bold } \\ & \text { Fringe of beard } \\ & \text { Boxer short } \\ \text { Tattoo } \\ \text { Swastika } \\ \text { Barbed wire } \\ \text { Shoes } \\ \text { Gun } \\ \text { Three } \\ \text { Black } \\ \text { Hat } \\ \text { Two man down the stairs } \\ \text { Brother has to wait } \\ \text { Perpetrator looks through spy hole } \\ \text { Perpetrator } \\ \text { Perpetrator opens door } \\ \text { Perpetrator shoots } \\ \text { Shoots man in front of door } \\ \text { Shoots other attacker } \\ \text { Shoots car } \\ \text { Gun is empty } \\ \text { Car leaves } \\ \text { Car windows breaking } \\ \text { One attacker on curb } \\ \text { Perpetrator kicks head } \\ \text { Brother shouts 'no' } \\ \text { Perpetrator spits } \\ \text { Police car arrives } \\ \text { Siren } \\ \text { Brother collapses } \\ \end{array}$

\section{Results}

\section{Manipulation checks}

After exposure to the movie fragment, participants gave higher anxiety ratings than before the fragment, means being $23.46(S D=20.26)$ and $7.08(S D=9.31)$, respectively $[t(51)=5.63 ; p<.001]$. Much the same was true for tension ratings, means being $36.38(S D=22.72)$ and $23.29(S D=19.8)$, respectively $[r(51)=3.82$; $p<.001]$. Mean rating of the impact of the movie fragment was $79.62(S D=12.86)$, which is relatively high given the fact that the maximum score is $\rrbracket 00$. 


\section{Memory performance}

Accuracy. Descriptive statistics for written accounts on both test occasions are shown in table 3.2. Bonnferoni corrected paired $t$-tests $(a=1 \%)$ were conducted on the number of correctly reported details, commissions, distortions, and on accuracy rates of written accounts obtained during the first and second test occasion. Number of correct details decreased from the first to the second test occasion $[t(40)=5.72 ; p$ $<.01]$. Commissions and distortions did not change significantly over time (both $t$ 's $<2.1$; both $p$ 's $>.01$ ). Overall, participants' testimonies were rather accurate, with average accuracy rates being .89 for the first account and .88 for the second account. In other words, testimonies were relatively free of commission and distortion.

Significant Pearson correlations were found between numbers of correctly reported details $(r=.73, p<.01)$, and between accuracy rates in both accounts $(r=$ $.47, p<.01)$. For numbers of commissions and distortions, these correlations remained non-significant ( $r=.27, p=.08$ and $r=.02, p=.91$, respectively).

Completeness. Witnesses made more omission errors on the second than on the first test occasion $[t(40)=-6.56 ; p<.001]$. As a consequence, completeness rate decreased over time $[t(40)=6.56 ; p<.001]$. Significant correlations were found between omissions in both accounts $(r=.70, p<.001)$ and between completeness rates in both accounts $\left(r^{*}=.70, p<.001\right)$.

Consistency. Mean number of inconsistencies was $6.13(S D=2.41$; range 2-13). Pearson correlations were computed between accuracy rates, completeness rates, and inconsistencies in both test occasions. As can be seen in Figure 3.1, number of inconsistencies was not related to the accuracy rate of either the first or the second account: $r=.03$ and $r=-.14$, respectively (both $p ' s>.05$ ). However, for the first but not the second account, a significant but moderate correlation emerged between inconsistencies and completeness $(r=32, p<.05$. Moreover, for both test occasions significant but moderate correlations were found between accuracy and completeness $(r=.30$ and $r=.31$; both $p$ "s $<.05)$.

Table 3.2 Nwmber of correctly reported details, commissions, distortions, and omissions, and accuracy and completeness rates for accounts obtained during test occasion I and 2 (standard deviations between parentheses)

\begin{tabular}{lll}
\hline & Test occasion 1 & Test occasion 2 \\
\hline Correctly reported details & $16.46(3.91)$ & $13.85(3.51)$ \\
Commissions & $0.56(0.80)$ & $0.71(1.03)$ \\
Distortions & $1.46(1.11)$ & $1.10(1.02)$ \\
Omissions* & $13.08(3.93)$ & $16.05(3.43)$ \\
Accuracy rate & $.89(0.09)$ & $.88(0.09)$ \\
Completeness rate $^{*}$ & $.58(0.13)$ & $.48(0.11)$ \\
\hline
\end{tabular}

$p<.05$ 

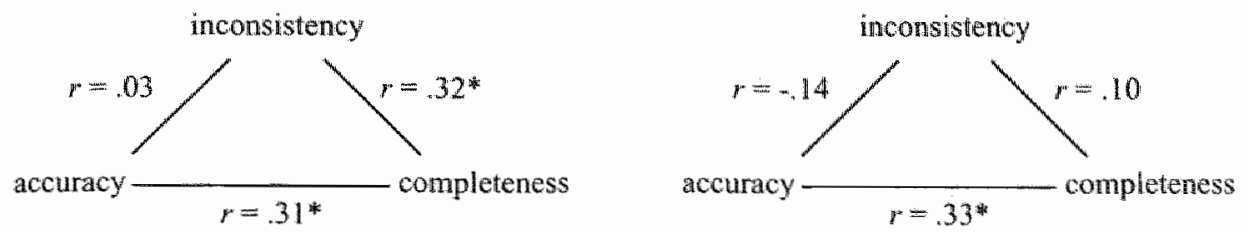

$* 0.05$

Figure 3.1 Pearson product-moment comelations between accuracy and completeness rates of the first account (left pane) and of the second account (right panel) and inconsistencies between both accounts

\section{Discussion}

The main results of the current study can be summarized as follows. To begin with, on the whole, reports of witnesses were highly accurate. On both test occasions, accounts were relatively free of distortions and commissions. Secondly, after a delay of three to four weeks, participants became more incomplete. Thirc, inconsistencies were not related to the accuracy of either the first or the second account.

Our finding that participants were rather accurate is well in line with field studies of Yuille and Cutshall (1986), Bidrose and Goodman (2000) and Peterson, Moores, and White (2001). In the Yuille and Cutshall's study (1986), 13 witnesses who observed a shooting incident were interviewed twice about the event. The first interview took place within 2 days after the event, while the second interview was conducted 4 to 5 months after the event. Accuracy levels ranged from $73 \%$ to $89 \%$. Moreover, as was the case in the current study, Yuille and Cutshall (1986) noted that there was virtually no change in accuracy over time. Bidrose and Goodman (2000) evaluated testimonies of four girls about sexual abuse against forensic evidence contained in photographs and audio taped records of the abuse. Again, accuracy rates were found to be relatively high (i.e, $80 \%$ ). Peterson, Moores, and White (2001) interviewed children four times about an injury that required hospital Emergency Room treatment. Details recalled during every interview were virtually always accurate.

Despite their high accuracy levels, participants' accounts in the current study were far from complete. This finding is consistent with that of Bidrose and Goodman (2000) who reported that victims failed to describe $39 \%$ of the sexual acts. Note, however, that in our study, the completeness depends on the number of critical elements derived from the story (i.e., 31). With the length and complexity of the story in mind, one could counter that these 31 elements provide a very rough 
estimate of completeness. However, our point is that these elements represent the most obvious and straightforward features of the story, thereby providing a conservative approach to completeness. Further, our data show that participants become less complete over time, a finding that fits with the traditional Ebbinghausian (e.g., 1885/1954) view that memory performance deteriorates at a decreasing rate as a function of retention-interval length. Interestingly, some studies on repeated eyewitness recall noted that time-limited recall might become more complete with repeated interviews (e.g., Bornstein, Liebel \& Scarberry, 1998; Turtle \& Yuille, 1994), a phenomenon termed hypermnesia. Although the hypermnesia phenomenon appears to contradict with the typical forgetting effect obtained in the current study, Wheeler and Roediger (1992) found evidence suggesting that short intervals (i.e., minutes) may lead to hypermnesia, while long intervals (i.e., weeks) promote forgetting. Since long intervals are typical for forensic settings, it is intuitively plausible to assume that with repeated interrogations, omissions will increase and completeness will decrease.

The received view among lawyers as well as lay people is that inconsistent testimonies are inaccurate testimonies (see, for examples, Brewer et al., 1999; Herlihy, Scragg \& Turner, 2002). Our findings concur with those of Brewer et al. (1999) and Fisher and Cutler (1995) in showing that this popular view lacks firm empirical basis. Thus, two testimonies can be both accurate and inconsistent. In the current study, inconsistent testimonies were in general characterized by omission errors in the second account. Admittedly, to the extent that inconsistencies involve contradictions, at least one testimony is inaccurate. However, such contradictions are caused by distortions and our data show that they are relatively rare. Our data indicate that omissions account for the large majority of discrepancies. Therefore, the fact that initially complete testimonies are vulnerable to inconsistencies $(r=.32$; $p<.05)$ mainly originates from the typical forgetting effect.

As far as we know, only Yuille and Cutshall (1986) looked at the relationship between accuracy and completeness. In their study, the accuracy of reported details was not related to the proportion of correct details, with Pearson correlations ranging from 05 to 23 . Our results replicate Yiulle and Cuthall's (1986) finding in that they show that the link between accuracy and completeness is, at best, a modest one $(r=31)$.

In sum, then, the results of the current study indicate that accuracy, completeness, and inconsistency are three loosely coupled dimensions of testimonial quality. The implication of this is that, in contrast to prevailing notions, one cannot rely on inconsistencies to evaluate the accuracy or completeness of testimonies. 


\title{
Chapter 4 Boundary distortions for neutral and emotional pictures*
}

\begin{abstract}
In two experiments, we examined Safer et al.'s (1998) claim that when remembering enotional material, tunnel memory (i.e., the tendency to remember less of a scene than was actually shown) occurs. In experiment 1,81 undergraduate students drew photographs out of memory after having briefly seen either 4 neutral or 4 emotional photographs. Both neutral and emotional drawings revealed boundary extension (i.e., the tendency to remember more of a scene than was actually shown). Experiment 2 relied on the "camera distance" paradigm (Intraub et al, 1992). In a recognition test, 60 undergraduate students judged the camera distance of previously seen neutral or emotional photographs. The majority of them demonstrated accurate judgements and neither extended nor restricted picture boundaries. Those participants who made an error more often displayed a boundary extension than a tunnel memory error. Taken together, our results suggest that boundary extersion for neutral and emotional photographs is a more robust phenomenon than its counterpart, tunnel memory.
\end{abstract}

* Candel, I., Merckelbach, H., \& Zandbergen, M. (in press). Pyychonomic Bullerin d Review.

Acknowledgement

We would like to thank Professor Intraub for her comments on an earlier draft of this section. 


\section{Introduction}

Over the past few years, memory illusions have been the object of numerous studies (see for a review, Schacter, 1999). One type of illusion that occurs when people try to remember neutral photographs is known as the boundary extension phenomenon. This phenomenon refers to the tendency to remember information that was not in the picture, but that was likely to have existed just outside the camera's field of view (Intraub \& Richardson, 1989). Evidence for this distortion has been obtained with a wide variety of memory tests. For example, when participants are exposed to neutral photographs and then asked to draw these photographs as accurate as possible from memory, their drawings tend to contain a greater proportion of background than was actually shown (Intraub \& Richardson, 1989; Intraub \& Bodamer, 1993). Extended boundaries can also be demonstrated with recognition tests (e.g., the camera distance paradigm; Intraub, Bender \& Mangels, 1992; Intraub \& Bodamer, 1993; Nyström, 1992). Typically, following exposure to neutral photographs, participants are confronted with test photographs. They are asked to judge whether the test photographs are the same, closer-up or farther away compared to the originals. In general, participants tend to accept wide-angled distracters as copies of the originals, indicating that they remember more of the scene than was actually shown. Nyström (1993) found evidence for boundary extension when he asked participants to move - physically - boundaries of test pictures in order to match their recollections of the original photographs.

Although boundary extension is a robust phenomenon, it appears to have some constraints. For example, the amount of extension is maximal when the original pictures are "close-ups". The degree of boundary extension decreases as original photographs become more wide-angled and at some point no distortion occurs. Another limiting condition is time. With the passage of time between exposure to original photographs and reproduction during a subsequent test, boundary extension disappears (e.g., Intraub et. al., 1992).

Intraub and her colleagues (e.g., Intraub, Gottesman \& Bills, 1998) argue that boundary extension is the result of an automatic perceptual schema activation. When viewing a picture - which is a part of a scene - general expectations about that scene are activated. Eventually, these expectations are incorporated into memory and give rise to incorrect extensions when people try to reconstruct the original picture. In the words of Gottesman and Intraub (1999; p. 86): "When we view a picture of a scene, the visual system rapidly and automatically extrapolates beyond the borders of that view. Boundary extension is thought to occur because the expected regions just outside a picture's borders are so integral to comprehension of the picture that the expected information becomes incorporated in the viewer's mental representation." 
There is a paucity of experimental work addressing representations of emotional photographs. One exception is the study by Safer, Christianson, Autry. and Osterlund (1998). These authors argue that when viewing emotionally arousing photographs, attention automatically narrows to details that constitute the source of the emotional arousal (i.e., attentional-narrowing hypothesis, Christianson, 1992a). This would result in what the authors call tunnel memory, which refers to pool memory for information in the mental periphery and a relatively strong memorial representation of critical and central details. The experiments by Safar and coworkers (1998) provide some support for such a pattern. In their studies, participants saw a series of photographs that formed a story line. Half of the participants were shown a neutral story, while the other half saw an aversive story. The two stories differed in two photographs, the targets. During the recognition test of experiment 4, test pictures of the target scenes were presented, but they had been photographed with different focal lengths (i.e., the camera distance recognitionparadigm; Intraub et al., 1992). Participants had to judge whether the camera distance was much closer, slightly closer, identical, slightly farther, or much farther than the original. They tended to accept a more close-up version of the emotional target (i.e., tunnel memory) and a more wide-angle version (i.e., boundary extension) of the corresponding neutral target. However, in their experiment 3 , Safer et al. found the opposite pattem. During the recognition phase of that experiment, participants evaluated photographs that were exact copies of the targets. They were led to believe that the test stimuli had been photographed with different focal lengths. For the first test picture, participants were quite accurate in recognizing that the camera distance was the same as that of the original target. That is, no boundary distortion occurred for neutral or emotional material. However, on the second test picture, the neutral and the emotional group displayed boundary extension. Taken together, these results suggest that under some conditions that are not well understood, tunnel memory for negative material might accur. Boundary distortions in remembering emotionally negative photographs therefore warrants further study. The current experiments address this issue by using two different methods for testing memory for negative photographs. Experiment 1 relied on a drawing task, while experiment 2 employed camera distance evaluation.

\section{EXPERIMENT 1}

Boundary distortions for emotional material has not been examined with what appears to be one of the most straightforward and relliable methods for studying such distortions, namely the drawing task described by Intraub and co-workers 
(1989, 1993). With this in mind, we conducted experiment 1 . On the basis of the Safer et al. (1998) findings (experiment 4), we anticipated that tunnel memory (boundary restriction) would occur for drawings of aversive photographs, but boundary extension for drawings of neutral material.

\section{Method}

\section{Participants}

Participants were 81 Maastricht University undergraduates (60 women). Their mean age was 20 years (SD $=1.33$; range: $18-23$ years). Participants were tested individually. They received a small financial compensation in return for their participation.

\section{Materials}

There were two types of stimuli, namely neutral and emotional photographs. Neutral photographs used in previous studies of Intraub and her colleagues (e.g., Intraub \& Berkowits, 1996; Intraub, Gottesman, Willey \& Zuk, 1996) were downloaded from the web ${ }^{4}$. Emotional photographs were drawn from the International Affective Picture System (IAPS; Lang, Bradley \& Cuthbert, 1995). For this experiment, we selected 4 aversive photographs. Like the neutral photographs, they depicted single objects (i.e., a decomposed dog, a wounded hand, a wounded face, and a gun) against a simple background. In the normative sample of Lang and co-workers (1995), the aversive targets used in the current experiment were rated as highly unpleasant and highly arousing. The amount of space occupied by the objects was exactly the same for the photogtaphs. So, the potential for axtension or restriction was similar for the two types of photographs. Photographs were 100 by $150 \mathrm{~mm}$ (approx, 4 inch $x 6$ inch) and were presented on a computer screen with a grey background.

\section{Design and procedwre}

Participants were assigned to either the neutral $(n=42)$ or the emotional $(n=39)$ condition. In both conditions, participants saw 4 photographs, for $15 \mathrm{~s}$ each after they had read the following instructions (Gottesman \& Intraub, 1999): "You will be presented with 4 photographs, for $15 \mathrm{~s}$ each. Please pay close attention to each picture and try to remember the main object and the background in as much detail as possible. Try to remember everything in the picture, including its layout. That is,

\footnotetext{
http:/faculty-staflou.edu/G/Carmela.Gottesman-1/web
} 
the size and location of everything in the picture space. In other words, try to retain an exact copy of each picture in your memory."

Photograph sequence was counterbalanced and their presentation was followed by a drawing test. Response sheets were handed out in the same order as the picture presentation. The instruction for this task was taken from Gottesman and Intraub (1999; p. 90) and was as follows: "In each rectangle, draw the picture named above in as much detail as possible. Don't worry if you are not a great artist; just do your best to represent everything you saw in the picture. Consider the edges of the rectangle to be the edges of the picture you saw. Try to capture the layout of the picture. That is, try to draw everything in the same relative size and position as in the picture. After you draw each picture, make all the changes you think are necessary, and if you want to clarify any part of your drawing please feel free to use words as labels." Following the drawing test, participants were asked to rate the photographs on 9-point scales in terms of experienced pleasure, arousal, and threat (anchors: $1=$ not at all; $9=$ very much).

\section{Area Measurement}

All drawings were made within $100 \times 150 \mathrm{~mm}$ (approx. 4 inch $\times 6$ inch) rectangles. To measure the area of the pertinent object, we used the paper-and-pencil method described by Gottesman and Intraub (1999). Thus, all drawings were covered with a transparent graph paper (5 square/mm). Next, we counted the number of grid squares that each object covered and divided this number by the number of grid squares that the object in the original stimulus covered.

\section{Results and discussion}

\section{Manipulation check}

As can be seen in table 4.1, emotional photographs were rated as less pleasant [t(78) $=15.09 ; p<.001]$, more arousing $[t(78)=-7.39 ; p<.001]$ and more threatening $[t(78)=-8.88 ; p<.001]$ than neutral photographs.

Table 4.1 Mean ratings on pleasure, arousal, and threat of the photographs of participants in the neutral $(n=42)$ and the emotional $(n=38)$ condition (standard deviations are given between parentheses)

\begin{tabular}{llll}
\hline & Pleasure & Arousal & Threat \\
\hline Neutral & $5.74(.94)$ & $3.38(1.68)$ & $2.10(1.12)$ \\
Emotional & $2.75(.82)$ & $5.97(1.44)$ & $4.99(1.75)$ \\
\hline
\end{tabular}




\section{Drawings}

Due to technical problems, one participant's data were lost, leaving 80 participants for analysis. A total of 320 drawings (168 neutral and 152 emotional drawings) were obtained. An independent judge counted the number of grid squares that the main object covered in each drawing. By dividing the number of grid squares of the pertinent object in each drawing by the number of grid squares that the object covered in the original stimulus, we obtained the relative proportion that the reproduced object took up. A proportion of 1 is obtained when the object"s size is accurately captured in the drawing. A proportion smaller than 1 occurs when the object covers a smaller area in the drawing than in the original, thus indicating boundary extension. A proportion exceeding 1 occurs when the object covers a larger area in the picture space, thus indicating boundary restriction. Proportions ("proportions drawn"; Intraub \& Bodamer, 1993) were averaged across drawings of both categories (see table 4.2). The mean proportion drawn was significantly smaller than 1 for both neutral $[t(41)=21.21 ; p<.001]$ and emotional $[t(37)=$ $16.22 ; p<.001]$ objects, indicating that participants displayed extended boundaries for both neutral and emotional photographs. The amount of extension did not differ between the two picture categories $[t(78)=1.2 ; p=.23]$.

Table 4.2 Mean proportion drawn for each photograph and oweraged for newtral and emotional stimuli (standard deviations are given between paremtheses)

\begin{tabular}{lll}
\hline & Picture name & Mean proportion drawn \\
\hline Neutral & Bear & $.41(.17)$ \\
& Bananas & $.41(.25)$ \\
& Bucket & $.45(.23)$ \\
Mean & Tyre & $.57(.25)$ \\
Emotional & & $.46(.14)$ \\
& Decomposed dog & $.52(.16)$ \\
& Wounded hand & $.49(.27)$ \\
Mean & Wounded Face & $.34(.25)$ \\
\hline
\end{tabular}

Figures 4.1 and 4.2 show typical examples of boundary extension. The tendency to extend boundaries was not orly typical for proportions averaged over photographs. For each individual drawing in each category, the proportion drawn was less than 1 , except for 5 neutral drawings $(3 \times$ tyre, $1 \times$ bananas, $1 \times$ bucket) and 3 emotional drawings $(2 \times$ wounded hand, $1 \times$ wounded face). 

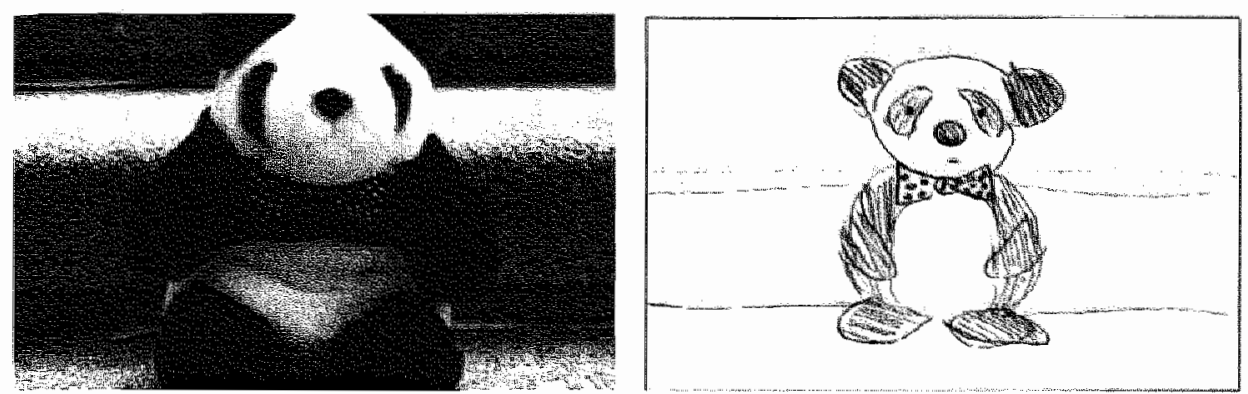

Figure 4. 1 Example of a neutral photograph (left) and a drawing showing boundary extension (right)
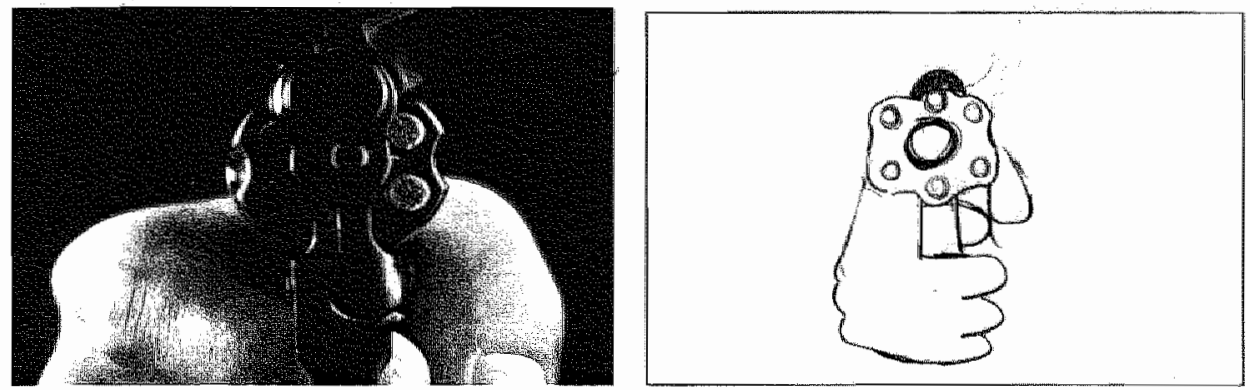

Figure 4.2 Example of an emotional photograph (left) and a drawing showing boundary extension (right)

The main results of experiment $\mathbb{1}$ can be summarized as follows. To begin with, our findings provide a straightforward replication of earlier work by Intraub and associates (e.g., Intraub \& Richardson, 1989; Intraub et al., 1992; Intraub \& Bodamer, 1993; Intraub et al. 1996) in that clear boundary extension occurred for neutral photographs. Secondly, in contrast to the tunnel memory phenomenon (i.e., boundary restriction) for aversive stimuli obtained by Safer et al. (1998) in their experiment 4 , our participants also extended boundaries for emotional photographs. Note that our findings are very similar to those found in Safer et al.'s (1998) experiment 3. The current findings seem to replicate those of Intraub et al. (e.g., $1989,1992,1993$ ) in showing that boundary extension occurs when remembering single, neutral photographs. Moreover, our results indicate that the same memory illusion occurs for emotional photographs. The perceptual schema hypothesis proposed by Intraub et al. (1998) offers the most parsimonious account for these results. Apparently, photographs activate perceptual schemata irrespective of their emotional valence. The information implicated by the schema is then incorporated 
in menory. Consequently, in remembering photographs, more background is assumed than was actually present ${ }^{3}$.

\section{EXPERIMENT 2}

The findings obtained in our first experiment are difficult to reconcile with those of Safer et al. (1998) who reported tunnel memory for emotional photographs in their experiment 4 . One reason for this discrepancy might be that the current experiment relied on isolated photographs, while Safer et al. made use of photographs that formed a story line. Perhaps, then, stories yield a schema that is superimposed on schemas for separate photographs. Such a higher order schema might give rise to tunnel memory, especially when a story is emotionally compelling. In experiment 2 , we tested whether tunnel memory would occur when emotional photographs form a story line. Furthermore, we adopted the "camera distance" paradigm described by Intraub et al. (1992) to assess boundary distortions in memory for neutral and matched emotional photographs.

\section{Method}

\section{Participants}

Participants were 60 Maastricht University undergraduates (44 women). Their mean age was 19 years $(S D=1.25$; range: $18-23$ years). Participants were tested individually. They received a small financial compensation in return for their participation.

\section{Materials}

Two series of colour photographs were used as stimulus material. The series consisted of three phases that formed a storyline. The storyline was inspired by that of Safer et al. (1998). The first phase of the neutral series showed a man arriving in his car at a house, where a woman opens the front door ( 4 photographs). The second

\footnotetext{
"One could counter that boundary extension has nothing to do with the activation of a perceptual schema. Individuals might just use less space when they draw previously viewed pictures. Gottesman and Intraub (2002) address this issue in a study in which they used pictures depicting a truncated view of a continuous world and pictures that did not. The results indicate that boundary extension only occurs when the background depicts parts of a continuous surface or when it can be construed as such. Boundary extension is eliminated wher backgrounds do not represent truncated views. So, boundary extension is related to background features rather than an artifact of drawing.
} 
and critical phase consisted of two photographs (target $I$ and 2): one of the man giving the woman a present and the other of the woman smiling (Figure 4.3). The third phase ( 3 photographs) showed the man leaving by car. The emotional series was identical to the neutral series with respect to the first and the third phase. The second phase of the emotional series also consisted of two photographs (target 1 and 2). However, here the first target showed the man threatening the woman with a knife and the second target showed the woman bleeding from a wound in her neck (Figure 4.4). Neutral and emotional pictures of all phases were photographed from identical distances and angles.
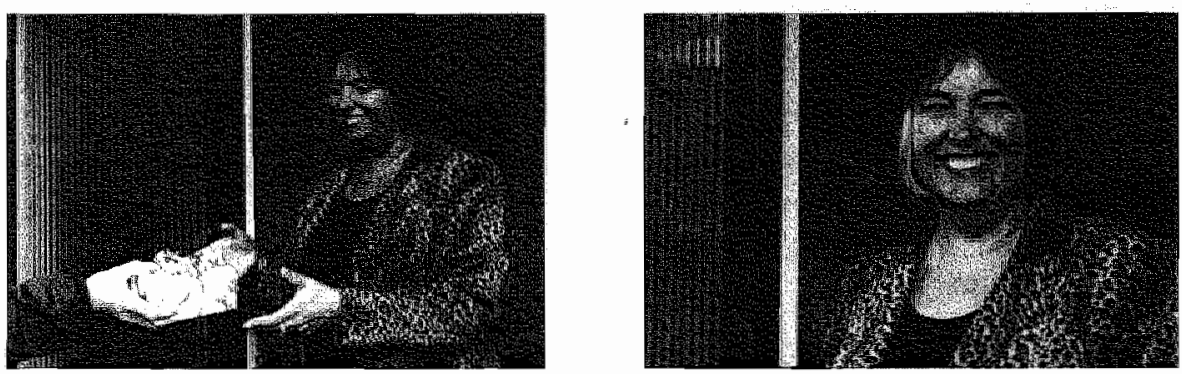

Figure 4.3 Target 1 and 2 in the neutral condition
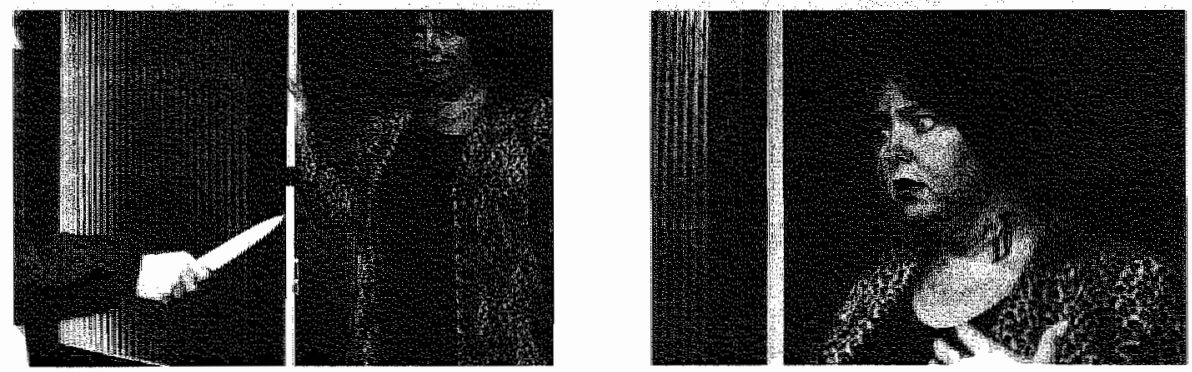

Figure 4.4 Target 1 and 2 in the emotional condition

\section{Design and procedure}

Participants were assigned to either the neutral $(n=30)$ or the emotional condition $(n=30)$. In both conditions, participants saw 9 photographs, for $5 \mathrm{~s}$ each. Photographs were presented on a computer screen with a grey background. The presentation was followed by 7 -min filler task that involved rating the story in terms of emotionality on a $100-\mathrm{mm}$ Visual Analog Scale $(0=$ not emotional at all, $100=$ extremely emotional) and answering questionnaires. Next, participants were given the camera distance instructions. They were told that they would see some of the 
photographs again, but that scenes might now be photographed from different camera distances. In fact; test photographs were exact copies of the original targets. Participants were asked to judge the camera distance on a 3-point scale: $-1=$ farther than original, $0=$ no change, and $+1=$ closer than original. They were given a practice item with an unrelated neutral photograph to make sure that they understood the instruction. Next, the two targets were presented for $15 \mathrm{~s}$ each.

\section{Results and discussion}

\section{Manipulation check}

The emotional story was rated as more emotional than the neutral story $[t(58)=$ $3.49 ; p<.01]$, theans being $42.10(S D=22.49)$ and $21.63(S D=22.99)$, respectively.

\section{Recognition test}

Chi-square tests (group by judgements) yielded no significant differences between the neutral and the emotional condition (all $p$ 's $>41$; Pearson Chi-Square, Likelihood Ratio, Linear by Linear) indicating that in both groups an equal number of participants endorsed the three answers options. Moreover, as can be seen in table 4.3 , the large majority of participants in both groups accurately recognized that test pictures were exact copies of the targets. Accordingly, in both groups, mean scores for target 1 and 2 did not differ significantly from zero ("no change"), all $t$ 's $<1.0$, all $p$ 's $>.05$. Hence, neither group showed boundary extension or boundary restriction. However, those individuals who did endorse an incorrect option for target 1 significantly more often reported boundary extension ("closer") than boundary restriction ("farther") $\left[\chi^{2}(1)=6.37 ; p<.01\right]$. No such difference was found for target $2\left[\chi^{2}(1)=0.74 ; p=.39\right]$.

The main results of experiment 2 can be summarized as follows. To begin with, participants were quite accurate in recognizing that boundaries of test stimuli in the camera distance task were the same as those of the original targets. In addition, for the first but not the second target, individuals who gave an incorrect camera distance judgement, displayed a tendency to extend boundaries, irrespective of the emotional valence of the targets. To a certain degree, these results resemble those found in Safer et al.'s (1998) experiment 3. In that experiment, the authors also failed to obtain tunnel memory or boundary extension for the neutral or the enotional target 1 . Moreover, contrary to their prediction, both groups extended boundaries for target 2 . 
Table 4.3 Frequency and percentage of paricipants that endorsed edet camera distance oprion for the wo target photographs

\begin{tabular}{llcll}
\hline & Neutral $(n=30)$ & \multicolumn{2}{c}{ Emotional $(n=30)$} \\
\hline & Target 1 & Target 2 & Target 1 & Target 2 \\
\hline Farther & $2(7 \%)$ & $4(13 \%)$ & $2(7 \%)$ & $2(7 \%)$ \\
No change & $20(67 \%)$ & $23(77 \%)$ & $21(70 \%)$ & $24(80 \%)$ \\
Closer & $8(26 \%)$ & $3(10 \%)$ & $7(23 \%)$ & $4(13 \%)$ \\
\hline
\end{tabular}

\section{General Discussion}

Using two different sets of stimuli and two different memory tests, the findings of our experiments do not support Safer et al. "s claim that compared to neutral scenes, aversive scenes are remembered in a tunnel-like fashion. More specifically, in the free-recall drawing task of experiment $I$, participants extended rather than restricted boundaries for neutral as well as emotional photographs, indicating that they remembered a wide-angle version of both types of targets. In experiment 2 , the majority of participants in the neutral as well as the emotional condition were quite accurate in recognizing that test stimuli were exact copies of the targets. Moreover, most participants who did display a boundary distortion for target 1 extended ther than restricted photograph boundaries.

The current results demonstrate that when boundary distortions occur in memory for neutral or emotional pictures, they are likely to be extensions rather than restrictions implicated by the concept of tunnel memory. Thus, our findings support Intraub's (e.g, 1998) view that when remembering scenes, people rely on a perceptual schema that elicits extension tendencies. Perhaps, then, boundary extension is immune to emotional content because it involves early perceptwal processes rather than relatively late reconstructive memory processes.

At first sight, boundary extension for emotional material appexts to contradict the well-documented phenomenon of weapon focus (Steblay, 1992). Weapon focus is defined by good memory for central details and poor memory for peripheral details. However, it should be stressed that boundary extension refers to proportional relations between central and peripheral details and not to their accuracy per se. That is to say, a highly extended representation is defined by reduced central details and enlarged peripheral details. Such pattern does not necessarily imply an inaccurate memory for central details. Meanwhile, commission and/or omission errors in peripheral information may accompany boundary extension (see for an example, Intraub \& Richardson, 1989) and precisely these errors may also occur as by-products of the weapon focus phenomenon 
(Steblay, 1992). Boundary extension and weapon focus are therefore not necessarily competing phenomena.

How do our findings relate to those of Safer et al. (1998)? In our view, the data presented by Safer et al. (1998) are far less convincing than the title of their study suggests. Straightforward boundary restriction for emotional material did only show up in one of their studies (i.e., experiment 4), while boundary extension for emotional material was found in one of their other studies (i.e., experiment 3 ). On the basis of their findings and the current results, we would argue that boundary extension is a more common phenomenon than tunnel memory. It appears that the latter phenomenon only occurs under specific conditions. Interestingly, the experiment in which Safer et al. (1998) obtained a tunnel memory effect relied on a recognition test in which participants evaluated test stimuli that deviated from the original targets. It is possible that tunnel memory critically depends on this paradigm. However, if this would be the case, the question arises whether boundary restriction tells us something about the features of emotional memory or about confusion created by exposure to deviant test stimuli. Clearly, this issue requires further study. 


\title{
Chapter 5
}

\author{
How children remember neutral \\ and emotional pictures: Boundary \\ extension in children's scene \\ memories*
}

\begin{abstract}
Boundary extension refers to the tendency to remember more of a scene than was actually shown. The dominant interpretation of this memory illusion is that it originates from schemas that people construct when viewing a scene. Evidence for boundary extension has primarily been obtained with adult participants who remember neutral pictures. The current study addressed the developmental stability of this phenomenon. Thus, we investigated whether children aged 10-12 years display boundary extension for both neutral and emotional pictures. Eightyseven children drew pictures from memory after they had seen either neutral or emotional pictures. Both their neutral and emotional drawings revealed boundary extension. Apparently, the schema construction that underlies boundary extension is a robust and ubiquitous process.
\end{abstract}

\footnotetext{
"Candel, I., Merckelbach, H., Houben, K., \& Vandyck, I. (submitted for publication).
} 


\section{Introduction}

When people try to remember neutral pictures, they recall more of the scene than was actually shown. This phenomenon is called boundary extension (Intraub \& Richardson, 1989). Evidence for this memory illusion has been obtained in many studies using different memory tests. A nice example is provided by a study of Intraub and Richardson (1989). These authors presented participants with pictures of common, neutral objects (e.g., flowers, car, telephone). When participants drew these pictures from memory, they reproduced the pictures with more expansive boundaries. Similar results were obtained using a recognition test known as the camera distance paradigm (e.g., Intraub \& Richardson, 1989; Intraub \& Bodamer, 1993; Intraub, Bender \& Mangels, 1992). In this paradigm, participants are confronted with test pictures following exposure to neutral pictures. They are then asked to judge whether the test pictures are the same, closer-up or farther away compared to the originals. In general, participants tend to accept wide-angled distracters as copies of the originals, indicating that they remember more of the scene than was actually shown.

Safer, Christianson, Autry, and Österlund (1998) speculated that in remembering emotional pictures boundary restriction rather than extension might occur. Boundary restriction, which is sometimes termed 'tunnel memory', refers to the tendency to remember less of a scene than was actually shown. The authors argued that when viewing an emotional scene, attention automatically narrows to the critical details that are the source of the emotional arousal. Tunnel memory would be the result of this attentional narrowing. However, evidence for the occurrence of boundary restriction/tunnel memory is weak. Using a recognition test, Safer et al. (1998) obtained clear-cut boundary restriction in only one of their 4 studies (i.e., experiment 4), while boundary extension was found in one of their other studies (i.e., experiment 3 ).

Recently, Candel, Merckelbach, and Zandbergen (in press) obtained clear evidence for boundary extension in remembering emotional pictures. In their study (experiment 1), participants were asked to draw pictures from memory after they had seen either neutral or emotional pictures. Participants" reproduction of both neutral and emotional pictures revealed boundary extension. The degree of extension was highly comparable for the two classes of pictures. Thus, irrespective of their valence, people have the tendency to remember more of a scene than was shown.

Intraub and co-workers (e.g., Intraub, et al., 1992; Intraub, Gottesman \& Bills 1998) argued that the boundary extension phenomenon originates from perceptual schemata that people construct when they view scenes. According to this view, picture perception activates a mental scene schema that provides observers 
with an immediate understanding of what is likely to exist just outside the boundaries of a picture. Next, the information contained in the schema becomes incorporated in the observer's mental representation of that picture. The enpirical evidence for this perceptual schema account is fairly strong (see Intraub, at al., 1998; Candel et al., in press). Note further that the perceptual schema account more or less precludes occurrence of a boundary restriction/tunnel memory effect. Nevertheless, many questions remain. For example, do children exhibit extended boundaries in their memories for scenes? With the exception of a study by Seamon, Schlegel, Hiester, Landau, and Blumenthal (2002), no study has addressed this issue. In the Seamon et al. (2002) study, participants of different age categories (i.e., 6-7 years, 10-12 years, 18-21 years, and 58-84 years) drew pictures from memory after they had been briefly exposed to the originals. All age groups produced pictures with extended boundaries. However, children and older adults appeared to be more susceptible to the boundary extension illusion than college students. Because Seamon et al. (2002) did not include emotional pictures, the aim of the current study was to explore whether children have the tendency to remember both neutral and emotional pictures with extended boundaries. Arguably, this issue bears relevance to the legal domain. In the past years, children's eyewitness testimonies have been the object of many heated controversies (e.g., Bruck, Ceci \& Hembrooke, 1998). To evaluate their boundary extension tendencies, we asked children to draw pictures from memory after they had seen either neutral or emotional pictures.

\section{Method}

\section{Children}

The study involved 87 primary school children ( 58 girls). Their mean age was 10.71 years $(S D=0.59$; range: $10-12$ years). Children were tested individually and participated in the experiment after parents and teachers had given informed consent.

\section{Materials}

We used two types of stimuli, neutral and emotional pictures. Neutral pictures (i.e., a tyre, bananas, a bucket, and a bear) were used in previous studies of Intraub and her colleagues (e.g., Intraub \& Berkowits, 1996; Intraub, Gottesman, Willey \& Zuk, 1996 ) and were downloaded from the web ${ }^{6}$. Emotional pictures were selected from the International Affective Picture System (IAPS; Lang, Bradley \& Cuthbert, 1995). Like the neutral pictures, emotional pictures depicted single objects (i.e., a shark, a

${ }^{6}$ http://faculty-staff.ou.edu/G/Carmela.Gottesman-1/web 
snake, a gun, and a knife) against a simple background. In a study of Lang and coworkers (1995), children rated the aversive targets used in the current experiment as highly unpleasant and highly arousing. The amount of space occupied by the objects was exactly the same for the two classes of pictures $[t(6)=-.25 ; p=.81]$. So, the potential for extension or restriction was similar for neutral and emotional pictures. Pictures were 100 by $150 \mathrm{~mm}$ (approx. 4 inch $\times 6$ inch) and were presented on a computer screen with a grey background.

\section{Design and procedure}

Children were assigned to either the neutral $(n=43)$ or the emotional $(n=44)$ condition. The groups were matched on age and sex. In both conditions, participants were instructed as follows (Gottesman \& Intraub, 1999): "You will be presented with 4 pictures, for $15 \mathrm{~s}$ each. Please pay close attention to each picture and try to remember the main object and the background in as much detail as possible. Try to remember everything in the picture, including its layout. That is, the size and location of everything in the picture space. In other words, try to retain an exact copy of each picture in your memory."

Children then viewed the pictures. Picture sequence was counterbalanced and their presentation was followed by a drawing test. The instruction for this task was taken from Gottesman and Intraub (1999; p. 90) and was as follows: "In each rectangle, draw the picture named above in as much detail as possible. Don't worry if you are not a great artist; just do your best to represent everything you saw in the picture. Consider the edges of the rectangle to be the edges of the picture you saw. Try to capture the layout of the picture. That is, try to draw everything in the same relative size and position as in the picture. After you draw each picture, make all the changes you think are necessary, and if you want to clarify any part of your drawing please feel free to use words as labels." Response sheets were handed out in the same order as pictures had been presented. A one-word title on the top of the sheet indicated the picture to be drawn. Moreover, each sheet contained a rectangle, which measured $100 \times 150 \mathrm{~mm}$ (approx. 4 inch $\times 6$ inch). Thus, rectangles had the same size as original stimuli. Following the drawing test, participants were asked to rate pictures on 5-point scales in terms of experienced pleasure, comfort, and threat (anchors: $1=$ not at all; $5=$ very much). Either a smiling or a frowning face accompanied the anchors to clarify their meaning.

\section{Area Measwrement}

To measure the area of the main object, we used the paper-and-pencil method described by Gottesman and Intraub (1999). Thus, all drawings were covered with a transparent graph paper ( 5 square/mm). Next, the number of grid squares that each object covered was counted and divided by the number of grid squares that the 
original stimulus covered. A proportion of 1 , then, indicates that the object"s size is accurately captured in the drawing. A proportion smaller than 1 indicates boundary extension (i.e., the object covers a smaller area in the drawing than in the original). A proportion exceeding 1 indicates boundary restriction (i.e., the object covers a larger area in the picture space).

\section{Results}

\section{Manipulation check}

Emotional pictures were rated as less pleasant than neutral pictures $[t(85)=-9.44 ; p$ $<.001]$, means being $2.56(S D=0.87)$ and $4.08(S D=0.56)$, respectively. Moreover, emotional pictures were rated as more uncomfortable than neutral pictures $[t(85)=-6.10 ; p<.001]$, means being $4.06(S D=0.63)$ and $3.00(S D=$ 0.95), respectively. Similarly, emotional pictures were evaluated as more threatening than neutral pictures $[t(85)=-7.89 ; p<.001]$, means being $4.38(S D=$ $0.75)$ and $2.73(S D=1.16)$, respectively.

\section{Drawings}

We obtained a total of 348 drawings (172 neutral and 176 emotional drawings). An independent judge measured the area each object covered. The obtained proportions ("proportions drawn"; Intraub \& Bodamer, 1993) were averaged across drawings of both categories (see table 5.1). The mean proportion drawn was significantly smaller than 1 for both neutral $[f(42)=-11.41 ; p<.001]$ and emotional $[t(43)=-$ $19.94 ; p<.001]$ pictures, indicating that children displayed boundary extension for both neutral and emotional pictures. The amount of extension did not differ between the two classes of pictures $[\imath(85)=-0.38 ; p=.71]$.

Table 5.1 Mean proportion drawn for each pholograph and aweraged for newral and emorional stimuli (standard deviations are given between parentheses)

\begin{tabular}{lll}
\hline & Picture name & Mean proportion drawn \\
\hline Neutral & Tyre & $.57(.50)$ \\
& Bananas & $.57(.50)$ \\
& Bucket & $.39(.30)$ \\
Mean & Bear & $.39(.28)$ \\
Emotional & & $.48(.30)$ \\
& Shark & $.48(.21)$ \\
& Snake & $.52(.34)$ \\
& Gun & $.26(.17)$ \\
Kean & Knife & $.58(.38)$ \\
\hline
\end{tabular}


Figure 5.1 shows an example of a drawing displaying boundary extension. The tendency to extend boundaries was not only typical for proportions averaged over pictures. The proportion drawn was less than $I$ for all individual drawings of both categories, except for 14 neutral drawings ( $4 \times$ tyre, $7 \times$ bananas, $2 x$ bucket, $1 \times$ bear) and 9 emotional drawings ( $4 \times$ snake, $5 \times \mathrm{knife}$ ).
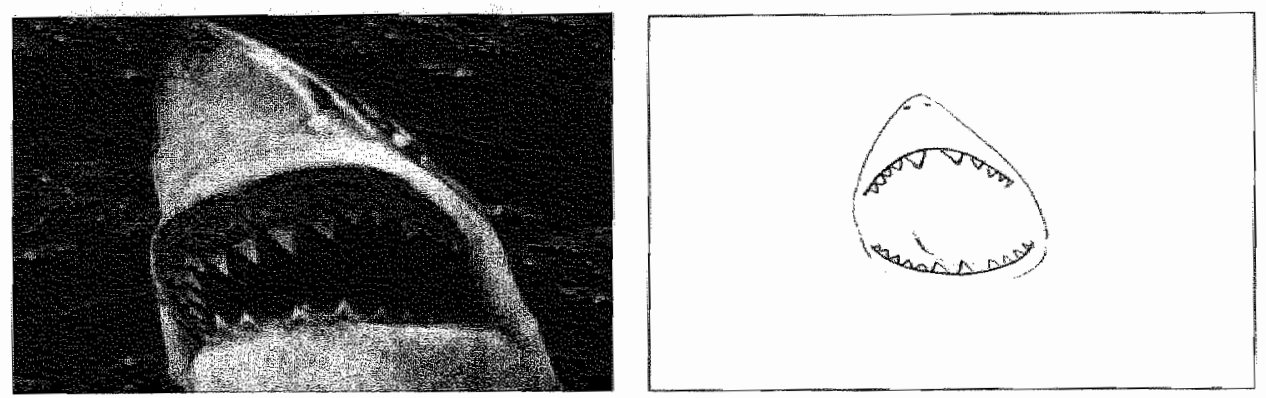

Figure 5.1 Example of an emotional picture and a drawing showing boundary extension

\section{Discussion}

The results of the current study can be summarized as follows. In a free-recall drawing task, children tend to extend boundaries of both neutral and emotional pictures. Moreover, the degree of extension is highly similar for neutral and emotional pictures. These results provide a straightforward replication of our previous study (Candel et al., in press) with adult participants. In that study, we obtained mean proportions drawn of .46 for neutral and .42 for emotional stimuli. The mean proportions drawn in the present study were .48 and .46 for neutral and emotional stimuli, respectively. Thus, both adults and children remember wideangled versions of neutral and emotional scenes. Our finding that children remember neutral pictures with extended boundaries provides a replication of the results of Seamon et al. (2002). Our study extends previous work in this domain by showing that children's susceptibility to boundary extension does also occur with emotional material. Apparently, boundary extension is a robust and ubiquitous phenomenon that crosses developmental borders and stimuli classes. As to the underlying mechanism, the most parsimonious explanation for boundary extension is Intraub's perceptual schema hypothesis (e.g., Intraub, et al., 1992; Intraub, et al., 1998), according to which schematic reconstructions during perception determine subsequent memory for scenes. The current results suggest that such reconstructions occur relatively early during developmental maturation and do not require the extensive cognitive experience of adults. In Seamon et al.'s 2002 ; p. 163) words: "[...] even 6-year-old children have sufficient experience with perceiving framed 
scenes to understand implicitly that objects and backgrounds can extend beyond the boundaries of a picture."

The phenomenon of boundary extension is highly relevant to the legal context. As a result of boundary extension, children's eyewitness testimonies about relative sizes of main objects and/or individuals in scenes might be unreliable. This does not necessarily mean that their reports about details of these objects and/or individuals are inaccurate. The drawing task paradigm used in the current study does not allow for a systematic evaluation of accuracy because this task focuses on the contextual embedding (i.e., size and location) of objects rather than their inherent features. However, an enlargement of the mental periphery (i.e., remembering more than is seen) increases the risk of commission errors. This might especially be true for children since "[...] children's memories are more malleable and prone to falsification than adult's memories" (Brainerd, Reyna \& Poole, 2000; p. 104). Clearly, the probability of commission errors increases when scenes involve a complex background (see also Seamon et al., 2002). In our study, relatively simple backgrounds were used and it is therefore not surprising that only 1 child made commission errors. This child drew another fish next to the shark and another animal next to the snake. We suppose that more "real-life backgrounds" would activate more complex perceptual schemata, which might create room for commissions. Given its relevance to the legal domain, this issue warrants further study. 



\title{
Chapter 6 Korsakoff patients' memories of September 11, 2001 ${ }^{*}$
}

\begin{abstract}
The current study investigated whether Korsakoff patients are capable of remembering a highly emotional event and to what extent they form thashbulb memories of such an event. On two test occasions, Korsakoff patients and healthy control participants were interviewed about their memories for September 11, 2001. Moreover, semantic knowleche about the event was assessed. Sixty-seven percent of the patients recalled what happened on September 11 compared to $100 \%$ of the control participants. Many patients reported having flashbulb memories for the events, although such reports were more frequently found among controls. Also, Korsakoff patients' flashbulb memories were far less consistent than those of controls. Our data suggest that Korsakoff patients" flashbulb memories often involve confabulations.
\end{abstract}

"Candel, I., Jellicic, M., Merckelbach, H., \& Wester, A. (in press). Joumal of Nervous and Mental Disease. 


\section{Introduction}

Flashbulb memories (FBMs) refer to detailed and vivid memories for circumstances under which one first heard news about unexpected, dramatic events (i.e., reception events; Brown \& Kulik, 1977). For example, almost all Americans of a certain age remember what they were doing when they heard about the assassination of John $F$. Kennedy. Brown and Kulik (1977) postulated a special neural mechanism that might underlie these detailed memories, the "Now Print!" mechanism. These authors assume that activation of this "Now Print!" mechanism would result in accurate and long lasting memories. However, FBMs are not as accurate and permanent as the term suggests. Several studies have looked at the consistency of flashbulb memories. In these studies, participants' initial reports of reception events were compared to their subsequent recalls. In general, results indicate that consistency of FBMs is far from perfect. Winningham, Hyman, and Dinnel (2000) reviewed research in this domain and noted that studies in which initial reports were obtained shortly after the pertinent event generally found less consistency than studies in which initial reports were obtained after some weeks or months elapsed since the event. The authors propose two possible explanations for this finding. First, in the days following the event, people's initial reports might become tainted by post-event information provided by newspapers and television (Loftus, 1975). Second, inconsistencies might be an artefact of forgetting since most information is lost shortly after an event (Ebbinghaus, 1885/1913). Note, however, that the forgetting curve of FBMs is less steep than that of other types of memories. On the other hand, like other memories, FBMs are vulnerable to suggestive influences. Thus, Crombag, Wagenaar, and Van Koppen (1996) and Ost, Vrij, Costall, and Bull (2002) demonstrated that it is relatively easy to distort FBMs by asking participants misleading questions about the reception events. Accordingly, Christianson (1989; p. 435) summarizes the literature on FBMs as follows: "FBMs are special, but not so special."

Several determinants of FBMs have been identified. Brown and Kulik (1977) proposed that both surprise and importance-consequentially are necessary for FBMs to develop (see also Wessel, Peeck, Foster, Merckelbach \& Wiers, 2002). Additionally, these authors suggested that rehearsal is a mediating variable that leads to further development of FBMs. Emotional intensity of the event also acts as an antecedent of FBMs (e.g., Conway et al., 1994; Schmolck, Buffalo \& Squire, 2000). Conway and co-workers (1994) argued that prior knowledge plays a key role in the formation of FBMs. Prior knowledge would facilitate the assimilation of new information into the existing memory structures (see for an overview Finkenauer, Luminet, Gisle, El-Ahmadi, Van der Linden \& Philippot, 1998). 
An interesting question is whether amnesic patients are able to fom FBMs. Ikeda, Mori, Hironto, Imamura, Shimomura, Ikejiri, and Yamashita (1998) addressed this issue by interviewing Alzheimer Disease (AD) patients from the Kobe district area about the Kobe earthquake in 1995. Ten weeks after the disaster, participants" $(N=51)$ memory of the earthquake was assessed. Eighty-six percent of the patients who could not recall events that happened minutes or hours ago did remember the earthquake. However, semantic knowledge about this event was not retained. According to the authors, the emotional significance of the event might explain why many of their AD patients had some recollections of the earthquake. Referring to the amygdala's role in emotional memory (see for an overview Cahill \& McGaugh, 1996), Ikeda et al. (1998) speculated that relative sparing of the amygdala in $\mathrm{AD}$ could underlie FBMs of their patients. In a follow-up study, these authors used Magnetic Resonance Imaging (MRI) to determine amygdala and hippocampal volumes in a subset of their patients (Mori, Ikeda, Hirono, Kitagaki, Imamura \& Shimomura, 1999). It was found that impairment of memory for the earthquake was related to amygdala damage and to a lesser extent, to hippocampal damage. Thus, the results provide further evidence for the amygdala"s involvement in the formation of FBMs.

The aim of the current study was to examine flashbulb memories and their consistency in another ammesic population, namely patients with the Korsakoff syndrome (KS; Kopelman, 1995). Previous studies by Ikeda and co-workers (1998; Mori et al., 1999) on flashbulb memories in amnesic patients did not address their consistency. We interviewed patients as well as healthy controls twice about September 11, 2001. On that day, terrorists attacked the New York Twin Towers and the Pentagon by plane and were responsibie for more than 3,000 deaths.

\section{Method}

\section{Participants}

The clinical group comprised 15 Korsakoff inpatients ( 4 women). Their mean age was 53.80 years $(S D=6.47$; range: $43-63)$ and their mean educational level 4.07 $(S D=1.28$; Verhage, 1965). All Korsakoff patients had been diagnosed with Korsakoff disease by an experienced clinician before September 11, 2001 and they were all hospitalised at the time the terrorist attacks took place. The control group included 15 individuals ( 4 women). Their mean age was 52.27 (SD $=7.83$; range 40-67) and their mean educational level $4.40(S D=1.76)$. The two groups did not differ with regard to age and education level $(t ' s<1.0)$. 


\section{Materials and procedure}

The initial semi-structured interview took place approximately 7 months after the target event. During that interview, flashbulb memory questionnaires were asked. These questions were based on flashbulb memory questionnaires (FMQs) developed by Cohen, Conway, and Maylor (1994), Conway, Anderson, Larsen et al. (1994), and Davidson and Glisky (2002). The first question asked participants what happened on September 11, 2001 (Section A: Event recall). If participants were not able to recall the specific event, 1 or 2 cues (i.e., New York, planes) were given. When participants were not able to recall the event after cues had been given, the interview stopped. Event recall was followed by questions about the reception events (Section B: Personal memory: Where were you?, What were you doing before you heard the news?, What did you do after you heard the news?, Who were you with?, and How did you hear the news, i.e., from what source?) and by selfreports about the emotional impact of the event on a 5-point scale (anchors: $1=$ not at all; $5=$ extremely). Finally, 6 forced-choice, semantic knowledge questions about the event were asked (Section C: Semantic knowledge). See table 6.1 for items of the FMQ.

\section{Table 6.1 Flashbulb Memory Questionnaire}

\section{Section A: Event Recall}

Do you know which disaster took place on September 11, 2001"?

\section{Section B: Personal Memory}

Where were you when you heard the news?

What were you doing before you heard the news?

What did you do after you had heard the news?

Who were you with?

What time of the day did you hear the news?

How did you hear the news? From what source?

\section{Section C: Semantic knowledge}

How many planes were involved in the attack on the World Trade Centre?

What was the time interval between the crash of the second plane into the WTC and the collapse of the first tower?

What other building was attacked on September 11, 2001?

What time (Dutch time) was it when the first attack took place?

A third plane crashed. Do you know near which town this plane crashed?

Which company did the planes belong to?

The retest was conducted approximately two months after the initial test. Participants were asked exactly the same questions. Those participants who were not able to recall the specific event at initial testing ( 5 Korsakoff patients) were excluded from follow-up. Moreover, 2 patients were discharged from hospital leaving 8 Korsakoff patients for the retest. Two control participants were not available for follow-up leaving 13 for the retest. 


\section{Scoring}

Answers to the first question ("What disaster took place on September 11, 2001?") were scored as follows. Participants were assigned a score of 0 when they did not provide an answer to the questions, a score of 1 when they gave a vague, nonspecified description of the event (e.g., "it was war"), and a score of 2 when they gave a specified description of the event. Scoring format for reception questions (Section B) on the initial and delayed test was derived from Davidson and Glisky (2002). For the initial test, participants were assigned a score of 0 when they did not provide an answer to a question and a score of 1 when they did. Flashbulb memory scores (FBM scores) ranged between 0 and 6 . For the delayed test, two independent judges rated the consistency between the answers on the initial and delayed test. They assigned a score of 0 when at retest no answer was provided or when the answer was completely inconsistent. A score of 1 was given when initial and retest answers were essentially the same, but differed in specificity (e.g. "My daughter told me by telephone" vs "My daughter told me"). A score of 2 was given when the retest answer was highly consistent with the initial answer. When no answer was provided at the initial test, this item was eliminated from the consistency measurement. Interrater reliabity score for the consistency measures was .85 (inconsistencies between the two judges were solved by a third judge). The scores on the 6 reception questions at retest were summed. Next, we computed a consistency score. Because some items were excluded for some participants, proportions were calculated by dividing summed consistency scores by FBM scores. Next, this score was divided by 2 . Thus, consistency scores ranged from 0 to 1 , with a score of 0 indicating complete inconsistency and a score of 1 indicating complete consistency between initial test and retest. Semantic knowledge questions were assigned a score of 0 for a wrong answer and a score of 1 for a correct answer. Thus, semantic knowledge scores varied from 0 to 6 .

\section{Results}

\section{Event recall}

On the initial test, 10 Korsakoff patients $(67 \%)$ recalled the target event ( 2 nonspecific answers). One patient needed 1 cue to recall the event, while two patients needed both cues. Five patients were not able to answer the first question, even after two cues had been given. In contrast, all of the 15 control participants were able to recall what happeried on September 11 without cues $\left[\chi^{2}(2)=10.91 ; p<.01\right]$. During the retest. $3(37.5 \%)$ patients recalled the target event without cues, 2 patients needed 1 cue ( 1 non-specific answer), and 2 needed 2 cues to recall the event. 
Again, all control participants recalled the event without cues $\left[\chi^{2}(2)=10.66 ; p<\right.$ $01]$.

\section{Personal memory}

Korsakoff patients obtained lower FBM scores than controls, means being 5.10 (SD $=0.88)$ and $6.00(S D=0.00)$, respectively $[t(23)=-4.03 ; p<.01]$. Also, Korsakoff patients displayed lower consistency scores than controls, means being $.28(S D=$ $0.21)$ and $.65(S D=0.18)$, respectively $[(18)=-4.16 ; p<.01]$. On both test occasions, however, patients and controls did not differ with regard to their subjective impact ratings $\left(t^{3} s<1.5 ; p^{3} s>\|\|\right)$.

\section{Semantic knowledge}

On the initial test, Korsakoff patients obtained slightly lower scores on Section $C$ of the interview (semantic knowledge) than control participants, means being 2.70 (SD $=0.82)$ and $3.53(S D=1.25)$, respectively. However, this difference attained only borderline significance $[t(23)=-1.86 ; p=.08]$. Note that none of the participants answered all questions correctly, maximum scores being $4(n=2)$ and $5(n=4)$ for Korsakoff patients and controls, respectively. On the retest, Korsakoff patients obtained lower scores on Section $C$ than controls, means being $1.86(S D=1.57)$ and $4.15(S D=1.14)$, respectively $[f(1.8)=-3.76 ; p<.01]$. This time, 2 controls obtained the maximum score of 6 , while none of the Korsakoff patients attained this score. Korsakoff patients' decrease of semantic knowledge over time was borderline significant $[t(6)=2.12 ; p=.08]$. Similarly, increase of semantic knowledge in controls was borderline significant $[t(12)=-1.86 ; p=.09]$.

\section{Discussion}

The results of the current study can be summarized as follows. To begin with, despite dense amnesia, more than hatf of the Korsakoft patients remembered the attack on September 11, 2001. Second, these patients displayed FBMs. Third, although FBMs of healthy controls were rather consistent, those of Korsakoff patients were not. In contrast, patients and controls did not differ in their subjective impact ratings of the attacks. Fourth, on both test occasions, Korsakoff patients tended to have less semantic knowledge about the target event than controls on both test occasions. Moreover, their semantic knowledge tended to decrease over time. Controls" semantic knowledge, on the other hand, tended to increase.

Our findings are, to some extent, in line with those reported by Ikedea et al.. (1998). These authors found that the majority of their AD patients from the Kobe area were able to remember the Kobe earthquake. The relative sparing of the 
amygdala in $\mathrm{AD}$ as well as in KS, may account for retained emotional memory in both patient groups. During the early stages of AD, brain damage is largety confined to the hippocampus and adjacent areas (Morris, 1996), while in KS, lesions are limited to the mammillary bodies, the anterior part of the thalamus, and sometimes the frontal lobes (Kopelman, 1995). The present results are also consistent with Hamann, Cahill, and Squire (1997) who found that both healthy controls and amnesic patients (including those with KS) remembered pictures with high emotional intensity better than neutral material. Likewise, in their experimental study with KS patients, Johnson, Kim, and Risse (1985) showed that patients developed a clear preference for photographs of people who had been described in favourable terms on an earlier test occasion, although they had great difficulties in remembering the semantic details of the favourable information. Note that the AD patients studied by Ikeda et al. (1998) did not exhibit semantic memory for the disaster, whereas our KS patients had some semantic knowledge about the terrorist attacks on September 11,2001. This latter finding is in accordance with previous studies showing that amnesic patients may be able to learn new semantic information (Tulving, Hayman \& MacDonald, 1991).

In contrast to healthy controls, our KS patients did not report consistent FBMs. This suggests that FBMs of patients with $\mathrm{KS}$ are not very accurate. It is well documented that patients with this disorder have the propensity to confabulate, mainly because of reality monitoring deficits brought about by frontal lobe dysfunction (Weinstein, 1996). Hence, it could well be the case that FBMs of KS patients involve confabulations. We have anecdotal evidence for this notion: some of the patients said that they were at home (they mentioned their former residence) when they heard the news of September 11 while in fact they were all residing in the clinic. However, this issue warrants further study.

Our study suffered from several limitations. First, the sample of KS patients was relatively small and drop-out at retest was considerable. Second, information about memory performance of patients on formal tests or about structured brain abnormalities was not available. Meanwhile, such information would have allowed for a more thorough analysis of the antecedents of KS patients FBMs

Summing up, our results show that amnesic patients are capable of remembering a highly emotional event, including some semantic details. However, they do not seem to have accurate FBMs for such events. 



\title{
Chapter $7 \quad$ Peritraumatic dissociation as a predictor of PTSD: A critical review* $^{*}$
}

\begin{abstract}
In psychiatric literature, dissociative reactions at the time of a traumatic event (i.e, peritraumatic dissociation) are considered to be risk factors for the development of posttraumatic stress disorder (PTSD). In this article, we critically review research concerned with the link between peritraumatic dissociation and PTSD. Our main point is that studies in this area heavily rely on retrospective reports of dissociative reactions during the trauma. We argue that this methodology has important limitations since people in general and PTSD patients in particular find it difficult to give accurate descriptions of past emotional states. Restrictive factors that play a role in this context have to do with forgetting, attribution, and malingering.
\end{abstract}

Candel, I., \& Merckelbach, H. (accepted pending revision). Comprehensive Psychiary.

This chapter is a translation of the following Dutch anticle: Candel, 1., \& Merckelbach, H. (in press). Peri-traumatische dissociatie als voorspeller van PTSS: Een kritische noot. Tijdschrift noor Psychiatrie. 


\section{Introduction}

Dissociation refers to phenomena like depersonalisation, derealization, amnesia, and identity disturbances (APA, 1994). A considerable percentage of psychiatric patients as well as "healthy" people report dissociative experiences. Therefore, Bernstein and Putnam (1986) conceptualize dissociation on a continuum with "normal" dissociation at one end and pathological dissociation at the other end of the continuum. A recurrent theme in clinical literature is that dissociative symptomatology is a reaction to traumatic events (Van der Kolk, 1987; Van der Kolk, Van der Hart \& Marmar, 1996). However, some trauma victims report dissociative experiences at the time of the traumatic event. This form of dissociation is termed peritraumatic dissociation. According to many authors (e.g., Van der Kolk, 1987; Van der Kolk, Van der Hart \& Marmar, 1996), peritraumatic dissociation would serve a defensive and adaptive function (e.g., it would reduce pain and humiliation). But, in the long term it would have harmful consequences. Thus, these authors assume that peritraumatic dissociation increases the risk of psychopathology in general and of posttraumatic stress disorder (PTSD; APA, $1994)$ in particular. For example, Fullerton et al. (2000; p. 267) claim that "dissociation at the time of a traumatic event increases the risk of acute and chronic stress disorder." In a similar vein, Marmar, Weiss, and Metzler (1998; p. 233) summarize the literature on peritraumatic dissociation and PTSD as follows: "Dissociation at the time of a trauma is one of the most important risk factors for the subsequent development of chronic PTSD." Such claims may suggests that the causal relationship between peritraumatic dissociation and PTSD is a wellestablished fact. In this article, we critically evaluate research that is often cited as strong support for the view that peritraumatic dissociation is an important antecedent of PTSD. The large majority of the studies in this research domain relied on retrospective reports and this fact is the starting point of our critical analysis.

A Psyclnfo search from 1990 to current using "peritraumatic dissociation" and "posttraumatic stress disorder" as key words provided us with 23 articles. The same search using Medline's database yielded 15 articles that to some extent overlap with studies from the Psyclnfo search. We have not the ambition to evaluate all these studies in detail. Instead, we focus on the methodology of these studies and consider variables that might obscure the causal relationship between peritraumatic dissociation and PTSD. In doing so, we draw on often cited studies about memory for aversive events (e.g., Roemer, Litz, Orsillo, Ehlich \& Friedman, 1998; Wagenaar \& Groeneweg, 1990). 


\section{The relation between peritraumatic dissociation and PTSD}

Most studies on the link between peritraumatic dissociation and PTSD are retrospective and longitudinal in nature. More specifically, trauma victims are interviewed about current psychological symptoms and about dissociative experiences at the time of a traumatic event that took place several days (e.g., Freedman, Brandes, Peri \& Shakev, 1999; Shalev, Freedman, Peri \& Brandes, 1997) weeks (e.g., Fullerton et al., 2000; Holeva \& Tarrier, 2001; Ursano et al., 1999 ) or months (e.g., Marmar, Weiss, Metzler, Delucchie, Best \& Wentworth, 1999 ) before. During a follow-up session, researchers evaluate whether or not victims have developed PTSD symptoms. A standardized instrument for assessing peritraumatic dissociation is the Peritraumatic Dissociation Experiences Questionnaire (PDEQ; Marmar et al., 1994). The PDEQ asks respondents to what extent they experienced depersonalisation, derealisation, and amnesia at the time of the traumatic event. This questionnaire has two versions: a self- report version and a rater version. In both versions, peritraumatic symptoms like "I felt as if I was floating above the scene" and "I found myself acting on a automatic pilot" are rated on a 5 -point scale. In both versions ratings rely on victims" retrospective selfreports.

Several studies noted that retrospective reported peritraumatic dissociation statistically predicts PTSD symptoms (Ursano et al., 1999; Shalev, Peri, Canetti \& Schreiber, 1996). A case in point is a longitudinal study by Shalev et al. (1996). Fifty-one patients with physical injury due to a traumatic event were assessed 1 week and 6 months after the trauma. The 1-week session included the PDEQ. Six months later, a psychiatric social worker evaluated whether patients met PTSD criteria. Those who met these criteria $(n=13)$ had significantly higher PDEQ scores than those without PTSD, means being $15.2(S D=6.9)$ and $10.2(S D=8.8)$, respectively. In the Shalev et al. study, the retrospective period involves only one week, but in other studies on peritraumatic dissociation and PTSD this period is considerably longer (Tichenor, Marmar, Weiss, Metzler \& Ronfeldt, 1996; O'Toole, Marshall, Schureck \& Dobson, 1999; Johnson, Pike \& Chard, 2001 ). In these studies, trauma victims with and without PTSD think back about a traumatic event that occurred months or even years ago and report their peritraumatic reactions during the trama. For example, O'Toole et al, (1999) interviewed Austalian Vietnam veterans about their peritraumatic experiences during the Vietnam War. In line with many other studies, self-reported peritraumatic dissociation was found to predict both current and lifetime PTSD symptoms.

However, some longitudinal studies failed to find a connection between peritraumatic dissociation and PTSD. For example, Freedman et al. (1999) had their trauma victims complete the PDEQ 1 week after the traumatic incident. After 4 months and 1 year, a clinician evaluated the presence of PTSD symptoms. Thus, at 
1 year follow-up, there were three groups: victims with PTSD, victims who recovered from PTSD, and victims who had never been diagnosed with PTSD. The first and the second group did not differ with respect to their PDEQ score, means being $24.7(S D=6.9)$ and $25.1(S D=7.6)$, respectively. However, only victims who recovered from PTSD reported significantly more peritraumatic experiences than victims who never developed PTSD, the latter group having a mean PDEQ score of $18.5(S D=7.9)$. This pattern suggests that reports of peritraumatic experiences provided 1 week after a trauma are not powerful predictors of persistent PTSD symptoms. At most, such experiences are related to the development of PTSD symptoms at some point in time. Another example in this category is a study in which victims of road traffic accidents were interviewed shortly after the accident about their peritraumatic experiences (Holeva \& Tarrier, 2001). After several months, PTSD symptoms were assessed. Although peritraumatic experiences were correlated with subsequent PTSD symptoms, these experiences were not independent predictors of PTSD as were neuroticism and psychoticism.

The studies cited above have in common that they relied on victims" retrospective reports of peritraumatic experiences. This raises the question as to how accurate such retrospective reports are. Literature on the psychology of selfreports (e.g., Schwarz, 1999) indicates that their accuracy should not be overestimated. Below, we consider several factors that might undermine the accuracy of retrospective reports.

\section{Retrospective reports: forgetting}

To begin with, people simply tend to forget prior experiences. This is true for both neutral and emotional experiences. For example, Schwarz, Kowalski, and McNally (1993) interviewed eyewitnesses of a shooting incident about their emotional experiences. Interviews took place 5 and 17 months after the incident. After 17 months, eyewitnesses did not report experiences described at 5 months follow-up and wice versa. These findings accord well with those of Christianson and Engelberg (1999). These authors interviewed participants twice about the circumstances under which they heard the news about the sunken ferry "Estonia". The first interview took place shortly after the disaster while the second was administered 14 months later. After 14 months, participants reported the gist of the circumstances, but they omitted all sorts of details. Similarly, people have a tendency to forget within two weeks such emotional events as near car accidents (Chapman \& Underwood, 2000).

Retrospective studies on peritraumatic dissociation and PTSD often involve Vietnam veterans (Marmar et al., 1994; Tichenor et al., 1996; O'Toole et al., 1999). Since the Vietnam War took place during the sixties and seventies of the previous 
century, veterans are asked to go back more than 30 years in time. Wagenaar and Groeneweg (1990) showed that trauma victims tend to forget important details after such a delay. In their study, survivors of a German prison camp were interviewed twice about their experiences in the camp. The first interview took place at the end of WOII, while the second was conducted after 40 years. Although most survivors reported accurate information after 40 years, a number of them omitted specific, but important details.

These studies indicate that individuals' retrospective reports about negative events that they have experienced are far from accurate. Much the same is true when people report about past mental states or symptoms. A fine illustration is provided by Henry, Moffitt, Caspi, Langley, and Silva (1994). In their longitudinal study, participants were followed from birth till their $18^{\text {th }}$ year. On several occasions, they were interviewed about mental complaints. Retrospective accounts at age 18 did underreport past symptoms. The authors conclude that "[retrospective reports] may be less useful for testing hypotheses that demand precision in estimating event frequencies..." (p. 100). A study of Andrews, Anstey, Brodaty, Issakidis, and Luscombe (1999) found similar results. In that study, participants were interviewed about depressive symptoms they experienced 25 years ago. Half of the respondents who were treated for a depression 25 years earlier retrospectively reported symptoms for that episode that did not fit diagnostic criteria for depression.

\section{Attribution}

People tend to forget or to underestimate symptoms experienced long ago. However, there are exceptions to this rule. In some cases, people tend to exaggerate their past symptoms. A good example is provided by a study of Linton and Melin (1982). People suffering from back pain gave baseline pain ratings shortly before their scheduled treatment admission. After the treatment, participants were asked to rate how much pain they had experienced at baseline. Retrospective ratings were much higher than actual baseline ratings. Why do people sometimes give inflated estimations of past symptoms? According to Ross (1986), this phenomenon thas to do with the reconstructive quality of memory. We do not have direct access to past symptoms. We have to reconstruct parameters of these symptoms (i.e., intensity) on basis of implicit theories. For example, after a treatment, we assume that our pretreatment symptoms must have been worse (Nisbett \& Ross, 1980). Thus, it may well be the case that patients who undergo treatment for their PTSD symptoms, overestimate their reactions during and/or shortly after the traumatic event. A factor that might contribute to such biased estimates is the widely used heuristic that great consequences (e.g., symptoms) must have great causes (e.g., reaction during the traumatic event). Marmar and co-workers (1994) agree that such heuristic might 


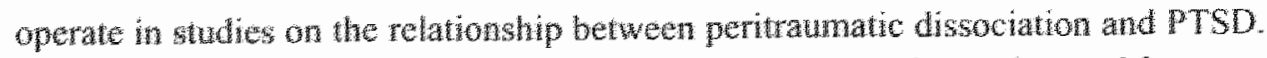

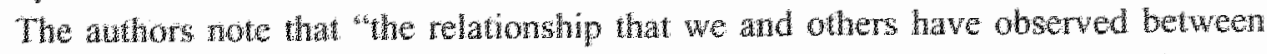
pertrumanc dissociation and subsequent stress symptoms may be, alleast in part.

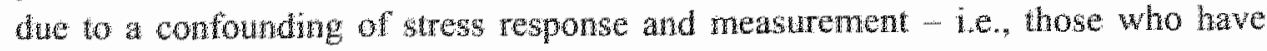
chronic stress responses mat "remember" more drssociation than those who do not have those responses" $(p .906)$.

The hewric described above is part of what soctal psychologists refer to as atributhonal processes. A close look at the precise order in which key variables were measued in studies on peritramatic dissociation suggests that atributional processes bear relevance to this research domain. In all but one study (Holeva \& Tarrier, 2001), tratma vichms were first asked about thetr actual complaints and symptoms and then were interviewed abou pentraumatic experiences. Attribution heory predicts that people who experience many symptoms will attribute such symptoms to prominent cuses and this will contribute to the retrospective report of many peritraumatic experiences (Marmar et al., 1999; Ursano et al, 1999). This theory also predicts that the link between peritraumatic dissociation and PTSD will become less impressive when reports on PTSD symptoms are preceded by those on peritramatic experiences. Indeed, this prediction is bome out by the facts (Holeva \& Tarrier, 2001 ). Field reports provide additional evidence for attribution playing a role in retrospective judgments of PTSD patients. Veterans of operation "Desert Storm" completed a questionnaire about traumatic events 1 month and 2 years after this operation (Southwick, Morgan III, Nicolaou \& Chamey, 1997). After 2 years, $70 \%$ of the respondents reported more exposure to traumatic events than they had reported after 1 month. This inflation was especially evident for veterans with PTSD symptoms. Roemer, Litz, Orsillo, Ehlich, and Friedman (1998) obtained similar results. These authors interviewed peacekeeping force members in Somalia twice about traumatic events during their stay in Somalia. Traumatic reports increased over time, especially for veterans with PTSD symptoms. Similarly, Harvey and Bryant (2000) interview victims of a motor vehicle accident (MVA) about their symptoms 1 month and 2 years postrauma. After 2 year, high levels of postramatic stress were associated with the recall of symptoms that were not reported during the first assessment. These studies show that retrospective reponts of people with PTSD symptoms may be inconsistent. That does not necessarily mean that their reports are inaccurate (Brewer, Potter, Fisher, Bond \& Luszcz, 1999). A definite answer about the accuracy of PTSD patients' retrospective reports can only be obtained when these reports can be verified against physical reconds (e.g.; audio or video material). However, the problem with peritramatic dissoctation is that it refers to subjective experiences for which there is no golden standard. 


\section{Malingering}

Forgetting and attributional processes might function as spurious factors in the link between peritraumatic dissociation and PTSD. That is, victims who do not suffer from PTSD may have forgotten their dissociative reactions to the trauma, while those victims who do suffer from symptoms may overestimate their dissociative reactions. There is a third variable that we should address: malingering. In psychiatric classifications (APA, 1994), malingering is defined as the intentional production of symptoms motivated by external incentives. Some authors (Rogers \& Cruise, 2000) assume that malingering is a rare phenomenon, but studies show that under some circumstances malingering of psychiatric symptoms might be a real problem. An illustrative study is that of Rosen (1995) on the "Aleutian Enterprise" disaster. In 1990, this ship sunk with 31 people on board. Two of the 22 survivors continued working. Nineteen ( $95 \%$ ) of the remaining 20 consulted a psychiatrist or psychologist. These experts made a diagnosis of PTSD in $86 \%$ of the cases. This percentage is extremely high compared to the usual prevalence of 3 to $58 \%$ (APA, 1994). Interviews with the survivors made it clear that in many cases $(30 \%)$, lawyers had approached survivors immediately after the incident and had provided them with information about PTSD and about financial compensation. Rosen's study concurs with that of Binder en Rohling (1996) who conducted a study on mental symptoms after mild brain trauma. More specifically, these authors examined to what extent involvement in a financial compensation might contribute to the frequency and intensity of reported symptoms. Patients involved in compensation-seeking reported considerably more symptoms as a result of the trauma than control patients, irrespective of the severity of the trauma. A similar overendorsement of symptoms has been suggested for Vietnam veterans involved in compensation-seeking (Smith \& Freuh, 1996). We emphasize this point because many studies on peritraumatic dissociation relied on samples of Vietnam veterans (e.g., Marmar et al., 1994; O'Toole et al., 1999; Tichenor et al., 1996). It cannot be ruled out that these samples included malingerers who intentionally overreported peritraumatic reactions and PTSD symptoms. Interestingly, there are good screening instruments for malingering of symptoms (Smith \& Burger, 1997; Merckelbach \& Smith, in press). To the best of our knowledge, no study on peritraumatic dissociation and PTSD made use of such an instrument.

\section{An empirical intermezzo}

Peritraumatic dissociation refers to internal experiences and symptoms that are supposed to be specific for traumatic events. We are not aware of a study that 
addresses this specificity. With this in mind, we conducted a study in which 89 undergraduates voluntarily participated. After they had given informed consent, they reported either the most aversive event they experienced last year $(n=44)$ or the most pleasant event they experienced last year $(n=45)$. Next, respondents rated to what extent they had displayed 8 peritraumatic reactions during the pertinent event. The items were derived from Marmar et al. (1994) and were rated on $100 \mathrm{~mm}$ Visual Analog Scales (anchors: $0=$ nearly; $100=$ extremely). Finally, subject completed the Dutch version of the Creative Experience Questionnaire (CEQ; Merckelbach, Horselenberg \& Muris, 2001), which is a measure of fantasy proneness. Fantasy proneness refers to a tendency to become engaged in fantasizing and daydreaming. Moreover, persons high on fantasy proneness tend to give exaggerated interpretations of ambiguous perceptions or sensations (Spanos, Cross, Dickson \& DuBrueil, 1993; Candel \& Merckelbach, in press). Interestingly, there is a considerable overlap between fantasy proneness and dissociative experiences (Merckelbach, Muris \& Rassin, 1999). Our results show that both undergraduates who recalled the most aversive events and those who recalled the most pleasant event reported peritraumatic reactions during these events. Although the first group reported higher levels of peritraumatic dissociation than the second group, means being $35.95(S D=21.75)$ and $26.90(S D=20.32)$, respectively, the difference was moderate and reached only borderline significance $[t(87)=-2.03, p=.05]$. Moreover, across both groups, reports of peritraumatic dissociation were significantly correlated with fantasy proneness levels $(r=.33)$.

Our study indicates that peritraumatic experiences are not unique to aversive events, but do also occur in relation to major events that are positive in nature. Germane to this issue is a study on novice skydivers in which hyperarousal was found to be the primary determinant of peritraumatic reactions to the skydive (Sterlini \& Bryant, 2002). The fact that we found fantasy proneness and reports of peritraumatic dissociation covary is relevant because people high on fantasy proneness tend to distort their retrospective experiences (Merckelbach \& Muris, 2001). Studies on peritraumatic dissociation and PTSD would gain in quality if they would correct for the reporting bias related to this personality characteristic.

\section{Conclusion}

In trauma literature, it is often taken for granted that peritraumatic dissociation is a risk factor for the development of PTSD. Thus, Morgan, Hazlett, Wang, Richardson, Schnurr, and Southwick (2001) claim that "peritraumatic symptoms of dissociation represent a significant risk factor for the subsequent development of PTSD." As said earlier, a number of studies did find a robust connection between peritraumatic dissociation and PTSD, but a few others did not. Those studies that 
noted a link between peritraumatic dissociation and PTSD often interpreted this link in causal terms. We do not want to argue that there is no such thing as peritraumatic dissociation. Our point is that these studies relied on retrospective accounts of peritraumatic dissociation, making causal interpretations difficult if not impossible. Symptom free victims may have forgotten their dissociative reactions, while victims with PTSD may retrospectively overestimate their dissociative reactions. Both phenomena could spuriously increase the correlation between peritraumatic dissociation and PTSD. Malingering in compensation-seeking PTSD victims may have a similar effect. Fantasy proneness is another factor that may spuriously amplify the link between peritraumatic dissociation and PTSD. Finally, it appears that dissociative reactions are not unique for aversive events. With these considerations in mind, we are able to specify how an ideal study on perituamatic dissociation and PTSD would look like. Such study would interview trauma victims shortly after the traumatic event, so as to circumvent the problem of rapid forgetting. Also, questions about peritraumatic dissociation would precede questions about psychiatric complaints and symptoms, so as to avoid attributional phenomena. Moreover, a screening tool for malingering would be included and compensation-seeking victims would be excluded from participation. Finally, fantasy proneness would be taken into account. A study that would fulfil these requirements would allow a more rigorous test of the relationship between peritraumatic dissociation and PTSD. Until such study has been done, claims like "dissociation at the time of a traumatic event increases the risk of acute and chronic stress disorder" (Fullerton et al., 2000; p. 267) are premature. 


\title{
Chapter 8
}

\section{Dissociative experiences are related to commissions in emotional memory $^{*}$}

\begin{abstract}
Two rival hypotheses of the link between dissociative experiences and emotional memory were tested: 1) the defence mechanism hypothesis that assumes that dissociation promotes fragmentation of emotional memory; and 2) the fantasy proneness hypothesis that claims that because of its overlap with fantasy proneness, dissociation is related to commissions in emotional memory. Undergraduates scoring high $(n=19)$ or low ( $n$ $=19$ ) on the Dissociative Experiences Scalle (DES) listened to an aversive story. Next, a free recall task was administered. While high dissociators made more commission errors in their free recall than low dissociators, fantasy proneness did not account for this difference.
\end{abstract}

* Candel, I., Merckelbach, H., \& Kuijpers, M. (in press). Behaviowr Research and Therapy. 


\section{Introduction}

Dissociation refers to a lack of normal integration of thoughts, feelings, and experiences into the stream of consciousness and memory (Bernstein \& Putnam, 1986). Over the past few years, etiological antecedents of dissociative symptoms and experiences have been the object of numerous studies (see for reviews, Gershuny \& Thayer, 1999; Merckelbach \& Muris, 2001). A recurrent theme in these studies is that dissociative symptoms originate from exposure to traumatic events (e.g., Van der Kolk \& Van der Hart, 1989; Gershuny \& Thayer, 1999). According to this trauma-dissociation view, dissociation would serve as a coping mechanism resulting in a reduced impact of the traumatic event. Many clinicians seem to share this view. For example, Apitzsch (1996; p. 334) opines that "dissociation at the moment of trauma is highly adaptive. It serves to defend selfconsciousness from being contaminated by overwhelming pain, humiliation, and feelings of helplessness."

Another prominent aspect of the trauma-dissociation view is the idea that repeated traumatization may lead to more or less chronic dissaciative symptoms that have trait-like qualities (e.g., Loewenstein., 1991). The standard measure for assessing such trait-like dissociation is the Dissociative Experience Scale (DES; Bernstein \& Putnam, 1986). The DES is a self-report scale that asks respondents to indicate on 100-mm Visual Analog Scales (anchors: $0=$ not at all; $100=$ very much) the frequency with which they experience 28 dissociative phenomena (e.g., "Some people have the experience of finding themselves in a place and having no idea how they got there. Please mark the line to show what percentage of the time this happens to you"). Scores are then averaged across items to obtain a mean DES score.

Advocates of the trauma-dissociation view argue that in contrast to its beneficial acute effects, the long-term effects of dissociation are largely negative. People who continue to dissociate over time become emotionally constricted and are vulnerable to develop various forms of psychopathology (e.g., Van der Kolk \& Fisler, 1995). Furthemore, people who have learned to cope with trauma by dissociating are vulnerable to continue to do so in response to minor stressors. As a result, emotional experiences will not integrate into al coherent narrative. Thus, habitual dissociation would undermine the capacity to fully retrieve emotional memories. Amnesia - which can be conceptualized as a radical form of autobiographical memory omission - is often related to chronic dissociation (e.g., Van der Kolk \& Fisler, 1995). So, the trauma-dissociation view would lead one to expect that high dissociative individuals display a relatively large amount of memory omissions when they try to retrieve emotional memories.

Although the trauma-dissociation view is a rather dominant framework, alternative interpretations of the origins and consequences of dissociative 
experiences deserve serious considerations. For example, one clearly established individual difference correlate of dissociation is fantasy proneness (e.g., Rauschenberg \& Lynn, 1995; Merckelbach, Muris \& Rassin, 1999). Fantasy proneness refers to a deep involvement in fantasy and imagination (Wilson \& Barber, 1983). For college students" samples, correlations between dissociation and fantasy proneness range from .42 (Silva \& Kirsch, 1992) to .63 (Merckelbach et al., 1999). Likewise, Pekala et al. (1999/2000) found a correlation of .41 between DES scores and fantasy proneness levels in a large sample of substance abuse patients. An approach emphasizing the substantial overlap between fantasy proneness and dissociation leads to completely different predictions as to how dissociative individuals react to emotional provocative material. For example, fantasy proneness has been found to be implicated in memory commissions (e.g., Merckelbach, Muris, Rassin \& Horselenberg, 2000) and false alarms in an auditory task (Merckelbach \& Van de Ven, 2001). In line with this, Porter and Birt (2001) found in their survey among undergraduates that self-reports of memory distortion are associated with heightened scores on the openness-to-experience factor which is closely related to fantasy proneness. With this in mind, one would expect that high dissociative individuals display commission rather than omission errors when they retrieve emotional memories. Interestingly, experimental studies relying on a variety of paradigms (e.g., imagination inflation, the Deese-Roediger-McDermott word list paradigm, reality monitoring tasks) found evidence that dissociative experiences are, indeed, related to memory commissions (e.g., Clancy, Schacter, McNally \& Pitman, 2000; Heaps \& Nash, 1999; Porter, Birt, Yuille \& Lehman, 2000; Winograd, Peluso \& Glover, 1998; Wilkinson \& Hyman, 1998). However, the majority of this work relied on neutral words or isolated autobiographical events.

The defensive qualities that the trauma-dissociation model attributes to dissociative experiences are primarily based on clinical observations. That is, a large number of studies noted that patients with dissociative symptoms report experiences that can be framed in terms of amnesia and/or numbing (e.g., Foa \& Riggs, 1995; Van der Kolk \& Fisler, 1995; Nijenhuis, Spinhoven, Vanderlinden, Van Dyck \& Van der Hart, 1998). So far, little experimental work on the defensive function of dissociation has been done. One notable exception is the study by Holtgraves and Stockdale (1997; see also DePrince \& Freyd, 1999). These authors showed that individuals with high DES scores recall fewer emotionally charged words than do individuals with low DES scores. Although this finding is well in line with the idea that dissociation promotes memory omissions, it was obtained with a word list paradigm that may have little relevance to autobiographical memory (Wilkinson \& Hyman, 1998).

The current study further explored the defensive qualities commonly attributed to dissociative experiences. Undergraduates who scored high or low on the DES were exposed to an emotionally provocative story. After they had heard the story, participants underwent a free recall task. If dissociation would have 
defensive qualities, one would predict a raised frequency of memory omissions in high DES individuals as compared to low DES individuals. Alternatively, to the extent that dissociation can be accounted for by fantasy proneness, one would predict more memory commissions in high DES individuals than in low DES individuals.

\section{Method}

\section{Design}

The experiment was a between-subjects factorial design, with DES status (high/low) serving as the between-subject variable. Memory performance served as dependent variable.

\section{Participants}

Participants were 38 Maastricht University undergraduates (29 women). Their mean age was 22 years $(S D=1.94$; range: 18-27 years). Participants were recruited on the basis of DES scores that had been obtained in a large, but unrelated experiment conducted 3 months before the current study. More specifically, we selected individuals with DES scores exceeding the clinical cut-off of 30 (high DES group; $n$ $=19$ ) recommended by Ross, Joshi, and Currie (1991) and individuals having a DES score below 6 (low DES group; $n=19$ ). Mean DES scores of the high and low DES group were $36.71(S D=5.73)$ and $3.09(S D=1.29)$, respectively $[t(36)=$ $24.93 ; p<.001]$. Groups did not differ with regard to age $[t(36)=1.54 ; p=.13]$. Participants were tested individually and received a small financial compensation in return for their participation.

\section{Materials}

As part of a filler task, participants completed the Creative Experience Questionnaire (CEQ: Merckelbach, Horselenberg \& Muris, 2001). The CEQ (Cronbach alpha $=.73$ ) is a 25 -item self-report instrument. An illustrative item is: "Many of my fantasies have a realistic intensity". Items are scaled in the true/false form. The number of yes-answers is summed to yield a total CEQ score, with higher scores indicating higher levels of fantasy proneness. There is sollid evidence for the reliability and validity of the CEQ (Merckelbach et al., 2001). Mean scores on the CEQ were $7.58(S D=2.57)$ for the high DES-group and $4.37(S D=3.61)$ for the low DES-group. High dissociators had higher fantasy proneness levels than low dissociators $[t(36)=-3.16 ; p<.01]$.

Participants listened to a tape-recorded emotional story (female voice), taken from Wenzlaff, Wegner, and Roper (1988). The story is about a student who causes 
a severe motor vehicle accident while (s)he is on his (her) way to a job interview. The story ends with a description of the victims, a mother and her baby. Participants were asked to identify with the main character of the story (i.e., the student who is responsible for the accident). Previous research in our lab indicated that participants find the story upsetting (Muris, Merckelbach, Van den Hout \& De Jong, 1992). In order to increase the emotional impact of the story, we added sounds to the story (e.g., breaking glass, csream).

\section{Procedure}

Participants were brought to a sound-isolated room and were asked to rate their mood on a $100-\mathrm{mm}$ Visual Analogue Scale $(0=$ very depressed, $100=$ very cheerfil). Next, the story was presented. Participants were instructed to relax and to imagine they were the main character of the story. The 5 min filler consisted of $100-\mathrm{mm}$ Visual Analog Scale's asking for mood ratings $(0=$ very depressed; $100=$ very cheerful $)$ and for subjective ratings of the impact of the story $(0=$ not moving at all; $100=$ very moving), and of the CEQ. Finally, participants completed a free recall task. They were asked. to write down the story as accurate and detailed as possible.

\section{Results}

\section{Manipulation checks}

Before they had heard the story, participants gave more positive mood ratings than after they had heard the story, means being $69.47(S D=13.32)$ and $64.74(S D=$ 13.55), respectively $[f(37)=32.16 ; p<.001]$. Mean rating of the impact of the story was $56.76(S D=20.39)$. This score is similar to that reported by Muris et al. (1992). High and low DES individuals did not differ with regard to their subjective impact ratings $[t(36)<1]$.

\section{Memory performance}

Two judges scored free recall in terms of hits (i.e., number of correctly reproduced elements of the story; maximum score $=38$ ), distortions, and commission errors. A distortion is a major change in the details of an existing element of the original narrative (e.g., "a red Volkswagen" instead of "a green Volkswagen"), while a commission error refers to the introduction of an entirely novel element (see Gudjonsson \& Clare, 1995). Only if there was agreement between the two judges, scores were assigned to one of the three categories. Percentage of omissions was calculated as number of omitted elements [i.e., 38 - (hits + distortions)] divided by 
38. Percentage of commissions was defined as number of commissions divided by total free recall output (i.e., hits, distortions and commissions). Table 8.1 gives an overview of the results. Independent and Bonnferoni-corrected $t$-tests (adjusted significance levels of .01) indicated that the high and low DES group did not differ with respect to mean percentage hits $[t(36)=-1.05 ; p=.30]$ and omissions $[t(36)=$ $1.19 ; p=.24]$. Similarly, percentage distortions made during free recall did not differ between the groups $[t(36)=-.11 ; p=.91]$. Mean percentage commissions was 2.9. This fits well with Dunning and Stern's (1992) finding that, in general, commissions account for less than $10 \%$ of the total free recall output. However, the high DES group made more commissions than the low DES group, means being $4.70 \%(S D=5.43)$ and $1.02 \%(S D=2.08)$, respectively $[r(36)=-2.75 ; p<.01]$. To examine whether the difference in commission errors between both groups was carried by fantasy proneness, we conducted an Analysis of Variance (ANOVA) with group as independent factor, percentage commission errors as dependent variable, and fantasy proneness as covariate. This analysis showed that the difference in percentage commission errors remained significant when the influence of fantasy proneness was corrected for $[F<1]$.

Table 8.1 Mean percentages hits, omissions, distortions, and commissions in free recall of high and low DES individuals (standard dewiations are given between parentheses)

\begin{tabular}{lll}
\hline & High DES $(n=19)$ & Low DES $(n=19)$ \\
\hline Hits & $47.64(11.06)$ & $43.63(12.42)$ \\
Omissions & $51.39(10.24)$ & $55.69(11.87)$ \\
Distortions & $2.17(3.43)$ & $2.03(4.35)$ \\
Commissions & $4.70(5.43)$ & $1.02(2.08)$ \\
\hline
\end{tabular}

\section{Discussion}

Although the defensive qualities of dissociation are often taken for granted (e.g., Gershuny \& Thayer, 1999), few attempts have been made to test predictions that flow from this prominent assumption of the trauma-dissociation model. This model would lead one to expect that compared to control persons, individuals high on dissociation display omission errors in their memory for emotional events. The current study tested this and its results can be summarized as follows. To begin with, in contrast to what one would anticipate on the basis of the defenceinterpretation, high and low dissociators did not differ with regard to their rates of memory omissions. Second, we found that high dissociators produced more commissions in emotional memory than low dissociators. Thirdly, in line with many other studies, participants who scored high on dissociation were also found to 
have raised fantasy proneness levels as compared to those low on dissociation. Fourthly, the group difference in commission errors was not mediated by fantasy proneness, a finding that is in contrast to what one would anticipate on the basis of a fantasy proneness interpretation of dissociation.

High DES individuals did not show more omission errors in free recall than did low DES individuals. This is clearly at variance with the defensive function that the trauma-dissociation model attributes to dissociation. Interestingly, there are other studies that found little or no evidence for the amnesic power of dissociation. For example, Wessel, Merckelbach, Kessels, and Horselenberg (2001) reported that high and low dissociators do not differ with regard to autobiographical memory specificity. In that study, individuals high on dissociation did not react with more overgeneral memories to positive or negative cue-words than did individuals low on dissociation. Furthermore, Kindt and Van den Hout (2003) found that individuals with high self-reports of peri-tramatic dissociation (i.e., dissociation during an emotional event) did not show evidence for fragmented memory of an emotional film. Their performance on a cued recall task and on a recognition task about the film did not differ from that of low dissociators.

On the other hand, compared to low DES individuals, high DES participants did produce more commissions during free recall. Although this observation is consistent with a number of previous studies documenting a robust connection between dissociation and pseudomemories (e.g., Hyman \& Billings, 1998; Clancy, Schacter, McNally \& Pitman, 2000; Merckelbach el al., 2000), it is not fantasy proneness that accounts for this relationship. Interestingly, Merckelbach, Horselenberg, and Schmidt (2002) pointed out that dissociation has two prominent correlates: fantasy proneness and absentmindedness. It may well be that absentmindedness rather than fantasy proneness is the crucial mediator in the connection between dissociation and memory commissions. Evidence for this comes from a study in which it was found that the heightened suggestibility levels of high dissociators were partially dependent on absentmindedness (Merckelbach, et al., 2000). Clearly, this possibility warrants further study.

Several limitations of the current study deserve comment. First, although the subjective impact of the story came close to that reported in previous studies (e.g., Muris et al., 1992), one might question whether it was powerful enough to elicit intense emotions. A second issue is that we did not evaluate to what extent our participants had a traumatic background. One could argue that the defensive function of dissociation only shows up in people who have been repeatedly traumatized. Thus, it is conceivable that there are two pathways to dissociativity: a benign fantasy proneness route that is not necessarily conmected to defensive coping and a traumatogenic pathway that is intimately linked to defence. In order to explore this possibility, studies comparing traumatized and non-traumatized dissociators on memory and arousal would be required. 
76 Chapter 8

To sum up, then, the current findings demonstrate that at least in an undergraduate sample and with moderately strong emotional material, dissociation does not seem to serve a defensive function. On the other hand, it is related to memory commissions. 


\title{
Chapter 9
}

\author{
Fantasy proneness and thought \\ suppression as predictors of the \\ Medical Student Syndrome
}

\begin{abstract}
This study examined individual differences correlates of the Medical Student Syndrome (MSS). A sample of 215 medical students completed a questionnaire measuring health complaints that had to do with their study as well as self-report scales tapping fantasy proneness, and habitual thought suppression attempts. Thirty percent $(n=$ 65 ) of the respondents reported MSS complaints related to a wide variety of diseases. Fantasy proneness and thought suppression were found to be independent predictors of these complaints.
\end{abstract}

"Candel, I., \& Merckelbach, H. (in press). Personality \& Individual Differences. 


\section{Introduction}

The Medical Student Syndrome (MSS), or the Medical Student Disease (MSD; Woods, Natterson \& Silverman, 1966) as it is sometimes called, refers to health complaints that are the results of medical expertise rather than genuine pathology. According to Ferguson (1996; p. 315), MSS "points to the important role played by factual medical knowledge in the interpretation of physiological signs and symptoms". By this view, some medical students would have a tendency to interpret vague bodily symptoms in terms of the latest disease they have learnt about. This tendency would become stronger as medical knowledge grows (Ferguson, 1996). Although both medical teaching staff and medical students are well aware of this phenomenon (Woods et al., 1966), little systematic research has been done on MSS. One exception is the older study of Woods and colleagues (1966) that was carried out to determine the incidence and various manifestations of MSS. These authors noted that $79 \%$ of the respondents in their sample of medical students $(N=33)$ had experienced MSS complaints at some point during their medical education. Interestingly, MSS seems not to be specific for medical students. Hardy and Calhoun (1997) studied worries about mental health in a sample of undergraduates who followed a course in abnormal psychology. Students who planned to major in psychology reported more worries about their psychological health than those planning to major in another discipline. However, it was also the case that the process of learning about various psychiatric diseases decreased students' worries about their mental health, which is quite the opposite of the MSS phenomenon.

The purpose of the current study was two-fold. Given the fact that so far only small-scale studies have been conducted in this domain, our first aim was to examine the prevalence of MSS complaints in a reasonably large sample of medical students. Secondly, we explored whether certain individual difference variables are related to MSS. In previous studies, MSS has been portrayed as a form of hypochondrias (Woods et al., 1966), but factors that may mediate this condition have not been studied so far. On the basis of our earlier work, we speculated that fantasy proneness and thought suppression might be interesting candidates in this respect. Individuals high on fantasy proneness spend a large part of their time fantasizing and daydreaming and they have a strong ability to experience intense sensations. For example, Wilson and Barber (1983) noted that individuals high on fantasy proneness often develop physical symptoms (e.g., pain or thermal sensations) that are directly related to fantasies and thoughts about illness or specific medical conditions. A case in point is pseudocyesis (false pregnancy), a phenomenon that seems to have a raised incidence among fantasy prone people. 
Habitual thought suppression refers to chronic attempts to dispel certain thoughts from the stream of consciousness (e.g.; Wegner, Schneider, Carter \& White, 1987). There are good reasons to believe that thought suppression is a counterproductive strategy in that it renders the to-be-suppressed topic hyperaccessible, an effect that has been dubbed "the white bear effect" (Wegner et al.; 1987; see review by Rassin, Merckelbach \& Muris, 2000). For example, it has been found that thought suppression directly increases PTSD symptoms (Ehlers \& Clark, 2000). On a related note, suppressing thoughts about pain has been found to delay rather than precipitate pain recovery (Cioffi \& Holloway, 1993). With these considerations in mind, we conducted a survey among medical students. We asked them whether they ever had experienced MSS complaints during their medical study. They also completed self-report measures of fantasy proneness and thought suppression. We speculated that raised scores on these measures would be related to MSS complaints.

\section{Method}

\section{Participants}

All third and fourth year medical students at Maastricht University $(N=419)$ received a booklet containing questionnaires and a cover letter that invited them to participate in a study on medical complaints. Participants received a small financial compensation in return for completing the questionnaires. Two hundred fifteen participants ( 158 women) completed and returned the questionnaires (response rate $51 \%)$. Mean age of the sample was 22 years $(S D=1.74$; range $=19-32$ years $)$. About half of the participants ( $n=106 ; 3$ missing) were third year students.

\section{Questionnaires}

Questionnaires included the Creative Experience Questionnaire (CEQ: Merckelbach, Horselenberg \& Muris, 2001), the White Bear Suppression Inventory (WBSI; Wegner \& Zanakos, 1994), and the Medical Student Syndrome Questionnaire that was specifically developed for the purpose of this study.

The CEQ (Cronbach alpha $=.73$ ) is a 25 -item self-report instrument that measures fantasy proneness. A sample item is: "Many of my fantasies have a realistic intensity". Items are scaled in the true/false form. The number of yesanswers is summed to yield a total CEQ score, with higher scores indicating higher levels of fantasy proneness. Merckelbach et al. (2001) summarized evidence that supports the reliability and validity of this scale.

The WBSI (Cronbach alpha $=.88$ ) is a 15 -item questionnaire measuring people's habitual tendency to suppress thoughts. Participants indicate on a 5-point 
scale the extent to which they agree $(1=$ strongly disagree; $5=$ strongly agree $)$ with statements such as: "There are things I prefer not to think about". Responses are summed to yield a total score, with higher scores indicating higher levels of thought suppression. Muris, Merckelbach, and Horselenberg (1996) found that WBSI scores are linked to levels of intrusive thinking.

The Medical Student Syndrome Questionnaire began with a case vignette describing a medical student who got concerned about having Chronic Non Specific Lung Disease (CNSLD) after having read about this disorder during a course. Next, respondents were asked whether they had had similar experiences. If so, they were invited to write down the complaints or the disease to which the complaints were related. Next, they were asked to rate on 10 -point scales $(0=$ not at all; $10=$ very much) how serious and frightening they had found their complaints. Finally, they were asked whether a doctor had confirmed the disease.

\section{Results}

\section{Medical Student Syndrome}

Thirty-six percent $(n=78)$ of the students reported MSS complaints. Seventeen students $(22 \%)$ consulted a medical specialist. However, in 13 students $(17 \%)$ a disease was diagnosed, indicating that their complaints had an objective medical ground. In our sample, then, $30 \%(n=65)$ of the medical students had a history of MSS. MSS data are based on this sample. Third and fourth year students did not differ with regard to MSS frequency $\left[\chi^{2}(1)=0.26 ; p=.61\right]$. Mean ratings of seriousness and fear of the complaints were $5.08(S D=1.80)$ and $5.03(S D=2.56)$, respectively. Seriousness ratings, but not fear ratings, of those who had actually a disease were higher than of those who had not, means being $8.00(S D=0.82)$ and $5.08(S D=1.80)$, respectively $[t(76)=-5.73 ; p<.001]$. The frequency of reported diseases are listed in table 9.1. For the purpose of this study, complaints (e.g., CNSLD, bronchitis) were grouped together in 12 non-overlapping categories: We created 1 category for non-specified complaints. As can be seen, MSS complaints pertained to a broad variety of diseases.

\section{Fantasy proneness and thought suppression}

Mean scores on the CEQ and WBSI were analyzed only for participants who answered all items (CEQ: $n=208$; WBSI: $n=213)$ and were $6.05(S D=3.46)$, and $43.60(S D=11.53)$, respectively. These scores come close to those that have been previously reported for nonclinincal samples (e.g., Merckelbach, Muris, Horselenberg \& Stougie, 2000; Muris et al., 1996). The Pearson product-moment correlation between CEQ and WBSI was significant, but modest $(r=.28 ; p<.01)$. 
To evaluate the independent contribution of fantasy proneness, thought suppression, age, and sex as predictors for MSS complaints, they were entered into a logistic regression analysis. Age and sex did not predict presence or absence of MSS complaints ( $W a l d=0.46 ; p=.50$ and $W$ ald $=0.44 ; p=.51$ ), while CEQ scores and WBSI scores were significant and independent predictors of such complaints (Wald $=4.46 ; p<.05$ and Wald $=4.14 ; p<.05$, respectively). To explore the robustness of these significances, CEQ and WBSI scores were dichotomised by using mediansplits. Next, fantasy proneness, thought suppression, age, and sex were entered as predictors into a logistic regression. This yielded odds ratios (OR's) for CEQ and WBSI of 2.28 ( Wald $=6.30 ; p<.05)$ and 1.79 (Wald $=2.95 ; p=.09$ ), respectively. When this analysis was repeated without those participants who did not specify their complaints OR's for CEQ and WBSI were 2.37 ( Wald $=6.02 ; p<.05)$ and $2.05($ Wald $=3.82 ; p=.05)$, respectively.

Table 9.1 Reported diseases and their frequency $(n=65)$

\begin{tabular}{ll}
\hline Diseases & Frequency \\
\hline Pulmonary disease & 9 \\
Coronary and vascular disease & 9 \\
Psychiatric disorder & 8 \\
Gastrointestinal disease & 7 \\
Neurological disorder & 6 \\
Cancer & 5 \\
Infectious disease (incl. STD/HIV) & 4 \\
Allergy & 1 \\
Skin disorder & 1 \\
Ear disorder & 1 \\
Diabetes & 1 \\
Gynaecological disorder & 1 \\
Not specified & 14 \\
\hline Total & $67^{*}$ \\
\hline
\end{tabular}

* Two participants reported two diseases

\section{Discussion}

The results of the current study can be summarized as follows. To begin with, about one third of our medical student sample reported a history of MSS. Secondly, MSS complaints pertained to a broad variety of diseases. Third, although both fantasy proneness and thought suppression were found to be independent predictors of MSS complaints, fantasy proneness seems to be the most powerful predictor.

Although a substantial percentage of medical students in our study reported a history of MSS, its prevalence was clearly below that reported in the small-scale 
study of Woods et al. (1966). On the other hand, our finding that MSS complaints pertain to a variety of diseases is in line with Wood et al. (1966) who reported that MSS may involve complaints about organic but also about psychiatric symptoms. In accordance with our expectation, relatively high fantasy proneness scores and a relatively strong habitual tendency to suppress unpleasant thoughts were related to the occurrence of MSS. In their study on fantasy prone individuals, Wilson and Barber (1983) emphasized the intimate association between vivid fantasies and physical concomitants. A surprisingly large number of fantasy prone individuals interviewed by these authors reported that they had experienced false pregnancies (pseudocyesis) and/or other illnesses that developed on the basis of a fantasy about being ill. We do not want to argue that the students who reported MSS complaints in the current study were fantasy prone individuals. Our point is that raised fantasy proneness levels may make undergraduates vulnerable when they relate newly acquired technical knowledge about a disease to vague bodily symptoms they experience. Further anecdotal evidence for this comes from an informal study that we conducted among bogus patients who volunteer to role-play certain diseases during practical courses in medical school. In that study, three out of 60 bogus patients said that they were familiar with the phenomenon of developing genuine complaints as a result of role-playing. These three bogus patients had raised CEQ scores $(M=11.33, S D=4.51$ ) relative to those who were not familiar with this phenomenon $(M=6.49 ; S D=4.05)$. Thus, it is conceivable that those who score relatively high on fantasy proneness tend to develop worse case scenariointerpretations of bodily sensations. On a related note, a relatively strong tendency to suppress worries about the meaning of bodily experiences may radicalise such worries through the ironic white bear-effect (e.g., Cioffi \& Holloway, 1993), especially if these worries are based on sophisticated knowledge about pathology.

An obvious limitation of the current study is that it was correlational in nature. Thus, we cannot be sure whether and to what extent fantasy proneness and habitual thought suppression are causal antecedents of MSS complaints. Clearly, prospective studies are required to resolve the causality issue. Such studies would bear relevance not only to the phenomenon of MSS, but also to other situations that involve communication of medical expertise. As an example, health promotion programs often aim at informing large groups of people about certain diseases. Perhaps, such information may have a paradoxical effect in individuals scoring high on fantasy proneness and/or thought suppression. Another example is provided by reseatch on screening instruments for malingering. This research is often based on naive undergraduates who are instructed to feign a certain disorder. Meanwhile, there are indications that malingering a disorder and believing that one has a disorder form a continuum (Christianson \& Bylin, 1999). If this is true, individuals high on fantasy proneness and/or thought suppression might be particularly talented to serve as instructed malingerers in experimental research on malingering. 


\section{Chapter 10}

\section{General discussion}

Experimental studies on memory have long been dominated by a quantity-oriented approach. In this approach, memory is viewed as a storehouse and is evaluated in terms of the number of items that can be retrieved (e.g., Ebbinghaus's list-learning paradigm). The emphasis is on quantity of correct responses rather than on errors. What matters is not what is remembered but how much. Thus, the focus of the quantity-oriented approach is on only one dimension of miscorrespondence between in- and output, namely omissions. More recently, however, memory research has shifted to a quality-oriented approach. In this approach, memory is viewed as a representation or reconstruction of the past in which errors might occur. The focus, then, is on the correspondence between what the person reports and what actually occurred (see Koriat, Goldsmith \& Pansky, 2000). This thesis aimed to combine both approaches. In doing so, memory was evaluated in terms of the three dimensions described in the introduction. The results of our studies will be presented and discussed with respect to these dimensions, that is accuracy, completeness, and consistency.

\section{Accuracy}

Accuracy of memory is reflected in the correspondence between the quality of memory input and menory output. As Roediger III (1996; p. 79) noted "lack of control over the original events - plagues many modern treatments of the question of accuracy and inaccuracy in memory." However, in the studies described in the chapters $3,4,5$, and 8 , we were able to compare memory output with the input. Memory input in these studies varied from a movie fragment (chapter 3), isolated pictures (chapters 4 and 5), pictures that formed a story line (chapter 4 ), to an auditory story (chapter 8 ). On the basis of the results found in these studies, we may conclude that memory for emotional material is far from perfect. Admittedly, this in itself, is not a ground breaking insight. However, previous work on emotional memories either emphasized the photographical qualities of such memories (e.g., flashbulb memories; Brown \& Kulik, 1977) or the abnormally incomplete state of such memories (e.g., amnesia; Bremner \& Marmar, 1998). In contrast, our findings. document errors in emotional memories. Errors do undermine the accuracy. In memory for visual as well as auditory-presented emotional material, we found distortions and commission errors to occur. Visual scene memory was found to be susceptible for boundary extension errors. Since boundary extension is defined as "the viewer's tendency to remember seeing information that was not in a 
photograph but that was likely to have existed just outside the camera's field of view" (Intraub \& Berkowits, 1996), we suggest that boundary extension can be classified as a conmmission error. One could argue that a boundary distortion error is not a straightforward memory illusion. According to Roediger III (1996), illusions can be classified as either perceptual or memorial in nature. However, some illusions operate in the continuum between these two categories. Indeed, boundary extension is a typical illusion illustrating that no sharp demarcation exists between perceptual and memorial distortions. Intraub, Gottesman, Willey, and Zuk's (1996) finding that a 250 -ms glimpse of a scene results in boundary extension when people try to remember these scene, lead Roediger III (1996) to conclude that the boundary extension illusion occurs in the area between perceiving and remembering. More specifically, the Intraub et al. results indicate that this illusion develops very rapidly, as the picture is still being interpreted. On the other hand, boundary extension does not occur when people are merely looking at a picture, so it is not a straightforward perceptual illusion. In a sense, the boundary extension illusion is very similar to the phenomenon of change blindness (Simons, 2000), which refers to observers" inability to detect ongoing changes in major details of a visual scene. Change blindness too occurs at the border between perception and memory.

There are several reasons as to why distortions and commission errors might occur. For example, schema theory holds that what people remember is the result of an interaction between the input information and pre-existing schemas. Researchers have long noted that schemas affect the correspondence between memory in- and output in a variety of ways. For example, Alba and Hasher (1983) identified five different types of schema processes. One of these processes might account for our results: interpretation. Interpretation effects involve actual changes (distortions) and additions (commissions) to the input information during encoding. These changes and additions become incorporated in memory for the particular event. Such inferences have previously been observed with both linguistic and nonlinguistic information.

Like schema theory, fuzzy-trace theory (FTT; Brainerd, Reyna \& Poole, 2000) suggests that experiences and expectancies might affect the accuracy of memories. More specifically, FTT suggests that people store verbatim (e.g., "don't move or I'll shoot") and gist traces (e.g., "armed robbery story") of target events. Retrieval of verbatim traces produces access to episodic information (e.g., the exact wording of "don't move or I'll shoot"). On the other hand, retrieval of gist memories produces access to semantic information. Verbatim traces rapidly decay over time, leaving gist traces to retrieve memories. Recollections based on gist traces are consistent with many specific possibilities (e.g., "robbers usually wear masks"). As a result, false memories (i.e., commission errors) might occur. In the words of Sulin and Dooling (1974; p. 256): "specific information $[. .$.$] decays with$ time, while the schema remains relatively stable and intact." 
Another theory that might explain the lack of accuracy of emotional memories is the attentional-narrowing hypothesis (Christianson, 1992a). According to this hypothesis, under stressful conditions, attention automatically narrows to the central, arousing details resulting in good memory for these central details and poor memory for peripheral details. However, the attentional-narrowing hypothesis (Christianson, 1992a) does only a good job in accounting for peripheral omissions in emotional memory. It does not, however, explain why distortions and commissions occur in emotional memories.

Our results also suggest that people high on dissociation are especially susceptible to commissions in emotional memories (chapter 8). This finding is difficult to reconcile with the defense mechanism theory of dissociation (e.g., Van der Kolk \& Fisler, 1995). According to this theory, dissociative experiences are related to omissions rather than commissions in emotional memories. Although our results do not support this defense idea, we also found that it is not fantasy proneness that accounts for our results. Nevertheless, we found that fantasy prone individuals have the tendency to exaggerate ambiguous sensation (chapter 9). Obviously, this does not mean that they are susceptible to commissions in emotional memories. In addition to dissociation, PTSD symptomatology seems to be related to commissions (see the paragraph on consistency).

\section{Completeness}

As our chapters 3 and 8 demonstrated, emotional memories are incomplete as well. Moreover, over time completeness of these memories decreases (chapter 3). This is what some (e.g., DSM IV; APA, 1994) have termed "normal" forgetting, but of course, the mechanisms behind "normal" or "ordinary" forgetting are a complex issue. Bjork and Bjork (1988) pointed out that it is often useful and/or necessary to forget information. Information that is no longer needed or less important will neither be retrieved nor rehearsed. As a result, this information becomes less accessible over time. This is what Schacter (2001) called transience. "Transience refers to a weakening or loss of memory over time $[. .$.$] and is a basic feature of$ memory" (Schacter, 2001; p. 4). According to the altentional-narrowing hypothesis (Christianson, 1992a), forgetting of emotional material might be limited to peripheral information. As explained earlier, this theory argues that memory for this information might be poor due to attentional narrowing to central information.

On first sight, this hypothesis does not account for our boundary distortions findings. These findings suggest that commissions rather than omissions are likely to occur in peripheral information. However, poor memory for peripheral information might increase the susceptibility for distortions and commissions. The point here is the principle known as discrepancy detection. In the words of Schooler 
and Loftus (1986, p. 107-108): "Recollections are most likely to change if a person does not immediately detect discrepancies between post-event suggestions and memory for the original event."

\section{Consistency}

Emotional memories are not consistent. With regard to eyewitness testimonies (chapter 3), inconsistencies seem to be primarily the result of omissions. However, inconsistency is not related to accuracy. That is, inconsistent testimonies may be quite accurate. For example, when an eyewitness states during the first interview that he/she saw a red Volkswagen and during the second interview that he/she saw a Volkswagen, the testimonies are inconsistent, but they may be accurate.

In a normal population, omission errors undermine the consistency of eyewitness testimonies. In a clinical population (e.g., PTSD patients) though, commission errors seem to be an important source of inconsistent testimonies. PTSD patients have the tendency to report more traumatic experiences during follow-up interviews than they reported during initial interviews. One possible explanation for this finding might be attribution. Studies (e.g., Linton \& Melin, 1982; Holeva \& Tarrier, 2001) suggest that attribution plays a role in the amplification of symptoms and traumatic experiences over time in traumatized people who have complaints. An important point here to note is that inconsistent reports include descriptions of one's own past mental state (e.g., subjective experiences) and are not restricted to descriptions of external features (e.g., intensity of the traumatic event). More specifically, in studies on the relationship between peritraumatic dissociative experiences and psychological complaints, trauma victims are asked about such complaints shortly after the traumatic experience and they are asked about complaints and peritraumatic experiences in follow-up interviews weeks or months later. Since people have the tendency to seek an explanation for their persistent complaints ("effort after meaning"; Tennant, 1983), this particular order of conducting interviews might contribute to key findings about peritraumatic dissociation. After reporting about mental complaints, respondents might want to attribute these complaints to peritraumatic experiences.

We made a first attempt to test the attribution hypothesis by asking 78 Maastricht University undergraduates (64 women) about mental complaints and peritraumatic symptoms (Candel, Merckelbach \& Simons, un-published lab report). Half of the participants (group 1) were first asked about anxiety (State-Trait Anxiety Inventory version 1 and 2, STAII and STAI2; Spielberger, 1983; $\alpha$ version $1=.86 ; \alpha$ version $2=.90$ ), depression (Beck Depression Inventory, BDI; Beck, Rush, Shaw \& Emery, 1979; $\alpha=.74$ ), and their most traumatic event (Impact of event Scale, IES; Horowitz, Wilner \& Alvarez, 1979; $a=.91$ ). Next, they 
completed a questionnaire on peritraumatic experiences (PDEQ; Marmar, Weiss, Schlenger, Fairbank, Jordan, Kulka \& Huogh, 1994; $\alpha=.81$ ). A typical PDEQ-item is "I found myself acting on the "automatic pilot". The other half (group 2) was first asked about peritraumatic experiences followed by questionnaires on anxiety, depression, and their most traumatic event. We hypothesized that participants who were first asked about mental complaints in relation to an emotional event, would then later try to find an explanation for these complaints resulting in an heightened level of self-reported peritraumatic experiences compared to participants who completed questionnaires in the reversed order. However, as can be seen in Figure 10.1 , both peritraumatic symptoms and mental complaints did not differ between the groups (all $p$ 's $>.1$ ). One explanation for our failure to find group differences might be that a majority of our participants only reported mild complaints that they have here and now. One could argue that attribution of symptoms to prior experiences will only show up in people who actually have severe symptoms, e.g., PTSD symptoms. In order to explore this possibility, question-order should be manipulated in a PTSD sample.

Apart from attributional phenomena, there are certain personality characteristics that may inflate people's reports about their peritraumatic feelings. For example, in one of our studies (chapter 7), we found that peritraumatic dissociation overlaps with fantasy proneness. In a similar vein, the study described in chapter 9 suggests that fantasy proneness plays a role in how vague bodily sensations develop into what is known as the Medical Student Syndrome.

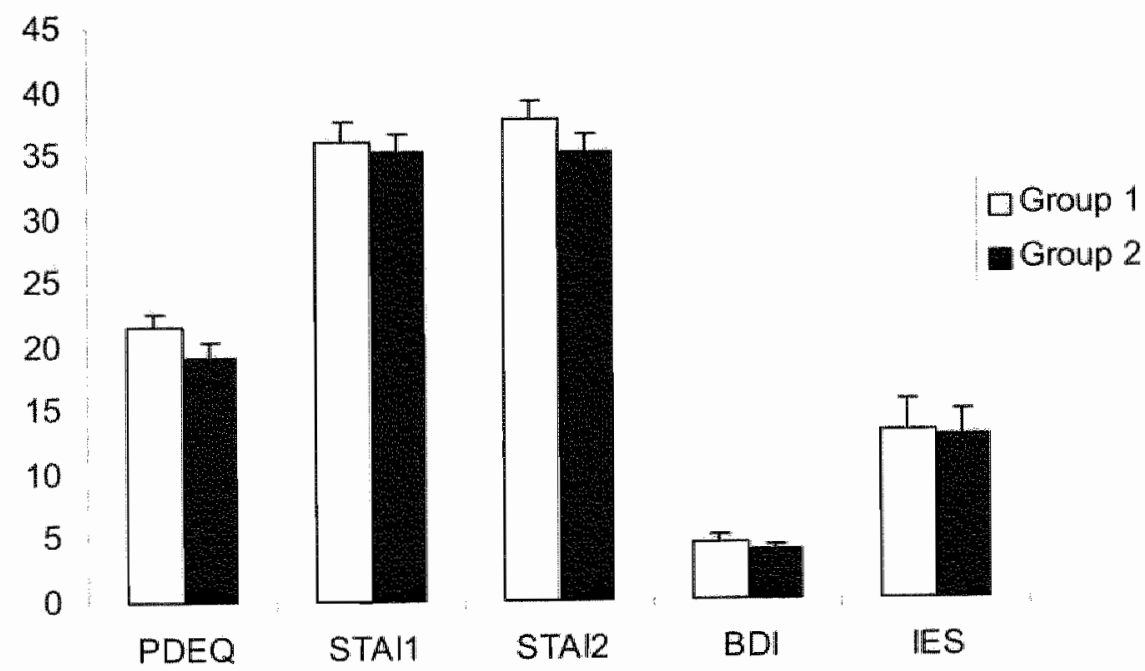

Figure 10.1 Mean scores on the PDEQ, STAII, STAI2, BDI, and IES for group I and group2 
Another paradigm that can be employed to examine the consistency of emotional memories is the flashbulb memory paradigm. Although it is often assumed that these memories are more consistent than neutral memories, they are not perfectly consistent. Moreover, we have good reason to suspect that in amnesic patients, flashbulb memories are the product of confabulation. Although Korsakoff patients in our study (chapter 6) reported flashbulb memories, they were inaccurate to some extent. Normally, little or nothing can be said about the accuracy of flashbulb memories due to the lack of objective records describing the circumstances under which participants first heard about the particular event. However, we had some objective information about the reception events of the Korksakoff patients participating in our study. For example, we knew for sure that all patients were residing in the clinic rather than at home when they heard the news about the September 11 attacks. Nevertheless, some patients $(n=3)$ reported that they were at their home at the time they heard the news. Although flashbulb memories in Korsakoff patients are inconsistent and inaccurate, these amnesic patients do have, to some extent, memories for the target event. However, their memories seem to be less detailed as compared to healthy controls (e.g., "planes into Twin Towers" vs "planes crashed into the World Trade Center in the United States of America"). According to the FTT, these patients are able to store vague gist traces about the target event, but rapidly forget about all the verbatim details. Our Korsakoff study fits nicely with that of Schacter, Verfaille, and Pradere (1996). These authors relied on the Deese-Roediger-McDermott paradigm (DRM-paradigm; e.g., Deese, 1959, Roediger \& McDermott, 1995) to study development of false memories in amnesic patients. In this paradigm, participants are presented with a list of related words (e.g., hill, valley, climb, summit, and top). All these words are associated with one non-presented target word (e.g., mountain). During the test phase, intrusion of the target word is measured, which is taken as an indicator of false memory development. In the Schacter et al. (1996) study, it was found that amnesic patients were less susceptible to falsely recall the target word than were controls. The authors argued that this relative immunity against false recall and recognition in amnesic patients indicates that the gist representation that normally supports recollective processes are impaired in these patients, relative to controls.

\section{Are emotional memories special?}

In sum, emotional memories are fallible and malleable in the sense that they are not fully accurate, far from complete, and fairly inconsistent. This raises the question as to whether emotional memories are special. Are emotional memories quantitatively and/or qualitatively different from neutral memories? This question is at the heart of a recurrent debate in literature. One widespread view is that emotional memories 
are processed in such a way that they are difficult to retrieve as coherent verbal narratives (e.g., Herman, 1992; Van der Kolk \& Fisler, 1995). At the same time this view assumes that emotional memories are well preserved in implicit memory. For example, the view that emotional memories are particularly well preserved at a perceptual/sensory level can be found in the recent articles by such leading authorities as Ehlers and Clark (2000) and Brewin (2001). Thus, Ehlers and Clark $(2000$, p. 324) argue that "reexperiencing mainly consists of sensory impressions, rather than thoughts." Similarly, Brewin (2001, p. 374) opines that "flashbacks contains more prominent perceptual features than ordinary memories." In contrast, a second view argues that compared to other memories, emotional memories do not have different qualitative and phenomenological characteristics (e.g., Krause Shobe \& Kihlstrom, 1997). Our results are more in accordance with this second view. The least that can be concluded from our results is that memory for emotional scenes does not have different qualities than memory for neutral scenes. After all, in both emotional and neutral scene memory, boundary extension occurs. Our finding that there are no qualitative or quantitative differences between emotional and neutral (scene) memory is also in line with that of Berntsen (2001). This author noted that flashbacks - assumed to be typical for emotional events - are not limited to trauma nor even to emotionally negative events. On the other hand, Porter and Birt (2001) reported that traumatic memories differ qualitatively from non-traumatic memories. These authors asked participants to give detailed accounts of their most traumatic and their most positive emotional experience. Traumatic memories appeared to have more details than non-traumatic memories. They conclude that "traumatic memories were found to be "special", but not in accordance with prominent fragmentation theories of trauma and memory" (p. 101). In contrast, Merckelbach, Dekkers, Wessel, and Roefs (in press) found no difference in sensory qualities between traumatic and neutral memories of concentration camp survivors. More specifically, these authors interviewed 29 Dutch concentration camp survivors who had been imprisoned in Dutch East Indies about their most traumatic memories and about neutral memories during their childhood. Similar sensory qualities were attributed to both memory categories. On a related note, a robust finding in both laboratory studies (e.g., Steblay, 1992) and field studies (e.g., Berntsen, in press) is that memory for central emotional details is better compared to memory for central neutral details, whereas the opposite is true for peripheral details. Moreover, memory for central details outperforms memory for peripheral details. Does this pattern imply that emotional memories are special? In our view, it does not. In both neutral and emotional memories the same types of errors occur. At the most, such errors do more often occur in the context of emotions, but this might be the result of rehearsal differences (events that are "emotional" are almost by definition meaningful and are therefore more likely to be shared with others). Rehearsal might also be the explanation for our finding that Korsakoff patients are able to form memories about an emotional event. 
This thesis could leave the reader with a pessimistic impression about the reliability of emotional memories. We would like to qualify this impression. First, emotional memories are perhaps more fallible and malleable than is often assumed by many laypeople and clinicians. However, in the past wo decades special attention has been paid to shortcomings in human memory. Thus, research has focused "on the dark side of memory, resulting in a somewhat biased picture" (Koriat, Goldsmith \& Pansky, 2000; p. 522). The point here is somewhat similar to the point Wells, Malpass, Lindsay, Fisher, Tuntle, and Fulero (2000) raise about eyewitness memory: indeed, eyewitness memory is in many respects far from perfect, but "eyewinesses could be more reliable if the justice system adopted certain procedural improvements that the research has shown to be effective in reducing eyewitness errors" (p. 587). Secondly, according to Schacter (1999), memory failures (i.e., forgetting, inaccuracy, and pathological remembrances) can be viewed as by-products of the otherwise adaptive features of memory. We discuss one memory failure that is particularly relevant to this thesis, namely "bias". Schacter (1999) argues that preexisting knowledge and schemas are important factors in many instances of bias. As illustrated in the chapters 3 and 4 , schemas may contribute to distorted recollections of the past. However, schemas also have important organizing functions. For example, they guide memory retrieval and promote memory for schema-relevant information.

\section{A research agenda for future studies}

The results discussed above raise many questions. Although it is justified to conclude that emotional memories are fallible and malleable, many issues warrant further study. For example, our boundary distortion results raise the question under which circumstances straightforward commission errors do occur. In our study described in chapter 5, 1 child confabulated in drawing ellements that were not shown in the original picture. In the study described in chapter 4 , at lleast 4 adults drew confabulated items (see figure 10.2 for an example). We hypothesize that complexity of background is related to the occurrence of commissions. More complex real-life backgrounds are more likely to activate a well-defined cognitive schema. As a result, commission errors that are consistent with that schema might occur. Interestingly, in both studies confabulations or commission errors only occurred in emotional drawings. This suggests that emotional memory is more susceptible to such peripheral commissions than is neutral memory. Perhaps, then, schema theory and attentional-narrowing theory might not be mutually exclusive. They might complement one other. More specifically, complex backgrounds may activate more complex schemata. Against a background of attentional focusing on central detaills, this complexity may promote commissions in the periphery. 
Since "children's memories are more malleable and prone to falsification than adult's memories" (Brainerd et al., 2000; p. 104), errors in children's memory warrant further study. For example, future research might investigate whether children high on suggestibility are more susceptible to errors in emotional memories than children low on this trait (Candel, Merckelbach \& Muris, 2000).
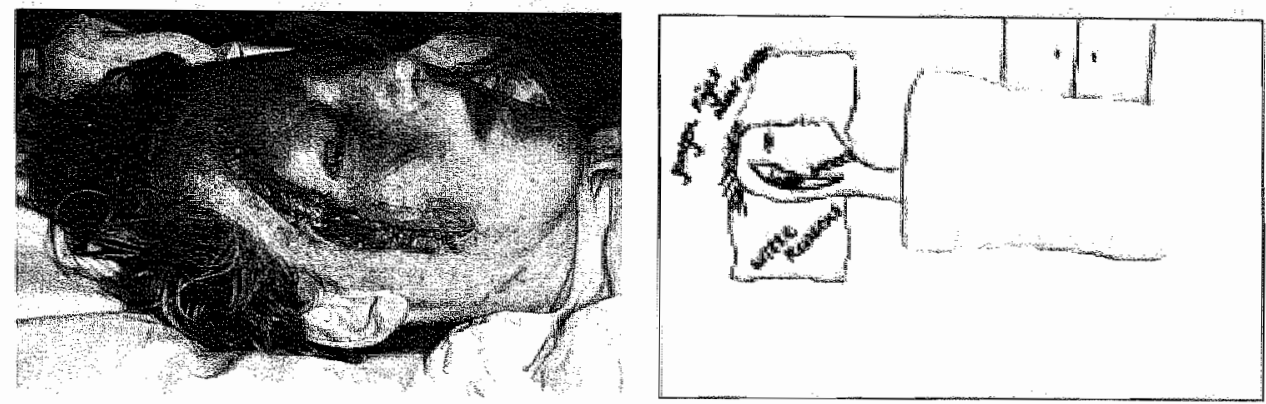

Figure 10.2 An example of an emotional picture and a drawing showing a commission error

Another area of interest for future studies is the increase in self-report of trauma exposure typical for trauma victims with PTSD symptoms. Why do these victims report more traumatic events over time? We already suggested that this might have to do with attribution. However, so far, we have not found support for this idea. A replication of our study with PTSD patients would be worthwhile. Availability heuristic (Tversky \& Kahneman, 1973) gives another explanation for the increased trauma reports of victims with PTSD symptoms. According to this heuristic, reports of events is related to the ease with which such events can be retrieved from memory. As victims with PTSD symptoms have intrusions of traumatic events, it might be much easier for them to recall such events compared to victims without PTSD symptoms. Again, we cannot fully rule out the possibility that victims with PTSD symptoms give more accurate appraisals of their trauma exposure over time. This area might be a challenge or future research.

\section{The implications for psychology and law}

There are some clear-cut implications of our results for the field of psychology and law. To begin with, expert witnesses often use the concepts of accuracy, completeness, and consistency in a way that suggests that they refer to the same key feature of memory. Let us give an example that is by no means rare. A professor of 
sexology who acts as an expert witness in a child abuse case writes: "in dit rapport wordt de vraag beantwoord naar de betrouwbaarheid [reljability], dat wil zeggen waarachtigheid [probability] en accuratesse [accuracy] van de verklaringen van de hiervoor genoemde getuigen $[\ldots]$." This quotation illustrates that this expert employs the concepts of accuracy, completeness, and consistency in a very cavalier way, thereby suggesting that one (e.g., consistency) can be taken as an index of the others (e.g., accuracy). This is a problematic state of affairs because triers of fact may adopt such undifferentiated view and may come to believe that inconsistency is an indication of inaccuracy. We strongly believe that it is important to emphasize that accuracy, completeness, and consistency are tree fairly loosely coupled phenomena.

Another case that illustrates the cavalier way terminology is used, is the "Schiedamse parkmoord". In that case, an expert witness involved "tunnell memory" to explain why an eyewitness provided the police with a description of the offender that did not match with the primary suspect. However, our findings show that the empirical merits of the tunnel memory phenomenon are fragile. As long as this is the case, expert witnesses would be well advised not to employ this idea.

Finally, we would like to make quick work of the idea that trauma victims "appear to have photographical recall of events that happened to them in the past" (Elin, 1995; p. 238). Our results show that emotional memories have shortcomings with respect to accuracy, completeness, and consistency. It is justified to let go of the idea that eyewitness testimonies are the truth and nothing but the truth. 


\section{References}

Alba, J.W., \& Hasher, L. (1983). Is memory schematic? Psychological Bulletin, 93, 2-3-231.

American Psychiatric Association (APA) (1994), Diagnostic and Statistical Manual for mental disorders, fourth edition (DSM IV). Washington: APA.

Andrews, G., Anstey, K., Brodaty, H., Issakidis, C., \& Luscombe, G. (1999). Recall of depressive episode 25 years previously. Psychological Medicine, 29, 787791.

Apitzsch, H. (1996). Trauma and dissociation in refugee patients. Nordic Joumal of Psychiatry, 50, 333-336.

Beck, A.T., Rush, A.J., Shaw, B.F., \& Emery, G. (1979). Cognitive therapy of depression. New York: Guilford.

Berman, G.L., Narby, D.J., \& Cutler, B.L. (1995). Effects of inconsistent eyewitness statements on mock-juror's evaluations of the eyewitness, perceptions of defendant culpability and verdicts. Law and Human Behavior, 19, 79-88.

Bernstein, E., \& Putnam, F.W. (1986). Development, reliability, and validity of a dissociation scale. The Journal of Nervous and Mental Disease, 174, 318-323.

Berntsen, D. (2001). Involuntary memories of emotional events: Do memories of traumas and extremely happy events differ? Applied Cognitive Psychology, 15, S135-S158.

Berntsen, D. (in press). Tunnel memories for autobiographical events: Central details are remembered more frequently from shocking than from happy experiences. Memory \& Cognition.

Bidrose, S., \& Goodman, G.S. (2000). Testimony and evidence: A scientific case study of memory for child sexual abuse. Applied Cognitive Psychology, 14, 197-213.

Binder, L.M., \& Rohling, M.L. (1996). Money matters: A meta-analytic review of the effects of financial incentives on recovery after close-head injury. American Journal of Psychiatry, 1, 7-10.

Bjork, R.A., \& Bjork, E.L. (1988). On the adaptive aspects of retrieval failure in autobiographical memory. In M.M. Gruneberg, P.E. Morris, \& R.N. Sykes (Eds.), Practical aspects of memory: Current research and issues (Vol. 1, pp. 283288). Chichester, England: Wiley.

Bornstein, B.H., Liebel, L.M., \& Scarberry, N.C. (1998). Repeated testing in eyewitness memory: A means to improve recall of a negative emotional event. Applied Cognitive Psychology, 12, 119-131.

Brainerd, C.J., Reyna, V.F., \& Poole, D.A. (2000). Fuzzy-trace theory and false memories. Memory theory in the courtroom. In D.F. Bjorklund (Ed.), False- 
memory creation in children and adults. Theory, research, and implications (pp. 93-126). Mahwah: Lawrence Erlbaum Associates, Publishers.

Bramsen, I., Dirkzwager, A.J.E., Van Esch, S.C.M., \& Van der Ploeg, H.M. (2001). Consistency of self-reports of traumatic events in a population of Dutch peacekeepers: Reason for optimism. Joumal of Traumatic Stress, 14, 733-740.

Bremner, J.D., \& Marmar, C.R. (Eds.) (1998). Trauma, memory, and dissociation. Washington DC: American Psychiatric Press.

Brewer, N., Potter, R., Fisher, R.P., Bond, N., \& Luszcz, A. (1999). Beliefs and data on the relationship between consistency and accuracy of eyewitness testimony. Applied Cognitive Psychology, 13, 297-313.

Brown, R., \& Kulik, J. (1977). Flashbulb memories. Cognition, 5, 73-99.

Bruck, M., Ceci, S.J., \& Hembrooke, H. (1998). Reliability and credibility of young children's reports: From research to policy and practice. American Psychologist, 53, 136-151.

Cahill, L., \& McGaugh, J.L. (1996), Modulation of memory storage. Current Opinion in Neurobiology, 6, 237-242.

Candel, I, \& Merckelbach, H. (in press). Fantasy proneness and thought suppression as predictors of the Medical Student Syndrome. Personality and Individual Differences.

Candel, I., Merckelbach, H., \& Muris, P. (2000). Measuring interrogative suggestibility in children: Reliability and validity of the Bonn Test of Statement Suggestibility. Psychology, Crime \& Law, 6, 61-70.

Candel, I., Merckelbach, H., \& Zandbergen, M. (in press). Boundary distortions for neutral and emotional pictures. Psychonomic Bulletin \& Review.

Chapman, P., \& Underwood, G. (2000). Forgetting near-accidents: The roles of severity, culpability and experience in the poor recall of dangerous driving situations. Applied Cognitive Psychology, 14, 31-44.

Christianson, S. $-\AA$. (1989). Flashbulb memories: Special but not so special. Memory and Cognition, 17, 435-443.

Christianson, S. $\AA$. (1992a). Emotional stress and eyewitness memory: A critical review. Psychological Bullerin, 112, 284-309.

Christianson, S.-A. (Ed.) (1992b). The handbook of emotion and memory: Research and theory. Hillsdale : Lawrence Erlbaum Associates.

Christianson, S.-A., \& Bylin, S. (1999). Does simulating amnesia mediate genuine forgetting for a crime event? Applied Cognitive Psychology, 13, 495-511.

Christianson S.-Å., \& Engelberg, E. (1999). Memory and emotional consistency: The MS Estonia Ferry disaster. Memory, 7, 471-482.

Christianson, S.-A., \& Lindholm, T. (1998). The fate of traumatic memories in childhood and adulthood. Development and Psychopathology, 10, 761-780.

Cioffi, D., \& Holloway, J. (1993). Delayed costs of suppressing pain. Journal of Personality and Social Psychology, 64, 274-282. 
Clancy, S.A., Schacter, D., McNally, R.J., \& Pitman, R.K. (2000). False recognition in women reporting recovered memories of sexual abuse. Psychological Science, 11, 26-31.

Cohen, G., Conway, M.A., \& Maylor, E.A. (1994). Flashbulb memories in older adults. Psychology and aging, 3, 454-463.

Conte, J.R. (1999). Memory, Research, and the law: Future directions. In L.M. Williams \& V.L. Banyard (Eds.), Trauma \& Memory (pp. 77-92). Thousand Oaks: Sage Publications.

Conway, M.A., Anderson, S.J., Larsen, S.F., Donnelly, C.M., McDaniel, M.A., McClelland, A.G.R., Rawles, R.E., \& Logie, R.H. (1994). The formation of flashbulb memories. Memory \& Cognition, 22, 326-343.

Crombag, H.F.M., Wagenaar, W.A., \& Van Koppen, P.J. (1996). Crashing memories and the problem of "source monitoring". Applied Cognitive Psychology, 10, 95-104.

Curci, A., Luminet, O., Finkenauer, C., \& Gisle, L. (2001). Flashbulb memories in social groups: A comparative test-retest study of the memory of French president Mitterrand's death in a French and a Belgian group. Memory, 9, 81-101.

Davidson, P.S.R., \& Glisky, E.L. (2002). Is flashbulb memory a special instance of source memory? Evidence from older adults. Memory, 10, 99-111.

Deese, J. (1959). On the prediction of occurrence of particular verbal intrusions in immediate recall. Joumal of Experimental Psychology: 58, 17-22.

DePrince, A.P., \& Freyd, J. (1999). Dissociative tendencies, attention, and memory. Psychological Science, 10, 449-452.

Dunning, D., \& Stern, L.B. (1992). Examining the generality of eyewitness hypermnesia: A close look at time delay and question type. Applied Cognitive Psychology, 6, 643-657.

Easterbrook, J.A. (1959). The effect of emotion on cue utilization and the organization of behavior. Psychological Review, 66, 183-201.

Ebbinghaus, H. (1885/1913). Memory: a contribution to experimental psychology. [H.A. Ruger \& C.E. Bussenius, Trans.]. New York: Colombia University, Teachers College.

Ehlers, A., \& Clark, D.M. (2000). A cognitive model of posttraumatic stress disorder. Behaviour Research and Therapy, 38, 319-345.

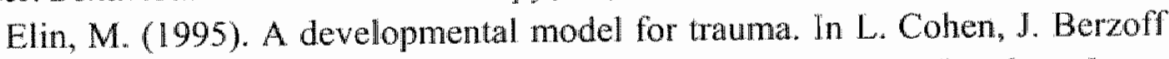
\& M. Elin (Eds.), Dissociative identity disorder (pp. 223-259). London: Jason Aronson.

Elliott, D.M. (1997). Traumatic events: Prevalence and delayed recall in the general population. Journal of Consulting and Clinical Psychology, 65, 811-820.

Ferguson, E. (1996). Hypochondriacal concerns: the role of raw and calibrated medical knowledge. Psychology. Health \& Medicine, I, 315-318. 
Finkenauer, C. Luminet, O., Gisle, L., El-Ahmadi, A., Van der Linden, M., \& Philippot, P. (1998). Flashbulb memories and the underlying mechanisms of their formation: Toward an emotional-integrative model. Memory \& Cogmition, 26, 516531.

Fisher, R.P., \& Cutler, B.L. (1995). The relation between consistency and accuracy of eyewiness testimony. In G.M. Davies, S.M.A. Lloyd-Bostock, M. McMurran \& C. Wilson (Eds.), Psychology, law and criminal justice: International developments in research and practice (pp. 21-28). Berlin: De Gruyter.

Fivush, R. (1993). Developmental perspectives on autobiographical recall. In G.S. Goodman \& B.L. Bottoms (Eds.), Child victins, child winesses: Understanding and improwing testimony (pp.1-24). New York, NY: Guilford Press.

Foa, E.B., \& Riggs, D.S. (1995). Posttraumatic Stress Disorder following assault: Theoretical considerations and empirical findings. Psychological Science, $4,61-65$.

Freedman, S.A., Brandes, D., Peri, T., \& Shalev, A. (1999). Predictors of chronic post-traumatic stress disorder. British Joumal of Psychiatry, 174, 353-359.

Fullerton, C.S., Ursano, R.J., Epstein, R.S., Crowley, B., Vance, K.L., Kao, T.-C., \& Baum, A. (2000). Peritramatic dissociation following motor vehicle accidents. Relationship to prior trauma and prior major depression. Jounnal of Nervous and Mental Disease, 188, 267-272.

Gershuny, B.S., \& Thayer, J.F. (1999). Relation among psychological trauma, dissociative phenomena, and trauma-related distress: A review and integration. Clinical Psychology Review, 19, 63!-657.

Gerson, A.R. (2002). Beyond the DSM-IV: A meta-review of the literature on malingering. American Journal of Forensic Psychology, 20, 57-69.

Gottesman, C.V., \& Intraub, H. (1999). Wide-angle memories of close-up scenes: A demonstration of boundary extension. Behavior Research Methods, Instruments \& Computers, 31, 86-93.

Gottesman, C.V., \& Intraub, H. (2002). Surface construal and the mental representation of scenes. Jownal of Experimental Psychology: Human Penception and Performance, $28,589599$.

Gudjonsson, G.H. \& Clare, I.C.H. (1995). The relationship between confabulation and intellectual ability, memory, interrogative suggestibility and acquiescence. Personality and Individual Differences, 19,333-338.

Hamann, S.B., Cahill, L., \& Squire, L.R. (1997). Emotional perception and memory in amnesia. Neuropsychology, 11, 104-113.

Hardy, M.S., \& Calhoun, L.G. (1997). Psychological distress and the "Medical Student Syndrome" in abnormal psychology students. Teaching of Psychology, 24, 192-193.

Harvey, A.G., \& Bryant, R.A. (2000). Memory for acute stress disorder symptoms: A two-year prospective study. Joumal of Nenous and Mental Disease, $188,602-607$. 
Heaps, C., \& Nash, M. (1999). Individual differences in imagination inflation. Psychonomic Bulletin and Review, 6, 313-318.

Henry, B., Moffitt. T.E., Caspi, A., Langley, J, \& Silva, P.A. (1994). On the "remembrance of things past".. A longitudinal evaluation of the retrospective method. Psychological Assessment, 6, 92-101.

Herlihy, J., Scragg, P., \& Tumer, S. (2002). Discrepancies in autobiographical memories: Implications for the assessment of asylum seekers. Repeated interviews study. Britisin Medical Journal, 324, 324-327.

Herman, J.L. (1992). Trawma and recowery. New York: Basic Books.

Hewer, F., \& Reisberg, D. (1990). Vivid memory of emotional events: The accuracy of remembered minutiae. Memory \& Cognition, 18, 496-506.

Holeva, V., \& Tarrier, N. (2001). Personality and peritraumatic dissociation in the prediction of PTSD in victims of road traffic accidents. Journal of Psychosomatic Research, 51, 687-692.

Holtgraves, T., \& Stockdale, G. (1997). The assessment of diccociative experiences in a non-clinical population: reliability, validity, and factor structure of the dissociative experiences scale. Personality and Individual Differences, 22, 699706 .

Horowitz, M., Wilner, N., \& Alvarez, W. (1979). Inopact of Event Scale: A measure of subjective stress. Psychosomatc Medicine, 41, 209-218.

Hyman, I.E., \& Billings, F.J. (1998). Individual differences and the creation of false childhood memories. Memory, 6, 1-20.

Hyman, I.E., \& Loftus, E.F. (1998). Errors in autobiographical memory. Clinical Psychology Review, 18, 933-947.

Ikeda, M., Mori, E., Hirono, N., Imamura, T., Shimomura, T., Ikejiri, Y., \& Yamashita, H. (1998). Amnestic people Alzheimer's disease who remembered the Kobe earthquake. British Jowrnal of Psychiatry, 172, 425-428.

Intraub, H. (2002). Anticipatory spatial representation of natural scenes: Momentum without movement? Visual Cogmition, 9, 93-119.

Intraub, H., Bender, R.S., \& Mangels, J.A. (1992). Looking at pictures but remembering scene. Journal of Experimental Psychology: Learning. Memory, and Cognition, 18, 180-191.

Intraub, H., \& Berkowits, D. (1996). Beyond the edges of a picture. American Jounnal of Psychology, 109, 581-598.

Intraub, H., \& Bodamer, J.L. (1993). Boundary extension: Fundamental aspects of pictorial representation or encoding artefact? Joumal of Experimental Psychology: Learning, Memory, and Cognition, 19, 1387-1397.

Intraub, H., Gottesman, C.V., \& Bills, A.J. (1998). Effects of perceiving and imagining scenes on memory for pictures. Journal of Experimental Psychology: Learning, Memory, and Cognition, 24, 186-201. 
Intraub, H., Gottesman, C.V., Willey, E.V., \& Zuk, I.J. (1996). Boundary extension for briefly glimpsed photographs: Do common perceptual processes result in unexpected memory distortions? Journal of Memory and Language, 35, 118-134.

Intraub, H., \& Richardson, M. (1989). Wide-angle memories of close-up scene. Journal of Experimental Psychology: Learning Memory, and Cognition, 15, 179-187.

Johnson, M.K., Kim, J.K., \& Rise, G. (1985). Do alcoholic Korsakoff's Syndrome patients acquire affective reactions? Journal of Experimental Psychology: Learning, Memory, and Cognition, 11, 22-36.

Johnson, D.M., Pike, J.L., \& Chard, K.M. (2001). Factors predicting PTSD, depression, and dissociative severity in female treatment-seeking childhood sexual abuse survivors. Child Abuse \& Neglect, 25, 179-198.

Kaye, T. (1998). American History $X$. New Line Productions.

Kindt, M., \& Van den Hout, M. (2003). Dissociation and memory fragmentation: experimental effects on meta-memory but not on actual memory performance. Behoviour Research and Therapy, 42, 167-178.

Kopelman, M.D. (1995). The Korsakoff syndrome. British Journal of Psychiatry, 166, 154-173.

Koriat, A., \& Goldsmith, M. (1994). Memory in naturalistic and laboratory contexts: Distinguishing the accuracy-oriented and quality-oriented approaches to memory assessment. Journal of Experimental Psychology: General, 123, 297-315.

Koriat, A., Goldsmith, M., \& Pansky, A. (2000). Toward a psychology of memory accuracy. Annual Review of Psychology, 51, 481-537.

Krause Shobe, K., \& Kihlstrom, J.F. (1997). Is traumatic memory special? Current Directions in Psychological Sciences, 6, 70-74.

Lang, P.J., Bradley, M.M., \& Cuthbert, B.N. (1995). International affective picture system (IAPS): Technical manual and affective ratings. Gainesville, FL. The Centre for Research in Psychophysiology, University of Florida.

Leippe, M.R. (1980). Effects of integrative memorial and cognitive processes on the correspondence of eyewitness accuracy and confidence. Law and Human Behavior, 4, 261-274.

Linton, S.I., \& Melin, L. (1982). The accuracy of remembering chronic pain. Pain, 13, 281-285.

Livingston, R.B. (1967). Reinforcement. In C.G. Quarton, T. Melnechuck \& F.O. Schmidt (Eds.), The neuroscience: A study program (pp. 568-576). New York: Rockefeller University Press.

Loewenstein, R.J. (1991). Psychogenic amnesia and psychogenic fugue: A comprehensive review. In A. Tasman \& S.M. Goldfinger (Eds.). American Psychiatric Press review of psychiatry (vol. 10, pp. 189-222). Washington, DC: American Psychiatric Press.

Loftus, E.F. (1975). Leading questions and the eyewitness report. Cognitive Psychology, 7, 560-572. 
Loftus, E.F. (1979). Eyewitness testimony. Cambridge, MA: Harvard University press.

Loftus, E.F., \& Castelle, G. (2000). Crashing memories in legal cases. In P.J. van Koppen \& N.H.M. Roos (Eds.), Rafionality, information and progress in law and psychology (p. 115-127). Maastricht: University Press Maastricht.

Malpass, R.S., \& Devine, P.G. (1981). Guided memory in eyewitness identification. Journal of Applied Psychology, 66, 343-350.

Marmar, C.R., Weiss, D.S., \& Metzler, T (1998). Peritraumatic dissociation and Posttraumatic Stress Disorder. In J.D. Bremner \& C.R. Marmar (Eds.), Trawma, Memory and Dissociation (pp. 229-252). Washigton DC: American Psychiatric Press, Inc.

Marmar, C.R., Weiss, D.S., Metzler, T.J., Delucchie, K.L., Best, S.R., \& Wentworth, K.A. (1999). Longitudinal course and predictors of continuing distress following critical incident exposure in emergency services personnel. Journal of Nervous and Mental Diseases, 187, 15-22.

Marmar, C.R., Weiss, D.S., Schlenger, W.E., Fairbank, J.A., Jordan, B.K., Kulka, R.A., \& Hough, R. L. (1994). Peritraumatic dissociation and posttraumatic stress in male Vietnam theater veterans. American Journal of Psychiatry, 151, 902907.

Merckelbach, H., Dekkers, T., Wessel, I., \& Roefs, A. (in press). Amnesia, flashbacks, nightmares, and dissociation in aging concentration camp survivors. Behaviour Research and Therapy.

Merckelbach, H., Horselenberg, R., \& Muris, P. (2001). The Creative Experience Questionnaire (CEQ): a brief self-report measure of fantasy proneness. Personality and Individual Differences, 31, 987-995.

Merckelbach, H., Horselenberg, R., \& Schmidt, H. (2002). Modelling the connection between self-reported trauma and dissociation in a student sample. Personality and Individual Differences, 32, 695-705.

Merckelbach, H., \& Muris, P. (2001). The causal link between self-reported trauma and dissociation: a critical review. Behaviour Research and Therapy, 39, 245-254.

Merckelbach, H., Muris, P., Horselenberg, R., \& Stougie, S. (2000). Dissociation, reality monitoring, and response bias. Personality and Individual Differences, $28,49-58$.

Merckelbach, H., Muris, P., \& Rassin, E. (1999). Fantasy proneness and cognitive failures as correlates of dissociative experiences. Personality and Individual Differences, 26, 961-967.

Merckelbach, H., Muris, P., Rassin, E., \& Horselenberg, R. (2000). Dissociative experiences and interrogative suggestibility in college students. Personality and Individual Differences, 29, 1133-1140. 
Merckelbach, H., \& Smith, G.P. (in press). Diagnostic accuracy of the Structured Inventory of Malingered Symptomatology (SIMS) in detecting malingering. Archives of Clinical Neuropsychology.

Merckelbach, H., \& Van de Ven, V. (2001). Another white Christmas: Fantasy proneness and reports of hallucinatory experiences in undergraduate students. Joumal of Behavior Therapy and Experimental Psychiatry, 32, 137-144.

Morgan III, C.A., Hazlett, M.G., Wang, S., Richardson, E.G., Schnurr, P., \& Southwick, S.M. (2001). Symptoms of dissociation in humans experiencing acute, uncontrollable stress: A prospective investigation. American Journal of Psychiatry, $158,1239-1247$.

Mori, E., Ikeda, M., Hirono, N., Kitagaki, H., Imamura, T., \& Shimomura, T. (1999). Amygdalar volume and emotional memory in Alzheimer's disease. American Journal of Psychiatry, 156, 216-222.

Morris, R.G. (1996). Neurobiological correlates of cognitive dysfunction. In R.G. Morris (Ed.), The cognitive neuropsychology of Alzheimer-type dementia (pp. 223-254). New York: Oxford University Press.

Muris, P., Merckelbach, H., \& Horselenberg, R. (1996). Individual differences in thought suppression. The White Bear Suppression Inventory: Factor structure, reliability, validity and correlates. Behaviour Research and Therapy, 34, 501-513.

Muris, P., Merckelbach, H., Van den Hout, M., \& De Jong, P. (1992). Suppression of emotional and neutral material. Behaviour Research and Therapy, $30,639-642$.

Nijenhuis, E.R.S., Spinhoven, P., Vanderlinden, J., Van Dyck, R., \& Van der Hart, O. (1998). Somatoform dissociative symptoms as related to animal defensive reactions to predatory imminence and injury. Journal of Abnormal Psychology, 107, 63-73.

Nisbett, R., \& Ross, M. (1980). Human inference: Strategies and shortcoming of social judgement. New Jersey: Prentice-Hall.

Nyström, M. (1993). Is picture memory wide-angle? Psychological Research Bulletin, 33, 1-16.

Orbach, Y., \& Lamb, M.E. (1999). Assessing the accuracy of a child's account of sexual abuse: A case study. Child Abuse \& Neglect, 23,91-98.

Ost, J., Vrij, A., Costall, A., \& Bull, R. (2002). Crashing memories and reality monitoring: Distinguishing between perceptions, imaginations and 'false memories'. Applied Cognitive Psychology, 16, 125-134.

O'Toole, B.I., Marshall, R.P., Schureck, R.J., \& Dobson, M. (1999). Combat, dissociation, and Posttraumatic Stress Disorder in Autralian Vietnam veterans. Joumal of Traumatic Siress, 12, 625-641.

Payne, D.G. (1987). Hypermnesia and reminiscence in recall: a historical and empirical review. Psychological Bulletin, 101, 5-27. 
Pekala, R.J., Kumar, V.K. Ainslie, G., Elloit, N.C. Mullen, K.J. Salinger. M.M., \& Masten, E. (1999/2000). Dissociation as a function of child abuse and rantasy proneness in a substance abuse population. Imagination, Cognition, and Personality, 19, 105-129.

Peterson, C., Moores, L., \& White, G. (2001). Recounting the same events again and again: Children's consistency across multiple interviews. Applied Cognitive Psychology, 15, 353-371.

Porter, S., \& Birt, A.R. (2001). Is traumatic memory special? A comparison of traumatic memory characteristics with memory for other emotional life experiences. Applied Cognitive Psychology, 15, 5101-5107.

Porter, S., Birt, A.R., Yuille, J.C., \& Lehman, D.R. (2000). Negotiating false memories: Interviewer and rememberer characteristics relate to memory distortions. Psychological Science, 11, 507-510.

Rauschenberg, S.L., \& Lynn, S.J. (1995). Fantasy proneness, DSM-III-R axis I psychopathology and dissociation. Journal of Abnormal Psychology, 104, 373 380 .

Rassin, E., Merckelbach, H., \& Muris, P. (2000). Paradoxical and less paradoxical effects of thought suppression: A critical review. Clinical Psychology Review, 20,973-995.

Rhue, J.W. \& Lynn, S.J. (1987). Fantasy proneness: Developmental antecedents. Joumal of Personality, 55, 121-137.

Roediger III, H.L. (1996). Memory illusions. Journal of Memory and Language, 35, 76-100.

Roediger III, H.L., \& McDermott (1995). Creating false memories: Remembering words not presented in a list. Jowmal of Experimental Psychology: Learning, Memory, and Cognition, 21, 803-814.

Roemer, L., Litz, B.T., Orsillo, S.M., Ehlich, P.J., \& Friedman, M.J. (1998). Increases in retrospective accounts of war-zone exposure over time: "The role of PTSD symptom severity. Joumal of Tratmatic Stress, 11, 597-605.

Rogers, R., \& Cruise, K.R. (2000). Malingering and deception among psychopaths. In C.B. Gacono (Eds.), The clinical and forensic assessment of psychopathy: A practitioner"s guide (pp.269-284). Mahwah: Lawrence Erlbaum Associates, Inc.

Rosen, G.M. (1995). The Aleutian Enterprise sinking and Postraumatic Stress Disorder: Misdiagnosing in clinical and forensic settings. Professional Psychology: Research and Practice, 26, 82-87.

Ross, M. (1986). Relation of implicit theories to the construction of personal histories. Psychological Review, 96, 341-357.

Ross, C.A., Joshi, S., \& Currie, R. (1991). Dissociative experiences in the general population: A factor analysis. Hospital and Community Psychiatry, 42, 297 301 . 
Safer, M.A., Christianson, S.-A., Autry, M.W., \& Österlund, K. (1998). Tunnel memory for traumatic events. Applied Cognitive Psychology, 12, 99-117.

Schacter, D.L. (1999). The seven sins of memory. Insights from psychology and cognitive neuroscience. American Psychologist, 54, 182-203.

Schacter, D.L. (2001). The seven sins of memory. How the mind forgets and remembers. Boston: Houghton Mifflin Company.

Schacter, D.L., Verfaellie, M., \& Pradere, D. (1996). The neuropsychology of memory illusions: False recall and recognition in amnesic patients. Jownal of Menory and Language, 35, 319-334.

Schelach, L., \& Nachson, I. (2001). Memory of Auschwitz survivors. Applied Cognitive Psychology, 15, 119-132.

Schmolck, H, Buffalo, E.A. \& Squire, L.R. (2000). Memory distortions develop over time: Recollections of the O.J. Simpson trial verdict after 15 and 32 months. Psychological Science, II, 39-45.

Schooler, J.W., \& Loftus, E.F. (1986). Individual differences and experimentation: complementary approaches to interrogative suggestibility. Social Behaviour, I, 105-112.

Schwartz, B.L., Fisher, R.P., \& Hebert, K.S. (1998). The relation of output order and commission errors in free recall and eyewitness accounts. Memory, 6 , $257-275$.

Schwarz, N. (1999). Self-reports. How the questions shape the answer. American Psychologist, 54, 93-105.

Schwarz, E.D., Kowalski, J.M., \& McNally, R.J. (1993). Malignant mernories: Post-traumatic changes in mernory in adults after a school shooting. Jounal of Traumatic Stress, 6, 454-553.

Scriver, E., \& Safer, M.A. (1988). Eyewitnesses show hypermnesia for details about a wiolent event. Jounnal of Applied Psychology, 73, 371-377.

Seamon, J.G., Schlegel, S.E., Hiester, P.M., Landau, S.M., \& Blumenthal, B.F. (2002). Misremembering pictured objects: People of all ages demonstrate the boundary extension illusion. American Jownal of Psychology, 115, 1.51-167.

Shalev, A.Y., Freedman, S., Peri, T., \& Brandes, D. (1997). Predicting PTSD in trauma survivors: prospective evaluation of self-report and clinical-administered instruments. British Journal of Psychiarry, 170, 558-564.

Shalev, A.Y., Peri, T., Canetti, L., \& Schreiber, S. (1996). Predictors of PTSD in injured trauma survivors: A prospeclive study. American Journal of Psychiatry, 153,219-225.

Silva, C.E., \& Kirsch, I. (1992). Interpretive sets, expectancy, fantasy proneness, and dissociation as predictors of hypnotic response. Joumal of Personality and Social Psychology, 63, 847-856.

Simons, D.J. (2000). Current approaches to change blindness. Visual Cognition, $7.1-15$. 
Smith, G.P., \& Burger, G.K. (1997). Detection of malingering: Validation of the Structured Inventory of Malingered Symptomatology. Joumal of the American Academy of Psychiatry and Law, 25, 183-189.

Smith, D.W., \& Freuh, B.C. (1996). Compensation seeking, comorbidity, and apparent exaggeration of PTSD symptoms among Vietnam combat veterans. Psychological Assessment, 8, 3-6.

Southwick, S.M., Morgan III, C.A., Nicolaou, A.L., \& Charney, D.S. (1997). Consistency of memory for combat-related traumatic events in veterans of operation Desert Storm. American Journal of Psychiatry, 154, 173-177.

Spanos, N.P., Cross, P.A., Dickson, K., \& DuBreuil, S.C. (1993). Close encounters: An examination of UFO experiences. Journal of Abnormal Psychology, $102,624-632$.

Spielberger, C.D. (1983). State-Trait Anxiety Imwentory. Palo Alto, California: Consulting Psychologists Press.

Steblay, N.M. (1992). A meta-analytic review of the weapon focus effect. Law and Human Behavior, 16, 413-424.

Sterlini, G.L., \& Bryant, R.A. (2002). Hyperarousal and dissociation: A study of novice skydivers. Behaviour Research and Therapy, 40, 431-437.

Sulin, R.A., \& Dooling, D.J. (1974). Intrusion of a thematic idea in retention of prose. Joumal of Experimental Psychology, 103, 255-262.

Tennant, C. (1983). Life events and psychological morbidity: The evidence from prospective studies. Psychological Medicine, 13,483-486.

Tichenor, V., Marmar, C.R., Weiss, D.S., Metzler, T.J., \& Ronfeldt, H.M. (1996). The relationship of peritraumatic dissociation and postraumatic stress: Findings in female Vietnam theatre veterans. Joumal of Consulting and Clinical Psychology, 64, 1054-1059.

Tulving, E. (1991). Memory research is not a zero-sum game. American Psychologist, 46, 41-42.

Tulving, E., Hayman, C.A.G., \& MacDonald, C.A. (1991). Long-lasting. perceptual priming and semantic learning in amnesia: A case experiment. Joumal of Experimental Psychology: Learning, Memory and Cognition, 17, 595-617.

Turtle, J.W., \& Yuille, J.C. (1994). Lost but not forgotten details : Repeated eyewitness recall leads to reminiscence but not hypermnesiat. Journal of Applied Psychology, 79, 260-271.

Tyersky, A., \& Kahneman, D. (1973). Availability: A heuristic for judging frequency and probability. Cognitive Psychology, 5, 207-232.

Ursano, R.J., Fullerton, C.S., Epstein, R.S., Crowley, B., Vance, K., Kao, T.C., \& Baum, A. (1999). Peritraumatic dissociation and Posttraumatic Stress Disorder following motor vehicle accidents. American Joumal of Psychiatry, 156, 1808 - 1810 .

Van der Kolk, B.A. (1987). Psychological Trauma. Washington, DC: American Psychiatric Press. 
Van der Kolk, B.A., Blitz, R., Burr, W.A., \& Hartmann, E. (1984). Nightmares and trauma: Life-long and traumatic nightmares in veterans. American Journal of Psychiatry, 141, 187-190.

Van der Kolk, B.A., \& Fisler, R. (1995). Dissociation and the fragmentary nature of traumatic memories: Overview and exploratory study. Joumal of Traumatic Stress, 8, 505-525.

Van der Kolk, B.A., \& Van der Hart, O. (1989). Pierre Janet and the breakdown of adaptation in psychological trauma. American Joumal of Psychiatry, $146,1530-1540$.

Van der Kolk, B.A., Van der Hart, O., \& Marmar, C.R. (1996). Dissociation and information processing in posttraumatic stress disorder. In B.A. Van der Kolk, A.C. McFarlane \& L. Weisaeth (Eds.), Traumatic Stress (pp. 303-330). New York, Guilford Press.

Verhage, F. (1965). Intelligence and age: Considered in review. Anthropology and Medicine, 13, 257-267.

Wagenaar, W.A., \& Groeneweg, J. (1990). The memory of concentration camp survivors. Applied Cognitive Psychology, 4, 77-87.

Wegner, D.M., Schneider, D.J., Carter, S.R., \& White, T.L. (1987). Paradoxical effects of thoughts suppression. Journal of Personality and Social Psychology, 53, 5-13.

Wegner, D.M., \& Zanakos, S. (1994). Chronic thought suppression. Journal of Personality, 62, 615-640.

Weinstein, E.A. (1996). Symbolic aspects of confabulation following brain injury: Influence of premorbide personality. Bulletin of the Menninger Clinic, 60 , 331-350.

Wells, G.L., Malpass, R.S., Lindsay, R.C.L., Fisher, R.P., Turtle, J.W., \& Fulero, S.M. (2000). From the lab to the police station. American Psychologist, 55, $581-598$.

Wenzlaff, R.M., Wegner, D.M., \& Roper, D.W. (1988). Depression and mental control: The resurgence of unwanted negative thoughts. Journal of Personality and Social Psychology, 55, 882-892.

Wessel, I., \& Merckelbach, H. (1998). Memory for threat-relevant and threatirrelevant cues in spider phobics. Cognition and Emotion, 12, 93-104.

Wessel, I., Merckelbach, H., Kessels, C., \& Horselenberg, R. (2001). Dissociation and autobiographical memory specificity. Clinical Psychology \& Psychotherapy, 8, 411-415.

Wessel, I., Peeck, V., Foster, J., Merckelbach, H., \& Wiers, R. (2002). Death of a princess: A study of flashbulb memory. Unpublished manuscript.

Wessel, I., Van der Kooy. P., \& Merckelbach, H. (2000). Differential recall of central and peripheral details of emotional slides is not a stable phenomenon. Memory, 8, 95-109. 
Wheeler, M.A., \& Roediger, H.L., III. (1992). Disparate effects of repeated testing: Reconciling Ballard's (1913) and Bartlett's (1932) results. Psychological Science, 3, 240-245.

Wilkinson, C., \& Hyman, I.F. (1998). Individual differences related to two types of memory errors: Word lists may not generalize to autobiographical memory. Applied Cognitive Psychology, 12, S29-S46.

Wilson, S.C., \& Barber, T.X. (1983). The fantasy-prone personality: Implications for understanding imagery, hypnosis, and parapsychological phenomena. In A.A. Sheikh (Ed.), Imagery. Current theory, research, and application (pp. 340-387). New York: John Wiley \& Sons, Inc.

Winningham, R.G., Hyman, I.E., \& Dinnel, D.L. (2000). Flashbulb memories? The effect of when the initial memory report was obtained. Memory, 8 , 209-216.

Winograd, E., Peluso, J, \& Glover, T.A. (1998). Individual differences in susceptibility to memory illusions. Applied Cognitive Psychology, I2, S5-S27.

Woods, S.M., Natterson, J., \& Silverman, I. (1966). Medical students" disease: Hypochondriasis in medical education. Journal of Medical Education, 4I, 785-790.

Woolnough, P.S., \& MacLeod, M.D. (2001). Watching the birdie watching you: Eyewitness memory for actions using CCTV recordings of actual crimes. Applied Cognitive Psychology, 15, 395-411.

Yuille, J.C., \& Cutshall, J.L. (1989). Analysis of the statements of victims, witnesses and suspects. In J.C. Yuille (Ed.), Handbook of emotion and memory: Research and theory (p. 201-215). Hillsdale, NJ: Erlbaum. 



\section{Summary}

Some authors assume that emotional memories have photographic qualities (e.g., Elin, 1995; Van der Kolk \& Fisler, 1995). However, both laboratory and field studies suggest that in these memories errors might occur. Eyewitnesses' memories are far from exact replicas of the facts. In this thesis, errors in emotional memory are differentiated and evaluated. Moreover, antecedents are examined that might affect these errors.

Chapter 1 reviews paradigms that are used to evaluate the reliability of emotional memories. A variety of laboratory and field studies are discussed. Both research areas indicate that errors occur in emotional memories. We differentiate distortions, commission errors, and omission errors. Distortions and commissions are related to the accuracy of memory whereas omissions are related to the completeness of memory. Moreover, memories can be evaluated in terms of consistency. There are shortcomings in both neutral and emotional memories with respect to these three parameters.

Chapter 2 describes the outline of this thesis. Five research questions are formulated, namely 1) What is the relation between accuracy, completeness, and consistency of emotional memories? 2) How accurate and complete are emotional memories? 3) Are emotional memories special? 4) Do victims who suffer from PTSD have accurate memories of their traumatic experience? 5) Are dissociation and/or fantasy proneness and/or thought suppression related to errors in emotional memories? The studies of this thesis are related to one of these questions.

Chapter 3 describes a study on the relation between accuracy, completeness, and consistency of emotional memory. Such a study is relevant for the area of psychology and law since some layers assume that inconsistent testimonies are inaccurate. Forty-one participants were shown an upsetting movie fragment. Several minutes later as well as several weeks later they were asked to give a detailed description of what they had seen. It was emphasized that all information (e.g., characteristics of the neighbourhood and of persons) was important. Eyewitness testimonies were evaluated in terms of correct information, distortions, commissions, omissions, accuracy, and completeness. Moreover, an index of consistency was callculated. Our results show that inconsistent testimonies might be accurate. Inconsistent testimonies are mainly characterized by omission errors. This finding belies the idea that inconsistent testimonies are incorrect. 
Chapter 4 reports a study that investigated whether a memory illusion, termed boundary distortion, occurs in emotional scene memory. There are two types of boundary distortions: boundary extension refers to having seen more of a scene than was actually shown whereas boundary restriction refers to having seen less of a scene than was shown. Boundary restriction has also been called tunnel memory. In order to investigate whether boundary extension or boundary restriction occurs in emotional memories, 81 participants were shown either 4 neutral or 4 emotional pictures in a first experiment. Next, participants were instructed to draw these pictures out of memory. Both neutral and emotional objects were depicted smaller than in the original pictures. This means that participants remembered more background than was shown. In a second experiment, pictures were shown that formed a story line. Sixty participants were shown either a neutral slide series or an emotional slide series. Except for 2 critical slides, both series were identical. In the test phase, the critical slides were shown once more. Participants had to judge the camera distance of these slides (i.e., "farther than original", "no change", "closer than original"). They were quite accurate in detecting no change. However, those participants who made an error more often displayed a boundary extension than a boundary restriction error. These two experiments indicate that boundary distortions in both neutral and emotional pictures tend to be extension rather than restriction. Our results support the idea that when looking at a scene schemata are activated that become incorporated in memory (perceptual schema hypothesis).

Chapter 5 presents the findings of a study on boundary distortions in children's scene memory. This is an important issue since children often act as witnesses. Eighty-seven children were shown either 4 neutral or 4 emotional pictures. Next, they were asked to draw these pictures out of memory. Both neutral and emotional objects were drawn smaller than the objects in the original pictures. These results show that boundary extension occurs in children's neutral and emotional scene memory. Again, the perceptual schema hypothesis accounts for the results. Obviously, boundary extension is a robust and universal phenomenon.

Chapter 6 is directed at the question whether amnesic patients develop flashbulb memories. Previous studies showed that Japanese patients with Alzheimer disease remembered the Kobe earthquake (1995). Moreover, these patients remembered the circumstances in which they received the news about the earthquake. These memories are termed flashbulb memories. Fifteen Korsakoff patients and 15 healthy control participants were asked what happened on September 11, 2001. Next, they were asked under which circumstances they received the news about the terrorist attacks on the USA. Finally, semantic knowledge questions about September 11 were asked. Eight patients and 13 control participants were interview a second time. By interviewing them twice, it was possible to evaluate the consistency of flashbulb memories. The results show that the majority of the Korsakoff patients remembered 
what happened on September 11. Moreover, these patients had semantic knowledge and flashbulb memories about the event. However, their flashbulb memories appeared to be inconsistent. It is supposed that their flashbulb memories are based on confabulations.

Chapter 7 reviews literature on the link between peritraumatic dissociation and Post- Traumatic Stress Disorder (PTSD). Many studies conclude that peritraumatic experiences predict the development of PTSD. However, the methodology of these studies does not allow such conclusion. More specifically, results are obtained with retrospective self-reports. There are several reasons for why these reports in general, and of PTSD patients in particular, are unreliable. Our review ends with indications for the most ideal study on the link between peritraumatic dissociation and PTSD.

Chapter 8 reports findings of a study on the relation between dissociation and emotional memory. Two hypotheses were tested. Defence theory assumes that sequential traumatization results in dissociative symptomatology. Dissociation, then, would serve a defensive function during sequential exposure to stressors. As a result, memory for the stressor would be limited (omissions). However, the "fantasy proneness" theory claims that dissociative experiences would result in commissions in emotional memory. Due to the overlap between dissociation and fantasy proneness, individuals high on dissociation would be excellent in empathizing with a story resulting in commissions in their memory. Nineteen participants low on dissociation and 19 participants high on dissociation listened to an emotional story. Next, they were asked to write down the story in as much detail as possible. The stories we evaluated in terms of correct reported elements, omissions, distortions, and commissions. Participants high on dissociation made more commissions compared to participants low on dissociation. However, statistical analysis indicated this result cannot be attributed to fantasy proneness. However, the defensive function of dissociation was not supported either.

In chapter 9 a detour is made. In some cases, emotional memories are exaggerations of the fact. "Fantasy proneness" might account for this inflation. Individuals high on fantasy proneness tend to give exaggerated interpretations to ambiguous sensations. Exaggeration might also be the result of thought suppression. Thought suppression appears to have a counterproductive effect. Moreover, it has been found that thought suppression increases PTSD symtomatology. To explore this phenomenon, two hundred fifteen medical students conducted a questionnaire on the Medical Student Syndrome (MSD). This syndrome refers to health complaints that are the results of medical expertise rather than genuine pathology. Next, participants completed questionnaires on fantasy proneness and on thought suppression. Thirty percent of the respondents reported MSD complaints. Fantasy 
proneness and thought suppression appeared to be independent predictors of the MSD.

In chapter 10, the main results of this thesis are presented and discussed in terms of accuracy, completeness, and consistency. Our results show that emotional memories are far from perfect. Distortions and commissions undermine their accuracy. Moreover, our findings give indications for phenomena that might affect the occurrence of commissions. More specifically, dissociation, fantasy proneness, and PTSD symptomatology seem to increase the number of commissions. With respect to completeness it is concluded that ernotional memories are incomplete and that incompleteness increases over time. Moreover, emotional memories are inconsistent. Especially PTSD patients and amnesic patients are susceptible to inconsistent memories. In a normal population, however, inconsistent memories do not imply inaccurate memories by definition. Shortcomings in accuracy, completeness, and consistency seem not to be typical for emotional memories. In neutrall memories these errors occur as well. Although these errors might be unwanted they appear to be inherent to the functioning of our memory. 


\section{Samenvatting}

Door sommige auteurs is wel beweerd dat herinneringen aan ingrijpende gebeurtenissen exacte replica's zijn van de gebeurtenissen zoals ze zich voordeden (o.a., Elin, 1995; Van der Kolk \& Fisler, 1995). Termen als "flashbacks" en "flashbulb memory" suggereren dat dergelijke herinneringen een fotografische allure bezitten. Maar zowel laboratoriumstudies als veldstudies laten zien dat deze opvatting moeilijk te verdedigen valt. Herinneringen van slachtoffers en getuigen stroken lang niet altijd met de feitelijke toedracht van het voorval. In deze dissertatie zijn de fouten die kunnen optreden in negatieve gekleurde herinneringen in kaart gebracht. Bovendien zijn antecedenten onderzocht die deze fouten kunnen beïnvloeden.

In hoofdstuk l wordt een beknopt overzicht gegeven van een aantal paradigma's dat gebruikt is om de betrouwbaarheid van emotionele herinneringen te onderzoeken. Zo worden verschillende laboratoriumstudies en veldstudies besproken. Wat beide onderzoeksterreinen laten zien is dat er fouten kunnen optreden in emotionele herinneringen. We onderscheiden distorties, commissie fouten en omissie fouten. Distorties en commissies zeggen iets over de accuraatheid van een herinnering terwijl omissies te maken hebben met de volledigheid. Bovendien kunnen herinneringen geëvalueerd worden in termen van consistentie. Herinneringen schieten op al deze parameters nogal eens tekort en emotionele herinneringen vormen daarop geen uitzondering.

In hoofdstuk 2 worden het kader en de doelstellingen beschreven van de studies die deel uitmaken van deze dissertatie. Er worden vijf onderzoeksvragen geformuleerd, te weten 1) Wat is de relatie tussen accuraatheid, volledigheid en consistentie wan emotionele herinneringen? 2) Hoe accuraat en volledig zijn emotionele herinneringen? 3) Zijn emotionele herinneringen speciaal? 4) Hebben slachtoffers met PTSS accurate herinneringen aan de traumatische gebeurtenis die ze meemaakten? 5) Zijn dissociatie en/of "fantasy pronenss" en/of grdachteonderdrukking gerelateerd aan fouten in emotionele herinneringen? Alle studies van deze dissertatie hebben betrekking op een van deze vragen.

In hoofdstuk 3 wordt een onderzoek beschreven waarin de relatic tussen accuraatheid, volledigheid en consistentie werd onderzocht. Een dergelijk onderzoek is vooral van belang voor de rechtspsychologie. Er zijn namelijk nogal wat rechters en advocaten die ervan uitgaan dat inconsistente getuigenverklaringen ook inaccurate en dus onware verklaringen zijn. Wij toonden aan 41 proefpersonen een zeer aangrijpend filmfragment. Zowel enkele minuten als enkele weken later 
kregen de proefpersonen die opdracht om, als betrof het een politieonderzoek, zo gedetailleerd mogelijk te noteren wat ze hadden gezien. Benadrukt werd dat alle informatie (bijvoorbeeld, omgevingskenmerken en persoonskenmerken) voor de politie van belang kon zijn. De getuigenverklaringen werden geëvalueerd in termen wan correct gerapporteerde informatie, distorties, commissies, omissies, accuratheid en volledigheid. Bovendien werd er een maat voor consistentie tussen de twee verklaringen berekend. Wat deze studie laat zien is dat inconsistente verklaringen in hoge mate accuraat kunnen zijn. Het zijn vooral omissies die er voor zorgen dat latere verklaringen niet geheel overeenkomen met eerdere verklaringen. Deze gegevens logenstraffen het idee dat inconsistente verklaringen onwaar zijn.

In hoofdstuk 4 werd onderzocht of er in herinneringen aan emotionele beelden een geheugenfout optreedt die te boek staat als "boundary distortie". "Boundary distorties" kennen twee vormen: bij "boundary extensie" herinnert men zich meer van een plaatje dan erop te zien was. De grenzen van het plaatje zijn als het ware verwijd. Bij "boundary restrictie", daarentegen, herinnert men zich minder dan dat er op een plaatje te zien was. Dit fenomeen wordt ook wel "tunnel memory" genoemd. Om te onderzoeken of er in emotionele herinneringen "boundary extensie" dan wel "boundary restrictie" optreedt, kregen in een eerste experiment 81 proefpersonen ofwel vier neutrale ofwel vier emotionele plaatjes te zien. Vervolgens werd de proefpersonen gevraagd deze plaatjes uit het hoofd te tekenen. Zowel neutrale als emotionele objecten werden door de proefpersonen kleiner afgebeeld dan het origineel. Dit geeft aan dat proefpersonen zich meer achtergrond herinnerden dan er daadwerkelijk te zien was. In een tweede experiment werden plaatjes aangeboden die deel uitmaakten van een verhaallijn. Aan 60 proefpersonen werd ofwel een neutrale ofwel een emotionele fotoserie getoond. Met uitzondering van twee kritieke foto's waren de series gelijk aan elkaar. In de testfase kregen de proefpersonen de kritieke foto's nogmaals te zien. Ze werden geïnstrueerd aan te geven of de testfoto's verder af of dichterbij waren genomen dan het origineel, of gelijk waren aan het origineel. Proefpersonen maakten hierbij weinig fouten. Wanneer er echter fouten werden gemaakt waren dat, voor zowel de neutrale als de emotionele dia"s, eerder extensie ("dichter bij") dan restrictie ("verder af") fouten. Deze twee experimenten geven aan dat "boundary distorties" in herinneringen aan neutrale en emotionele plaatjes eerder van het extensie- dan van het restrictie-type zijn. Deze resultaten ondersteunen de opvatting dat bij het kijken naar scènes schema's worden geactiveerd die onderdeel gaan uitmaken van herinneringen aan die beelden (de perceptuele schema hypothese).

Hoofdstuk 5 gaat in op "boundary distorties" bij kinderen. De kwestie is van belang omdat de vraag rijst hoe universeel zulke fouten in ontwikkelingspsychologische zin zijn. Bovendien treden kinderen nogal eens op als getuigen. Onderzocht werd of 
er bij kinderen "boundary distorties" optreden in hun herinneringen aan emotionele beelden. Aan 87 kinderen werden ofwel vier neutrale ofwel vier emotionele plaatjes aangeboden. Vervolgens werd hen gevraagd deze plaatjes wit hun hoofd te tekenen. Zowel de neutrale als de emotionele objecten werden kleiner getekend dan dat ze in het origineel te zien waren. Deze bevinding laat zien dat er bij kinderen "boundary extensie" optreedt in herinneringen aan neutrale en emotionele beelden, een bevinding die opnieuw aansluit bij de perceptuele schema hypothese. Blijkbaar is "boundary extensie" een tamelijk robuust en universeel fenomeen.

De studie die beschreven wordt in hoofdstuk 6 gaat in op de vraag of amnesie patiënten "flashbulb memories" hebben over een aangrijpende gebeurtenis. Eerder onderzoek toonde aan dat Japanse patiênten met de ziekte van Alzheimer herinneringen hadden aan de aardbeving in Kobe (1995). Bovendien zeiden deze patiënten nog te weten onder welke omstandigheden ze het nieuws over de aardbeving vernamen. Dit worden "flashbulb memories" genoemd. Vijftien Korsakoff patiënten en 15 gezonde controle proefpersonen werd gevraagd wat er gebeurde op 11 september 2001. Vervolgens werd gevraagd onder welke omstandigheden de proefpersonen het nieuws over de terroristische aanslagen op de VS vernamen. Tot slot werden semantische kennisvragen over 11 september 2001 gesteld. Acht patiënten en 13 controles werden 2 maanden later nogmaals ondervraagd. Door hen twee keer te ondervagen was het mogelijk de consistentie van "flashbulb memories" in kaart te brengen. De resultaten wezen uit dat een groot aantal Korsakoff patiënten zich herinnerde wat er op 11 september 2001 was gebeurd. Deze patiënten bleken bovendien semantische herinneringen en "flashbulb memories" te hebben over deze gebeurtenis. Er was echter weinig consistentie met de bij de tweede gelegenheid gerapporteerde "flashbulb memories". Dit doet sterk vermoeden dat hun "flashbulb memories" het product zijn van confabulatie.

In hoofdstuk 7 wordt een kritische blik geworpen op studies naar de relatie tussen peritraumatische dissociatie en Post Traumatische Stress Stoornis (PTSS). Veel onderzoek op dit gebied concludeert dat peritraumatische dissociatieve ervaringen voorspellers zijn van PTSS. De methodologie van deze studies laat een dergelijke uitspraak echter niet toe. Resultaten worden namelijk verkregen door middel van retrospectieve zelfrapportages. In een literatuuroverzicht wordt een aantal redenen genoemd waarom deze rapportages in het algemeen, en afkomstig van PTSS patiënten in het bijzonder, onbetrouwbaar zijn. Het overzicht eindigt met aanwijzingen voor een ideale studie naar de relatie tussen peritraumatische dissociatie en PTSS.

In hoofdstuk \& wordt een onderzoek beschreven naar de relatie tussen dissociatie en emotionele herinneringen. Twee opvattingen werden getoetst. De defensie-theorie gaat ervan uit dat herhaaldelijk traumatisering leidt tot dissociatieve 
symptomatologie. Bij subsequentiele blootstelling aan stressoren zou dissociatie een beschermende werking hebben op het individu. Het gevolg hiervan zou echter zijn dat de herinnering aan de desbetreffend stressor beperkt is (omissies). De "fantasy proneness" theorie, daarentegen, stelt dat dissociatieve ervaringen commissies in emotionele herinneringen tot gevolg hebben. Vanwege de overlap tussen dissociatie en "fantasy proness" zouden hoog dissociatieve mensen zich goed kunnen inleven in een werhaal en door hun fantasierijkheid zouden er commissies optreden in hun emotionele herinneringen. Negentien laag dissociatieve en 19 hoog dissociatieve studenten kregen een emotioneel verhaal te horen. Vervolgens werd er na een gedetailleerde beschrijving van dit verhaal gevraagd. De verhalen werden geëvalueerd in termen van correct gerapporteerde elementen, omissies, distorties en commissies. Hoog dissociatieve proefpersonen maakten inderdaad meer commissie fouten dan laag dissociatieve proefpersonen. Deze bevinding was echter niet toe te schrijven aan "fantasy proneness". De defensieve functie van dissociatie werd evenmin ondersteunt.

Hoofdstuk 9 maakt een zijsprong. Emotionele gebeurtenissen worden nogal eens overdreven. "Fantasy proneness" zou hier mogelijk van invloed op kunnen zijn. Mensen die in hoge mate over deze eigenschap beschikken hebben de neiging een overdreven interpretatie te geven aan ambigue sensaties. Ook gedachteonderdrukking zou van invloed kunnen zijn op het overdrijven van emotionele gebeurtenissen. Gedachteonderdrukking blijkt namelijk PTSS symptomen te doen toenemen. Om dit fenomeen verder te onderzoeken vulden 215 medische studenten vragen in over het medische studenten syndroom (MSS). Dit syndroom verwijst naar niet te objectiveren gezondheidsklachten die het resultaat zijn van medische expertise. Bovendien vulden de studenten vragenlijsten in die "fantasy proneness" en gedachteonderdrukking in kaart brengen. Dertig procent van de ondervraagden rapporteerde MSS klachten. "Fantasy proneness" en gedachteonderdrukking bleken onathankelijke voorspellers te zijn van MSS.

In hoofdstuk 10 worden de belangrijkste bevindingen van deze dissertatie op een rij gezet en besproken in termen van accuraatheid, volledigheid en consistentie. Wat de eerder beschreven studies laten zien is dat emotionele herinneringen niet perfect zijn. Distorties en commissies ondermijnen de accuratheid. De studies geven bovendien aanwijzingen voor fenomenen die van invloed kunnen zijn op het optreden van commissies. Te denken valt aan dissociatie, PTSS symptomen en "fantasy proneness". Met betrekking tot de volledigheid kan geconcludeerd worden dat emotionele herinneringen onvolledig zijn en dat de onvolledigheid toeneemt naarmate de tijd vordert. Emotionele herinneringen zijn bovendien inconsistent. Dit lijkt vooral het geval te zijn bij PTSS patiënten en bij amnesie patiënten. In een normale populatie hoeven inconsistente verklaringen echter niet per definitie onwaar te zijn. De tekortkomingen op het gebied van accuraatheid, volledigheid en 
consistentie lijken niet typisch te zijn voor emotionele herinneringen. Ook in neutrale herinneringen treden allerlei soorten fouten op. Hoewel deze fouten ongewenst kunnen zijn, lijken ze inherent te zijn aan de manier waarop ons geheugen werkt. 



\section{Dankwoord}

Dit proefschrift is mede tot stand gekomen dankzij de mogelijkheden, inspiratie en steun die ik van anderen kreeg. Deze bladzijde wil ik gebruiken om deze mensen te bedanken. Dus BEDANKT:

Harald, voor de tijd die je hebt gestoken in het brainstormen en in het corrigeren van de manuscripten die ik bij je inleverde. Hoewel de hoeveelheid rood niet altijd even bemoedigend was, heb ik er veel van geleerd. Ook bedankt voor je bemoedigende woorden als het even niet mee zat.

Leden van het IRP: Harald, Hans, Marko, Ineke, Robert, Kim, Maaike, Henk, Sander, Han en Timo. Het was altijd een hele klus om jullie bij elkaar te krijgen, maar de IRP-bijeenkomsten waren steeds weer al het ge-e-mail waard. Bedankt voor het delen van interessante bevindingen en casuïstiek.

Arie Wester, voor de mogelijkheid die je me gaf en geeft om onderzoek te doen in je kliniek.

Robert, Remco, Sjaan en Kim, voor de lol en de gezellige koffiepauzes.

Collega's van Experimentele Psychologie, voor alle gezelligheid. Mede door jullie is EP zo'n leuke club om bij te werken.

Marja en Remco, voor jullie glansrollen in de dia-serie.

Ankie en Robert, fijn dat jullie mijn paranimfen willen zijn.

Pap en mam, bedankt voor alles.

Stephan, voor zoveel meer dan alles wat met dit proefschrift te maken heeft. 



\section{Curriculum Vitea}

Ingrid Candel werd op 6 februari 1973 geboren in Maastricht. In 1991 behaalde zij het Gymnasium- $\beta$ diploma aan de Stedelijke Scholengemeenschap in Maastricht. In 1992 startte zij met de studie Gezondheidswetenschappen aan de Universiteit Maastricht en in 1996 met de studie Psychologie aan de Universiteit Utrecht. Van de eerstgenoemde studie behaalde zij het doctoraal diploma van de afstudeerrichting Geestelijke Gezondheidskunde in 1997. Een jaar later (1998) studeerde ze af aan de Universiteit Utrecht met als specialisatie Cognitieve Functiestoomissen. Van 1997 tot 1999 was zij als toegevoegd docent werkzaam bij de faculteiten Psychologie en Gezondheidswetenschappen van de Universiteit Maastricht. Na een jaar rond de wereld te hebben gereisd, werd zij in 2000 als Assistent in Opleiding (AIO) aangesteld bij de capaciteitsgroep Experimentele Psychologie van de Universiteit Maastricht. Vanaf april 2003 zal zij als post-doc werkzaam zijn bij dezelfde capaciteitsgroep.

\section{Publicaties}

Candel, I., Jelicic, M., Merckelbach, H., \& Wester, A. (in press). Korsakoff patients' memories of September 11, 2001. Journal of Nervous and Mental Disease.

Candel, I., \& Merckelbach, H. (2001). Traumatische herinneringen zijn niet perfect. De Psycholoog, 4, 170-174.

Candel, I., \& Merckelbach, H. (2002). Het geheugen voor negatieve gebeurtenissen. Nederlands Tijdschrifi voor de Psychologie, 57, 1-9.

Candel, I., \& Merckelbach, H (in press). Peri-traumatische dissociatie als voorspeller van PTSS: een kritische noot. Tijdschrift voor Psychiatrie.

Candel, I., \& Merckelbach, H. (in press). Fantasy proneness and thought suppression as predictors of the Medical Student Syndrome. Personality and Individual Differences.

Candel, I., \& Merckelbach, H. (in press). Boundary distortions for neutral and emotional pictures. Psychonomic Bulletin \& Review.

Candel, I., \& Merckelbach, H. (accepted pending revision). Peritraumatic dissociation as a predictor of PTSD: A critical Review. Comprehensive Psychiarry.

Candel, I., Merckelbach, H., Houben, K., \& Vandyck, I. (submitted for publication). How children remember neutral and emotional pictures: Boundary extension in children's scene memories. 
Candel, I., Merckelbach, H, \& Kuijpers, M. (in press). Dissociative experiences are related to commissions in emotional memory. Behowiow Research and Therapy.

Candel, I., Mercklebach, H., \& Muris, P. (2000). Measuring interrogative suggestibility in children: Reliability and Validity of the Bonn Test of Statement Suggestibility. Psychology, Crime \& Law, 6, 61-70.

Candel, 1., Merckelbach, H., Muris, P., Rasquin, S., \& Bollen, E. (1998). De Nederlandse versie van de BTSS: Een suggestibiliteitsschaal voor kinderen. De Psycholoog, 12, 554-559.

Candel, I., Merckelbach, H., \& Wessel, I. (2002). Traumatische herinneringen. In P.J. van Koppen, D.J. Hessing, H.L.G.J. Merckelbach, \& H.F.M. Crombag. Het Recht van Binnen (p. 417-431). Deventer: Kluwer.

Candel, I., Smeets, T., \& Merckelbach, H. (submitted for publication) Accuracy, completeness, and consistency of emotional memories.

Merckelbach, H., Jelicic, M., Candell, I., \& Horselenberg, R. (2002). Sleutelen aan geheugenverlies: Iatrogene elaboratie van een retrograde amnesie. Maandblad Geestelije volksgezondheid, 57, 923-935.

Rassin, E., \& Candel, I. (2002). Suggestie tijdens het verhoor. In P.J. van Koppen, D.J. Hessing, H.L.G.J. Merckelbach, \& H.F.M. Crombag. Het Recht van Binnen (p. 465-483). Deventer: Kluwer. 